Cahiers Charlevoix

Études franco-ontariennes
Cahiers Charlevoix Études franco-ontariennes

or Crevenerix of

\title{
L'Ontario français et les grands congrès patriotiques canadiens-français (1883-1952)
}

\section{Gaétan Gervais}

Volume 2, 1997

URI : https://id.erudit.org/iderudit/1039454ar

DOI : https://doi.org/10.7202/1039454ar

Aller au sommaire du numéro

\section{Éditeur(s)}

Société Charlevoix

Presses de l’Université d'Ottawa

ISSN

1203-4371 (imprimé)

2371-6878 (numérique)

Découvrir la revue

Citer cet article

Gervais, G. (1997). L'Ontario français et les grands congrès patriotiques canadiens-français (1883-1952). Cahiers Charlevoix, 2, 9-155.

https://doi.org/10.7202/1039454ar
Résumé de l'article

Gaétan Gervais sonde les plus éloquentes traces de l'identité canadienne-française qu'il trouve intactes dans les mémoires des grands congrès patriotiques canadiens-français. Avec raison, il note que ces déploiements, qui se sont tenus entre 1883 et 1952, fournissent, sur l'Amérique française - dans ses expressions canadienne, franco-américaine et acadienne -, une richesse documentaire unique. Tout en commentant la participation franco-ontarienne à ces assises nationales, à caractère patriotique, religieux et linguistique, l'auteur relève une même unité de pensée, manifestée par une même symbolique, soutenue par la même armature institutionnelle, diffusant la même idéologie clérico-nationaliste et le même projet de société, parce que fondée sur le même sentiment profond d'appartenance au Canada français. 
À la mémoire de mon père,

Lionel Gervais (1922-1996)

\section{L'ONTARIO FRANÇAIS \\ ET LES GRANDS CONGRÈS PATRIOTIQUES CANADIENS-FRANÇAIS (1883-1952)}

Gaétan Gervais

Département d'histoire

Université Laurentienne, Sudbury

Cahiers Charlevoix 2, 1997, pp. 9-155. 


\section{SommaIRE}

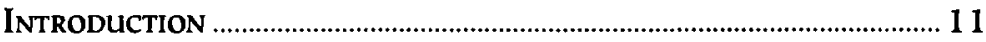

I - UNE CULTURE DE CONGRES .................................................................. 13

II - LES PREMIERS CONGRĖS PATRIOTIQUES

(États-Unis, Québec, Acadie)

A - La Société Saint-Jean-Baptiste

B - Les conventions américaines

C - Les conventions de Montréal (1874) et de Québec (1880)

1 - La convention de Montréal

2 - La convention de Québec

D - Les conventions acadiennes

III - LES CONGRÈS PATRIOTIQUES ONTARIENS

56

$A$ - Le congrès de Windsor (1883)

$B$ - Le congrès d'Ottawa (1910)

IV - LES CONGRÈS DE LA LANGUE FRANÇAISE

Au CANAdA $(1912,1937,1952)$

$A$ - Le congrès de 1912

$B$ - Le congrès de 1937

$C$ - Le congrès de 1952

ConcLusion 


\section{L'ONTARIO FRANÇAIS}

\section{ET LES GRANDS CONGRESS PATRIOTIQUES CANADIENS-FRANÇAIS (1883-1952)}

\section{INTRODUCTION}

Dans un sermon prononcé le 22 juin 1952, lors du Troisième Congrès de la langue française au Canada, l'archevêque coadjuteur de Saint-Boniface, Mgr Maurice Baudoux, résumait clairement l'idée que les élites canadiennes-françaises se faisaient alors du "Canada français». Quatre fondements, coïncidant parfaitement, en assuraient l'unité, à savoir une communauté d'histoire, une communauté de langue, une communauté de foi, une communauté d'aspiration ${ }^{1}$. Diffusée par les élites cléricales et répandue dans les maisons d'enseignement, cette vision du monde avait

\footnotetext{
${ }^{1}$ Voici le texte en question: «Notre communauté d'origine et d'histoire; notre communauté de langue, expression de notre culture particulière; notre communauté de croyance et de vie surnaturelle; enfin notre communauté d'aspiration vers un idéal qui s'élève au-dessus des contingences matérielles", dans Troisième Congrès de la langue française au Canada. Québec 18-26 juin 1952. Compte rendu (Québec, Editions Ferland, 1953), p. 105.
} 
depuis longtemps gagné toutes les communautés françaises du continent. Pour preuve de la durée de ces idées, il est significatif de relever qu'en juin 1883, lors d'une convention de la Société Saint-JeanBaptiste, tenue à Windsor, dans le Sud-Ouest ontarien, Thomas-Chase Casgrain, natif de la région et professeur à l'Université Laval, s'exprimait déjà en termes fort semblables: «Un peuple [...], c'est une grande famille dont les membres sont unis ensemble par les traditions, par les souvenirs, par le passé, par les aspirations de l'avenir ${ }^{2} »$. Ces deux textes, de 1883 et de 1952, attestent la pérennité d'une pensée qui contribua grandement à maintenir la cohésion des élites du Canada français autour d'un même projet socioreligieux.

Les élites du Canada français trouvèrent à leur vision du monde une justification inspirée par deux importants courants intellectuels du XIX ${ }^{\mathrm{e}}$ siècle, à première vue contradictoires: d'une part le catholicisme conservateur, dans sa forme ultramontaine, et, d'autre part, le nationalisme, invoqué pour défendre, en vertu du "principe des nationalités», la langue et la culture françaises partout au pays. Fusionnés, ces deux courants idéologiques ont produit, en sol canadien, un nationalisme catholique incarné dans un ensemble de valeurs et d'institutions, caractéristiques du Canada français. Ainsi s'expliquent, non seulement la maxime voulant que «Qui perd sa langue perd sa foi», tout à fait justifiée dans cette perspective, mais aussi l'ascendant durable du clergé sur cette société où un bon Canadien-Français se devait d'être à la fois catholique et français, donc méfiant

\footnotetext{
${ }^{2}$ Texte cité dans N.-E. Dionne, Fête nationale des Canadiens-Français célébrée à Windsor, Ontario. Le 25 juin 1883, Québec, Imprimerie Léger Brousseau, 1883, p. 83.
} 
des idées libérales, socialistes, gallicanes ou démocratiques.

La religion catholique et la langue française fondèrent l'identité canadienne-française où se reconnurent pendant un siècle les élites françaises du pays. Ainsi, avant les années 1960, les CanadiensFrançais de l'Ontario n'articulèrent pas une idéologie franco-ontarienne différente de l'idéologie canadiennefrançaise. Du point de vue de l'identité, la spécificité franco-ontarienne tenait à une certaine expérience historique distincte, notamment la lutte contre le Règlement XVII, c'est-à-dire surtout aux particularités dictées par la situation politique et économique de la province. Le "nous» de ces élites comprenait l'ensemble du Canada français. Presque tous les chefs de file franco-ontariens avaient des origines, plus ou moins lointaines, dans la province de Québec; plusieurs y étaient même nés, surtout les membres du clergé qui joua un rôle si important dans l'encadrement de la société franco-ontarienne.

\section{I - UNE CULTURE DE CONGRES}

L'unité de la pensée canadienne-française se traduisit de nombreuses façons, certes, mais se manifesta rarement avec plus d'éclats que lors des dizaines de congrès, tant patriotiques que religieux, qui ponctuèrent l'histoire de la nation canadienne-française. Ces rassemblements solennels fournirent aux élites, tant religieuses que laïques, l'occasion de se retrouver, de se concerter, de proclamer publiquement les hauts principes qui les inspiraient. La fonction de ces rencontres fut donc largement idéologique, leur caractère solennel les élevant, en quelque sorte, au niveau de symboles du Canada français. Car les faits 
et gestes des congressistes s'inscrivaient dans une démarche qui, par-delà la réalité (premier niveau) et l'imaginaire (deuxième niveau), se situait au plan symbolique (troisième niveau). Ainsi, les congrès devinrent eux-mêmes des "symboles", de véritables structures de signification, représentatives de l'ensemble du Canada français.

Il était inévitable alors que la question des symboles, des emblèmes et des représentations fût souvent abordée explicitement, au cours des congrès patriotiques, à propos du drapeau et de l'hymne national, au sujet des héros, des cérémonies, des monuments historiques. Ainsi s'explique, en outre, la litanie de dévoilements de plaques, d'attributions de médailles, de remises de prix, de collations de doctorats honorifiques, de processions religieuses, de défilés avec chars allégoriques, de dépôts de gerbes aux pieds des monuments, de déclarations solennelles de toute sorte. Car fidèlement, chaque congrès apporta son lot de paroles ou d'actions fortement révélatrices de l'univers mental canadien-français, avec ses valeurs, ses craintes, ses projets, ses espérances, c'est-à-dire, de manière ultime, son sens de la vie. Comment s'étonner alors que les actions des principaux acteurs prissent souvent une allure théâtrale ou rituelle?

Les trois fonctions d'un symbole sont de montrer, de réunir et de prescrire ${ }^{3}$. La première fonction, celle de montrer, veut rendre sensible ce qui ne l'est pas, comme les valeurs, les pouvoirs, les vices, les vertus, les liens qui unissent la communauté. Le symbole, par conséquent, doit, sans risque d'ambiguïté, être reconnu par toute la communauté et permettre d'ex-

\footnotetext{
${ }^{3}$ Voir l'article de D. Jameux, «Symbole», dans Encyclopadia Universalis (1980), volume 15, p. 613-616.
} 
clure ceux qui n'en font pas partie. Il acquiert ainsi le pouvoir de rassembler et de fabriquer un consensus. En montrant, le symbole en vient à jouer un rôle social. La deuxième fonction du symbole est de réunir. Il sert à marquer l'appartenance à un groupe, à souligner sa continuité dans le temps et dans l'espace. Cette fonction est sociologique. Le symbole, ainsi, devient collectif, il appartient à un groupe, comme les institutions, les costumes, les pratiques communes et tout le reste. Enfin, la troisième fonction du symbole est de prescrire. Plus ou moins explicitement, le symbole devient, pour le groupe auquel il appartient, une manière de favoriser des comportements, de dicter des conduites, d'assurer le respect aux pouvoirs représentés par le symbole, de donner les mots d'ordre. Discours et sermons, notamment ceux que des orateurs de marque prononcent en grande pompe devant des foules nombreuses, illustrent ces trois fonctions au cours des congrès. Les orateurs ont cherché à montrer les valeurs, les vertus, les pouvoirs du Canada français, mais aussi les dangers et les faiblesses menaçant l'avenir de la nation canadiennefrançaise; à réunir les représentants de la communauté pour raffermir leur appartenance au Canada français; enfin à prescrire certaines conduites pour assurer la survivance du peuple canadien-français.

On s'explique facilement, déjà, l'importance que les chefs de file canadiens-français ont pu accorder à ces grands déploiements. En même temps qu'une consécration de la légitimité des pouvoirs en exercice et de l'ordre des choses que les élites veulent maintenir, ces grands congrès s'avèrent aussi des révélateurs éloquents de ce que représentait le Canada français. D'une part, ils peuvent aider à comprendre comment une minorité culturelle particulière, plus 
précisément les "Canadiens-Français de l'Ontario", c'est-à-dire les Franco-Ontariens, a participé à ces grands rassemblements; d'autre part, ils permettent d'observer les rapports entre l'Ontario français et les autres communautés françaises du pays, notamment celle du Québec. Est-il nécessaire d'ajouter que les élites canadiennes-françaises de l'Ontario, en quête d'une solidarité culturelle, ont apporté leur concours enthousiaste à l'organisation des grands congrès de la langue?

La période canadienne-française de l'histoire de l'Ontario français, avant les années 1960 , se caractérise, spécifiquement, à la fois par un système de valeurs et par un réseau d'institutions sociales, l'ensemble correspondant à la conception du monde à laquelle adhéraient les Canadiens-Français de l'Ontario, notamment leurs élites du secteur de l'éducation et de la religion. Objet de ridicule aujourd'hui, cette vision du monde a pourtant permis, justement par ce ré seau d'institutions, d'assurer la survivance de l'Ontario français, comme aussi des autres minorités françaises du pays.

À tout prendre, l'Ontario français a grandement profité de sa cohésion culturelle, maintenue par l'adhésion des élites à une même idéologie et par leur intégration dans un réseau institutionnel canadienfrançais qui, tout clérical qu'il fût, eut le double mérite de fournir un encadrement social et de s'étendre à toutes les sphères de la vie en société: la famille, la religion, l'éducation, la presse, l'édition, la culture, les regroupements religieux et patriotiques, les loisirs, la vie sociale et politique, voire les activités économiques et syndicales. Ce réseau fixa la nation canadienne-française sur des assises sociales dura- 
bles, lui procurant, d'un bout à l'autre du Canada français, les moyens nécessaires pour continuer la lutte de la survivance, préoccupation constante qui a hanté pendant des générations le discours des nationalistes canadiens-français.

Malgré la présence de francs-tireurs libéraux qui ont pu, à l'occasion, contester l'hégémonie religieuse et conservatrice des élites et prétendre fonder sur d'autres bases la nationalité canadienne-française, les Canadiens-Français possédaient en fait un fort sentiment d'appartenance à une même communauté. Car le cri des contestataires s'éleva rarement audessus du murmure incessant des prières. En Ontario français, de fait, l'armature institutionnelle fut largement cléricale avant les années 1960 , lui permettant de profiter d'une solidarité pancanadienne et de recruter ailleurs un personnel spécialisé. Les nombreuses crises scolaires, comme celles du Manitoba (1890-1897) ou du Règlement XVII (1912-1927) en Ontario ${ }^{4}$, mirent à l'épreuve cette solidarité que confirmèrent les secours apportés par leurs «frères» des autres régions, notamment de la province de Québec. Une origine française commune, un attachement à la langue et à la culture françaises, une communauté de foi, voilà autant de facteurs qui définirent l'identité canadienne-française.

L'avenir du Canada français, menacé, dépendait de la survivance, que seules des institutions catholiques, préférablement françaises ou à tout le moins bilingues, pouvaient garantir. Or, dans des provinces anglaises comme l'Ontario, les institutions publiques étaient anglaises, parfois même francophobes. Cela

4 Gaétan Gervais, «Le Règlement XVII (1912-1927)», dans la Revue du Nouvel-Ontario 18, 1996, p. 123-192. 
explique que les institutions confessionnelles, surtout quand elles étaient françaises plutôt que bilingues, aient joué, auprès des minorités culturelles françaises, un inévitable rôle de suppléance. C'est un fait d'histoire qu'avant la reconnaissance, toute récente, des droits de la minorité franco-ontarienne, presque toutes les institutions spécifiques de l'Ontario français eurent un caractère confessionnel, y compris les organismes à vocation économique comme les caisses populaires et l'union des cultivateurs. Il est difficile d'imaginer, en ces temps où l'appartenance religieuse comptait autant que l'identité linguistique, comment l'Ontario français aurait pu développer des institutions françaises, sans le clergé et sans le gouvernement. L'appui du gouvernement étant exclu, il devenait inévitable que la communauté d'origine française se confondît avec la communauté de foi. Ainsi s'explique le repli des élites canadiennes-françaises, soucieuses de conserver leur langue et leur culture, sur les institutions-clés de la survivance, la paroisse et l'école, françaises et catholiques toutes deux, devenues d'importants points d'ancrage identitaire et social.

En l'absence d'un «gouvernement du Canada français», il n'existait pas d'institution politique habilitée à rassembler les représentants de l'ensemble des communautés françaises du continent, même si les assises de la Société Saint-Jean-Baptiste devinrent au $\mathrm{XIX}^{e}$ siècle un lieu privilégié pour discuter des affaires de la nation canadienne-française. Poussant cette logique encore plus loin, certains chefs de file de la ville de Québec, nommément la Société du parler français au Canada, voulurent réunir les représentants de toute la nation canadienne-française. 
Sous le couvert de la langue, c'est en fait de la culture, de la communauté et de leur avenir qu'on entendait discuter. Pour ces raisons, les trois Congrès de la langue française au Canada, en 1912, en 1937 et en 1952, occupent une place particulière dans l'histoire du Canada français au $\mathbf{X X}^{\mathrm{e}}$ siècle. Ils furent, on l'a souvent répété, «les états généraux de la race».

Paradoxalement, le congrès effectivement appelé les États généraux du Canada français (1966-1969), convoqué à Montréal, marqua la fin du Canada français. Alors que le Congrès de 1912 se termina par un serment de fidélité à la langue française, le Congrès de 1937 par un acte de foi en l'esprit français et le Congrès de 1952 par un programme de promotion de l'héritage français, les États généraux, eux, consommèrent l'éclatement de la nation canadiennefrançaise 5 . Ce dernier rassemblement général du Canada français exposa au grand jour la déchirure définitive entre le Québec et les minorités canadiennesfrançaises. La rupture procédait d'une scission fondamentale entre l'idéologie néonationaliste québécoise, rivée désormais sur la construction d'un Etat québécois séparé ${ }^{6}$, et le projet pancanadien des minorités françaises du pays, à la recherche, elles, d'une reconnaissance de leurs droits dans le cadre fédéral canadien. Ce schisme, pour conserver la terminologie religieuse, mettait fin à la forte solidarité, tant recherchée depuis plus d'un siècle par les

\footnotetext{
${ }^{5}$ Sur les États généraux et l'Ontario français, voir Michel Bock, «Les Etats généraux du Canada français, ou l'éclatement de la nation: une analyse des journaux de langue française de Sudbury", dans Revue du Nouvel-Ontario 19, 1996, p. 11-37.

6 Yves Couture, La Terre promise. L'Absolu politique dans le nationalisme québécois, [Montréal], Liber, [c1994], 222 p.
} 
élites nationalistes et religieuses, au sein de «la grande famille canadienne-française».

On pourrait aussi proposer une typologie des congrès. Ainsi, bien que certains rassemblements n'eurent qu'une envergure régionale ou particulière, d'autres, généraux, tentèrent de rassembler des participants provenant de plusieurs régions du pays, voire du continent. Par analogie religieuse, on pourrait qualifier les grands rassemblements généraux de congrès oecuméniques ${ }^{7}$, puisqu'ils réunissaient toute la «famille canadienne-française», à laquelle s'associèrent les Acadiens et les Franco-Américains. Ces congrès généraux, ou «œcuméniques", eurent tous lieu dans les trois capitales régionales du Canada français, c'està-dire Québec, Montréal et Ottawa. On peut d'ailleurs se demander, complémentairement, sì, dans chacun de ces trois centres, il ne s'est pas développé une forme particulière de nationalisme canadien-français.

Une deuxième manière de caractériser les congrès du Canada français, c'est selon leurs domaines d'intérêt. En effet, on distingue des congrès à caractère religieux (comme les congrès eucharistiques ou les congrès marials), patriotique (comme les congrès de la Société Saint-Jean-Baptiste), culturel (comme la convention littéraire de 1877 à Ottawa), social (comme les «semaines sociales»), politique (les congrès des partis politiques) ou économique. Pour l'étude de l'Ontario français, les congrès patriotiques apportent les plus riches informations parce qu'ils traitent explicitement des questions de langue, d'assimilation, de survivance, et du sort des minorités françaises

\footnotetext{
${ }^{7}$ D'ailleurs, le compte rendu du Premier Congrès de la langue française utilisa explicitement ce terme quand il décrivit la rencontre comme un «concile œcuménique de la langue française».
} 
partout en Amérique du Nord.

Les Congrès de la langue française au Canada qui, par leur importance, appartiennent à la catégorie cecuménique, font aussi partie de la classe des congrès patriotiques. Ils occupent une place spéciale car, pour la période canadienne-française de l'histoire de l'Ontario français, ils attestent l'homogénéité et l'unité de pensée des élites canadiennes-françaises avant 1960. Lors des interventions faites au cours de ces congrès, les orateurs rappelaient avec approbation les paroles et les actions de leurs devanciers. Le président du congrès de 1952, l'abbé Adrien Verrette, citait admiratif les discours de ses prédécesseurs, Mgr Camille Roy, président du Congrès de 1937, et Mgr Paul-Eugène Roy, président du Congrès de 1912. Plus qu'une continuité, ces Congrès de la langue française démontrent une vision commune de la société, basée sur ce qu'on appela jadis «l'idée catholique et française $e^{8}$, un projet "qui est notre héritage et notre force ${ }^{9}$.

Ainsi, les Congrès furent plus que des témoins éloquents, ils se transformèrent en véritables «symboles» du Canada français et de ce que pensaient ses chefs religieux et nationalistes. Qu'on partage ou non leurs idées, il faut au moins leur reconnaître le

${ }^{8}$ Il existe une abondante documentation sur cette idée, qu'on retrouve chez une foule d'auteurs, depuis l'évêque Louis Laflèche en passant par Jules-Paul Tardivel jusqu'à Mgr L. $-A$. Paquet, Henri Bourassa ou l'abbé Lionel Groulx. Pour un exemple parmi d'autres, voir Élie-J. Auclair, Articles et Études (Montréal, Cle de Publication de la «Revue Canadienne», 1903, 313 p.), où ces idées sont exposées, dans un texte intitulé "L'Idée française et catholique chez les Canadiens», p. 223244. Ce texte reprend une conférence donnée à Worcester (Mass.) en janvier 1902 et publiée en février 1902 dans la Revue Canadienne, avant de paraître dans Articles et Études l'année suivante.

${ }^{9}$ Auclair, Articles et Etudes, p. 243. 
mérite d'avoir proposé une doctrine cohérente et d'avoir défini une idéologie mobilisatrice, celle d'un nationalisme catholique. Les congrès religieux et patriotiques ouvrent donc des fenêtres sur l'histoire du Canada français dont ils illustrent les idées et les valeurs. Dans cette unité d'intention et d'idéologie, révélée au cours des rencontres, l'Ontario français trouva son compte parce que ces congrès se vouèrent au maintien de l'unité de la nation canadiennefrançaise et à la survivance du Canada français.

Certains rassemblements se tinrent en territoire ontarien, une région du Canada français qui connut à la fois des congrès patriotiques et des congrès religieux. Par exemple, la "Fête nationale des CanadiensFrançais célébrée à Windsor, Ontario ${ }^{10}$ » en 1883 , et le "Congrès d'éducation des Canadiens-Français d'Ontario ${ }^{11^{\prime}}$, tenu à Ottawa en 1910 , répondent à la double description de patriotique et de régional, tandis que le congrès eucharistique de Hawkesbury ${ }^{12}$, en 1942 , et le "Congrès marial d'Ottawa ${ }^{13}$ ", en 1947 , illustrent le cas des congrès religieux. On pourrait ajouter à cette liste, pour l'Ontario seulement, d'autres grands rassemblements, tels la convention littéraire ${ }^{14}$ d'Ottawa en 1877, ou le congrès de l'Association

${ }^{10}$ N.-E. Dionne, Fête nationale des Canadiens-Français célébrée d Windsor, Ontario le 25 juin 1883, Québec, Imprimerie Léger Brousseau, $1883,152 \mathrm{p}$.

"Congrès des Canadiens-Français d'Ontario 1910. Rapport officiel des séances tenues d Ottawa, du 18 au 20 janvier 1910 (Questions d'éducation et d'intérêt général), Ottawa, Association canadienne-française d'éducation [de l'Ontario], 1910, 363 p.

${ }^{12}$ Adrien Bergeron, Splendeurs eucharistiques de Hawkesbury. Congrès de 1942, Montréal, Pères du Saint-Sacrement, [1944], 448 p.

${ }^{13}$ Le Congrès marial d'Ottawa. Ad Jesum per Mariam, [Ottawa, Comité d'organisation du Congrès eucharistique, 1948], vili-346 p.

${ }^{14}$ Institut canadien-français d'Ottawa - 1852-1877. Célébration du $25^{\circ}$ anniversaire, Ottawa, Imprimerie du «Foyer Domestique», 1879, 
catholique de la jeunesse canadienne-française ${ }^{15}$, tenu à Ottawa en 1910, ou divers autres festivals et rassemblements. Toujours, ces congrès traduisaient la volonté des élites de mobiliser et d'encadrer la population canadienne-française.

Au fait, il est à peine exagéré de parler, en Amérique française, d'une certaine culture de congrès, le mot "culture" s'entendant au sens ethnologique de «formes acquises de comportements». Qu'il fût question des congrès patriotiques de la Société Saint-JeanBaptiste, des congrès religieux, des congrès régionaux ou des trois Congrès de la langue française au Canada, une même pensée anima leurs participants. En traitant des questions touchant l'ensemble de la nation canadienne-française, ces congrès produisirent une riche expression du discours des élites sur le Canada français, y compris l'Ontario français. On nota très tôt l'intérêt du phénomène ${ }^{16}$. Mais les organisateurs ne se contentèrent pas de la "gaîté" dont parlait Benjamin Sulte en 1881 , ils poursuivirent des buts plus sérieux: l'avenir du Canada français.

Il existe, dans le contexte de l'Église catholique, une tradition millénaire de réunir des conciles. Sur

xxxii-120 p. Ce rapport contient un compte rendu de la première "convention" des «littérateurs franco-canadiens".

${ }^{16}$ Le Congrès de la jeunesse à Ottawa en 1910. Rapport officiel du Congrès tenu d̀ Ottawa, par l'Association catholique de la jeunesse canadienne-française, les 24, 25, 26 et 27 juin 1910, Montréal, Imprimerie du «Messager», 1910, $146 \mathrm{p}$.

16 Voici ce qu'écrivait Benjamin Sulte: «Il y aurait une jolie étude à faire sur nos fêtes publiques en général. Nous ne sommes pas français pour rien. Les appels à la gaîté sont toujours les bienvenus parmi nous». Voir Benjamin Sulte, "Les Origines de la Saint-Jean-Baptiste», p. 14, dans H.-J.-J.-B. Chouinard, Fête nationale des Canadiens-Français célébrée d Québec en 1880 . Histoire - Discours - Rapports - Statistiques - Documents - Messe - Procession - Banquet - Convention, Québec, Imprimerie A. Côté \& Cie, 1881, xiv-632 p. 
cette coutume ancienne, il se greffa, au XIX ${ }^{\mathrm{e}}$ siècle, la convocation de grands congrès nationaux ou internationaux. Les premiers eurent lieu en Allemagne, mais ces réunions se multipièrent surtout en France. Ainsi, le clergé encouragea divers types de rassemblements, en passant par les congrès scientifiques, les congrès eucharistiques, les congrès de jeunesse et même, dans la foulée de Rerum Novarum (1891), les congrès ouvriers. À tel point que les autorités de Rome s'inquiétèrent de ces rassemblements mal surveillés où certains prêtres se croyaient tout à coup autorisés à discuter librement de questions relevant de la compétence exclusive du pape. Celui-ci fut ainsi amené à publier à ce sujet, en 1907, l'encyclique Pascendi. Rome, désormais, n'autorisait les rassemblements de prêtres qu'à la condition qu'on n'y engageât aucune discussion sur les questions relevant du Saint-Siège.

Ces rassemblements, et bien d'autres de moindre envergure, faisaient partie de la culture de congrès évoquée plus tôt. Outre le célèbre congrès eucharistique de Montréal (1910), on pourrait en aligner un grand nombre d'autres, comme les congrès sacerdotaux de 1913 et de 1915. Certains restaient d'importance locale (les Fêtes-Dieu par exemple), d'autres prenaient plus d'envergure, comme les congrès eucharistiques de Montréal (1925) ou de Québec (1926). En 1938, on organisa à Québec un congrès eucharistique «national" pour le Canada ${ }^{17}$. En fait, deux de ces congrès religieux se déroulèrent en Ontario avec un faste particulier. Il s'agit d'abord, en 1942,

\footnotetext{
${ }^{17}$ Congrès eucharistique national de Québec 22-26 juin 1938. Compte rendu officiel. Québec National Eucharistic Congress June 22nd - 26th 1938, [Québec, Action catholique, 1939], 812 p. [Page de couverture: Premier Congrès eucharistique national. First National Eucharistic Congress].
} 
d'un congrès eucharistique tenu à Hawkesbury, puis, en 1947, un congrès marial organisé à Ottawa à l'occasion du centenaire du diocèse d'Ottawa (Bytown).

Pour l'organisation de ces nombreux congrès, il existait même des "professionnels" expérimentés, capables d'aider une paroisse ou un diocèse à organiser des fêtes. Certains prêtres du Saint-Sacrement parcouraient le Canada français pour encourager, dans les paroisses, la tenue de ces congrès eucharistiques, dont on connut des douzaines, y compris celui de Hawkesbury en 1942. Ces congrès religieux rappellent beaucoup les congrès patriotiques, moins la dimension politique et nationale. Néanmoins, même ces rencontres religieuses comprenaient un volet culturel avec des pièces théâtrales, des jeux de scène, des chants ou des compositions littéraires à caractère religieux. Ici, plus encore que dans les congrès patriotiques, la déférence à l'autorité religieuse fut entière et sans nuance.

Parce que d'un plus grand intérêt pour l'Ontario français, il convient de s'attarder davantage aux congrès patriotiques. Il y en eut dans toutes les régions du Canada français: chez les Franco-Américains d'abord, puis au Québec, enfin en Acadie et en Ontario français. Au $\mathrm{XX}^{\mathrm{e}}$ siècle, ce sont les Congrès de la langue française au Canada qui prennent le relais. Tous, ils nous enseignent ce qu'était le Canada français et, partant, ce qu'était l'Ontario français avant les années 1960. 
II - LES PREMIERS CONGRÈS PATRIOTIQUES (ÉTATS-UNIS, Québec, AcadiE)

Les premiers congrès patriotiques se déroulèrent aux États-Unis, où les conventions, comme on les appelait alors, se réunirent à partir de 1865 . Neuf ans plus tard, en 1874, la Société Saint-Jean-Baptiste de Montréal lançait un appel général au rassemblement, suivi, six ans après, par l'invitation de son homologue de Québec qui, à son tour, convoquait tous les groupes canadiens-français, y compris les Acadiens et les Franco-Américains. Réunis à Québec en 1880, les représentants acadiens se donnèrent rendez-vous l'année suivante, quand eut lieu, à Memramcook, la première convention acadienne. En 1883, c'est à Windsor, en Ontario, que les patriotes de la Société Saint-Jean-Baptiste se donnèrent rendezvous.

\section{A - La SOcIETÉ SAINT-JeAN-BAPTISTE}

La Société Saint-Jean Baptiste naquit à Montréal, mais des sections indépendantes virent le jour partout en Amérique française. Ces sociétés constituèrent un riche terreau où se manifesta le volet laïque du nationalisme catholique au Canada français. Les revendications nationalistes eurent tant de succès, dans le long terme, que les symboles mêmes adoptés pour les Canadiens-Français (feuille d'érable, castor, hymne national) furent éventuellement adoptés par l'ensemble du Canada. Dans cette mouvance naquirent divers mouvements nationalistes aspirant à défendre les intérêts du Canada français.

Entre 1834 et 1837 , le journaliste Ludger Duvernay (1799-1852), un des chefs patriotes, voulant regrou- 
LES GRANDS CONGRÈS PATRIOTIQUES CANADIENS-FRANÇAIS

per les adversaires du gouvernement, les convoqua chaque année à un banquet, le jour de la Saint-Jean. De ce fait, saint Jean-Baptiste devint rapidement le patron des Canadiens, c'est-à-dire des CanadiensFrançais, comme on commençait à les nommer au milieu du siècle dernier. La rébellion de 1837, puis l'exil de Duvernay, mirent fin à ces activités. En 1842 , un an avant Montréal ${ }^{18}$, la ville de Québec célébra la Saint-Jean par un banquet. On retrouvait déjà les éléments des futures célébrations: la messe, le cortège sous les bannières, la devise («Nos institutions, notre langue, nos lois»), le banquet, le ruban tricolore au castor et à la feuille d'érable. Après 1843, la coutume du banquet annuel se maintint tant à Québec qu'à Montréal. Revenu d'exil en 1842, Duvernay fonda l'année suivante une société de bienfaisance «sous le nom d'Association Saint-JeanBaptiste ${ }^{19}$ ». L'organisme, toutefois, se fit surtout connaître par ses activités patriotiques, notamment ses défilés annuels. La section de Montréal, de manière exemplaire, fut de toutes les luttes pour la défense des intérêts des Canadiens-Français, tant au Canada qu'aux États-Unis, grâce à ses nombreuses sections, à ses ressources considérables et à sa direction militante.

\footnotetext{
18 Sur les origines des sociétés de Montréal et de Québec, voir une étude d'abord publiée en 1874 dans le Journal de Québec, mais reprise en 1881: L.-P. Turcotte, «Fondation des sociétés Saint-Jean-Baptiste de Montréal et de Québec", dans H.-J.-J.-B. Chouinard, Fête nationale des Canadiens-Français célébrée d̀ Québec en 1880, p. 21-32. Voir aussi Robert Rumilly, Histoire de la Société Saint-Jean-Baptiste de Montréal. Des Patriotes au Fleurdelisé 1834-1948, [Montréal], L'Aurore, [«Connaissance des pays québécois» 13, c1975], p. 67.

19 Pour la rédaction de la présente section, l'ouvrage de Rumilly, Histoire de la Société Saint-Jean-Baptiste de Montréal... a beaucoup servi.
} 
Au XIX ${ }^{e}$ siècle, la Saint-Jean-Baptiste devint ainsi la fête patronale de tous les Canadiens-Français, passant même près, en 1881 , de rester celle des Acadiens. La popularité de ce patron s'explique en bonne partie par les activités de la société patriotique qui portait son nom. En effet, la Société Saint-JeanBaptiste essaima partout en Amérique où vivaient des communautés françaises, tenant de plus en plus le rôle de sentinelle veillant aux intérêts de la nationalité canadienne-française.

Le Manifeste, publié le 14 octobre 1879 par la Société Saint-Jean-Baptiste de Québec, résume parfaitement l'objectif poursuivi par les nombreuses sociétés célébrant la Saint-Jean:

Ce jour-là, un peuple entier vient, à la face du soleil, affirmer son existence, et déclarer qu'il veut garder son autonomie, sans jamais permettre que le contact des races qui l'entourent lui enlève rien de son cachet national et de son caractère. Ce jour-là, un peuple entier oublie ses querelles de famille, les divergences d'opinion, pour n'avoir plus qu'un cœur et qu'une âme devant l'image adorée de la patrie. Ce jour-là, enfin, tous ensemble, nous CanadiensFrançais, nous consacrons quelques heures à faire revivre le passé, pour y puiser des leçons de patience et de force pour le présent et des espérances pour l'avenir. [...] En résumé, unir entre eux les Canadiens-Français de tous les rangs; prêter main-forte à tout ce qui peut contribuer au développement matériel, intellectuel et moral de la nation; conserver parmi nous le culte du passé et l'amour de notre belle langue; rappeler souvent au peuple les événements dramatiques de notre histoire et graver profondément dans leur mémoire les noms des grands citoyens qui ont aimé et servi la patrie: voilà la mission que la Société Saint-Jean-Baptiste s'est donnée parmi nous ${ }^{20}$.

20 «Manifeste de la Société Saint-Jean-Baptiste de Québec - Projet d'une convention canadienne-française à Québec», texte dans Chouinard, Fête nationale des Canadiens-Français célébrée d Québec en 1880..., p. 99-101. 
Ce texte éloquent, véritable programme d'action, définit bien le rôle de la Saint-Jean. Ce plan d'action fut subséquemment repris lors des congrès de la langue française du $\mathrm{XX}^{\mathrm{e}}$ siècle.

Regrouper les diverses sociétés, surgies un peu partout où vivaient des Canadiens-Français en Amérique du Nord, resta longtemps un rêve que divers projets tentèrent, périodiquement, de réaliser. Le projet de fédération fut discuté souvent, mais n'aboutit qu'un demi-siècle plus tard. Cependant, des fédérations régionales s'organisèrent.

Pourquoi ce patron? Très tôt, certains s'interrogèrent sur la nature du lien entre la fête religieuse de saint Jean-Baptiste et les Canadiens-Français ${ }^{21}$. Benjamin Sulte déjà s'y appliqua, opposant le caractère plus populaire de la Saint-Jean au caractère religieux de la Saint-Joseph, premier patron du Canada ${ }^{22}$. Un demi-siècle plus tard, le journaliste du Droit, Victor Barrette, établissait un lien entre saint JeanBaptiste et les Canadiens-Français qui ont imité leur patron par leur esprit d'apostolat, par la générosité de leur obéissance et par l'exercice de la charité et de la vérité23.

${ }^{21}$ Paul de Malijay, Saint Jean-Baptiste, l'Evangile et le Canada. Souvenir de la Fête nationale du 24 juin 1874, Montréal, Des Presses à vapeur de «La Minerve», "Méditations sociales», 1874, $218 \mathrm{p}$. La couverture porte la mention: «Se vend au profit de l'Union Allet». L'Union Allet regroupait les anciens zouaves.

${ }^{22}$ Benjamin Sulte, "Les Origines de la Saint-Jean-Baptiste», dans H.J.-J.-B. Chouinard, Fête nationale des Canadiens-Français célébrée d Québec en 1880..., p. 1-20.

${ }^{23}$ Victor Barrette, Saint Jean-Baptiste et les Canadiens-Français. En quoi avons-nous imité notre glorieux patron? Par l'esprit d'apostolat, la générosité de notre obéissance. Ce que nous enseigne le Précurseur. Allocution prononcée le 26 juin 1932, en la salle paroissiale SaintGérard d'Ottawa, sous la présidence de l'Association Saint-Jean-Baptiste d'Ottawa, Ottawa, Éditions du «Droit», [1932], 8 p. 
À la fois religieuse et patriotique, la fête de la Saint-Jean traduisait les valeurs de la communauté canadienne-française de l'Ontario dont le nationalisme catholique se manifestait sur deux plans: il y avait d'une part un «bras religieux», la puissante organisation du clergé, et d'autre part un «bras séculier», le mouvement nationaliste qu'incarna mieux que quiconque la Société Saint-Jean-Baptiste. Travaillant ensemble, ces deux «bras» façonnèrent profondément certaines facettes de la vie des Canadiens-Français, partout sur le continent nord-américain, entre le milieu du XIX ${ }^{\mathrm{e}}$ siècle et les années 1960. En outre, depuis 1926, s'organisait, dans l'ombre, le secret Ordre de JacquesCartier $^{24}$, société mise sur pied, à Ottawa d'abord, pour protéger les intérêts canadiens-français dans la fonction publique fédérale et pour intervenir, discrètement, dans divers dossiers concernant le Canada français.

Au titre de l'héritage laissé par ces organismes patriotiques, il faut citer la diffusion des symboles qui furent par la suite adoptés par l'ensemble du Canada: le castor, la feuille d'érable, l'hymne $\hat{O}$ Canada.

À Québec, en 1842, la Société Saint-Jean-Baptiste adoptait un hymne pris à la chanson française, $\grave{A} l a$ claire fontaine ${ }^{25}$. En 1845 , la section de Montréal choisissait «Vive la Canadienne» comme deuxième

\footnotetext{
${ }^{24}$ Sur l'histoire de l'Ordre de Jacques-Cartier, fondé en 1926 à Ottawa, voir surtout l'ouvrage de Raymond-G. Laliberté, Une société secrète: l'Ordre de Jacques Cartier, Montréal, Hurtubise HMH, «L'homme dans la société», [c1983], 395 p.; voir aussi Roger Cyr, La Patente, Montréal, Éditions du Jour, [c1964], 128 p. et Louis C. De Léry, Sociétés séditieuses secrètes suspectes, [Montréal, Imprimerie du "Messager Canadien", 1939], 31 p.

${ }^{25}$ Conrad Laforte, "À la claire fontaine», dans Dictionnaire des cuvres littéraires du Québec I: Des origines d 1900, Montréal, Fides, 1980, p. 8.
} 
«hymne national». Quant à la feuille d'érable, elle servit d'emblème dès le banquet de 1834 , alors que des branches d'érable décoraient la salle; deux ans plus tard, en 1836, l'érable fut explicitement adopté comme symbole. Par souci écologique, la société de Québec s'interrogea en 1883 sur l'opportunité de décorer les rues avec des arbres verts, surtout des érables, une pratique qui contribuait à «la destruction sur une grande échelle des jeunes arbres, surtout l'érable, si cher aux Canadiens-français qui l'ont choisi avec le castor, comme leur emblème national ${ }^{26}{ }^{\prime}$. Quant au castor, il a été reconnu comme symbole canadien dès l'époque de la Nouvelle-France, à cause de son rôle économique. C'est également dans cette mouvance patriotique que fut diffusé, comme étendard des Canadiens-Français, le drapeau de Carillon: croix blanche sur fond bleu, avec, dans chaque quartier, une fleur de lis pointant vers le centre. Avant les années 1960, ce drapeau fut diffusé partout au Canada, promu non comme le drapeau du Québec, mais comme «le drapeau des CanadiensFrançais». Il flotta à ce titre, même dans sa version duplessiste de 1948, sur bien des écoles francoontariennes. Mais quand le fleurdelisé fut récupéré comme symbole du néonationalisme québécois, durant les années 1960, il disparut rapidement partout ailleurs au Canada.

En 1881, Benjamin Sulte notait que «Il ne nous manque plus qu'un chant national ${ }^{27} »$, chant qu'il

${ }^{26}$ Chouinard, Fête nationale des Canadiens-Français... 1881-1889, p. 14. Sur l'histoire des drapeaux canadiens-français, voir le travail récent de Luc Bouvier, "Du tricolore canadien au fleurdelisé québécois», dans L'Action nationale, mars 1996, p. 123-134, avril 1996, p. 83-94, juin 1996, p. 83-94 et novembre 1996, p. 97-107.

${ }^{27}$ Benjamin Sulte, «Les Orlgines de la Saint-Jean-Baptiste», dans H.- 
espérait trouver dans le répertoire traditionnel. Pourtant, lors du grand rassemblement de Québec, en 1880 , on avait déjà joué, une première fois, le $\hat{O}$ Canada, dont les paroles, d'Adolphe-Basile Routhier, accompagnaient la musique de Calixa Lavallée. Cet hymne, chanté par tous les nationalistes canadiensfrançais depuis, se trouva désormais au programme de chaque congrès patriotique.

Il est donc facile de voir comment les symboles du nationalisme canadien-français (le castor, la feuille d'érable, l'hymne ô Canada, mais non le drapeau) furent éventuellement adoptés comme des symboles de l'ensemble du Canada. Les Sociétés Saint-JeanBaptiste ont joué dans ce domaine un rôle critique.

Alors que les conventions américaines ne s'adressaient qu'aux Franco-Américains, les grandes conventions de Montréal (1874) et de Québec (1880), elles, espéraient attirer des participants de toutes les communautés françaises du continent. Le principal foyer du Canada français se trouvait, hier comme aujourd'hui, dans la vallée laurentienne et les principales institutions sociales, culturelles et religieuses du Canada français se développèrent dans les trois villes de Québec, de Montréal et d'Ottawa.

\section{B - LES CONVENTIONS AMÉRICANES}

L'émigration canadienne-française en NouvelleAngleterre et au Mid-Ouest, commencée vers le milieu du siècle dernier, donna naissance, un peu partout aux États-Unis, à l'établissement de communautés de langue française. Si bien qu'à la fin du

J.-J.-B. Chouinard, Fête nationale des Canadiens-Français célébrée à Québec en 1880... p. 19. 
siècle, on parlait généralement de 800000 FrancoAméricains, dispersés dans leur pays d'adoption. Très tôt, les Canadiens-Français des États-Unis tentèrent de se regrouper pour conserver leur langue et leur religion, ouvrant des paroisses, fondant des journaux, organisant des associations. Aux États-Unis, les premières sections de la Société Saint-JeanBaptiste naquirent dès la fin des années 1840 . Ces sociétés locales, parfois appelées «unions», virent le jour ici et là, célébrant, comme à Montréal, Québec ou Ottawa, la fête patronale du 24 juin.

À la fois théâtre de ferveur patriotique et siège de rivalités persistantes, les grands rassemblements patriotiques des Franco-Américains se multiplièrent avant la fondation à Holyoke (New-York), en 1899, de l'Union Saint-Jean-Baptiste d'Amérique. Pour retracer ses origines, l'Union publia en 1927 une histoire des conventions canadiennes aux États-Unis, depuis la première, tenue "combien modestement" en 1865, jusqu'à la rencontre de $1901^{28}$. Le "compilateur" de cet ouvrage, Félix Gatineau, tenta de dénombrer et de mieux situer ces divers rassemblements. Faut-il attribuer au souvenir des anciennes divisions l'insistance, dans l'avant-propos, sur le «besoin de s'unir», sur l'idée que "L'union fait la force», ajoutant pour bonne mesure que «Sans union, c'est la défaite, c'est l'anéantissement, c'est la mort». En 1927, au creux de la crise sentinelliste, cette pensée n'a pas dû tomber dans des oreilles de sourds. D'ailleurs, cette crainte des divisions, thème habituel

\footnotetext{
${ }^{28}$ Pour l'histolre de ces conventions, volr: Félix Gatineau (compllateur), Historique des conventions générales de Canadiens-Français aux ÉtatsUnis 1865-1901. D'après les procès-verbaux officiels et les compterendus [sic] de presse, Woonsocket (Rhode-Island), Union Saint-Jean-Baptiste d'Amérique, 1927, 500 p.
} 
chez les nationalistes, rejoignait directement le souci constant de la survivance, objectif inévitablement compromis par les querelles internes.

Au XIX ${ }^{\mathrm{e}}$ siècle, les conventions nationales générales des Franco-Américains se tinrent annuellement de 1865 à 1876, alors que, de leur côté, les conventions de l'Union canadienne-française de secours mutuels des États-Unis se réunirent annuellement, de 1869 à 1876 , en même temps que les conventions générales, puis séparément en $1878,1879,1880$ et 1881 . Par la suite, les conventions générales, auxquelles étaient conviés les délégués de tous les regroupements canadiensfrançais, furent convoquées aux deux ans de 1880 à 1888 , enfin en 1893 et en 1901 . En outre, plusieurs autres réunions s'organisèrent dans les différents États américains où vivaient des Franco-Américains.

Les comptes rendus publiés par Gatineau rapportent, surtout pour les dernières réunions, les discours des participants, en plus des résolutions adoptées sur les sujets jugés les plus importants. Cette compilation permet déjà de repérer la thématique des autres congrès patriotiques tenus ailleurs. Ces chefs de file franco-américains partageaient les idées issues des milieux ultramontains du Canada français et caractéristiques de son nationalisme catholique. Ainsi, le préambule d'une résolution adoptée en 1884, au cours de la convention d'Albany, notait que les «représentants des CanadiensFrançais $[. .$.$] affirment de nouveau leur attachement$ à la foi catholique, à leurs nobles traditions nationales, à leur langue maternelle et à tout ce qui constitue leur nationalité et au gouvernement de ce pays ${ }^{29} »$.

${ }^{29}$ Cité dans Gatineau, Histoire des conventions générales..., p. 151. 
Dans le même esprit, le manifeste convoquant la convention de 1888, à Nashua (New-Hampshire), rappelait «ce que nous avons de plus cher: notre foi, notre langue et nos droits ${ }^{30}$ ». Les Canadiens-Français des États-Unis, héritiers des explorateurs, des missionnaires, des colons et des soldats de la NouvelleFrance, fondaient sur ces antécédents le «droit de conserver notre foi, notre langue, nos traditions ${ }^{31}$ m.

Pour protéger la foi, on comptait surtout sur le clergé. C'est à lui, en outre, qu'incombait la responsabilité de voir à la conservation de la langue. Comme ailleurs au Canada français, on invoquait la «mission civilisatrice que la Providence semblait avoir confiée aux Canadiens-Français ${ }^{32} »$. Quand la question scolaire fut étudiée en 1872 et en 1876 , on discuta des avantages de l'école confessionnelle ou de l'école publique, les partisans de la première l'emportant généralement. On encouragea aussi les écoles du soir. Toujours, on comptait sur le clergé pour ouvrir, avec l'accord des évêques et des prêtres, «de bonnes écoles françaises catholiques dans presque tous les centres canadiens ${ }^{33}$ ». Partout et toujours, la soumission au clergé restait entière. On adopta, comme en 1888 à Nashua, des résolutions déclarant que «la nation canadienne-française des États-Unis assemblée $[\ldots]$ fait profession de foi solennelle dans les enseignements de l'Église catholique et de soumission absolue à l'autorité du Saint-Père et à NN. SS. les Évêques ${ }^{34}$ ».

\footnotetext{
${ }^{30}$ Gatineau, Histoire des conventions générales..., p. 234.

${ }^{31}$ Gatineau, Histoire des conventions générales..., p. 4-5.

${ }^{32}$ Cité dans Gatineau, Histoire des conventions générales..., p. 155.

${ }^{33}$ Cité dans Gatineau, Histoire des conventions générales..., p. 147.

${ }^{34}$ Gatineau, Histoire des conventions générales..., p. 278.
} 
Après la foi et l'école, c'est la question de la langue qui sollicita l'attention des conventions. On considérait généralement que le français représentait une valeur fondamentale dont la conservation dépendait de l'enseignement, certes, mais tenait aussi à la lecture des journaux et à son usage en famille. Ainsi, dans les conventions, il fut souvent question des journaux, dont la diffusion faisait partie de la stratégie d'action des sociétés canadiennes-françaises établies aux États-Unis. En 1878, on recommanda aussi la fondation de bibliothèques.

Une autre question, de plus en plus importante et donc souvent discutée, fut la naturalisation des Canadiens-Français établis aux États-Unis. Très tôt, les Franco-Américains s'intéressèrent à cette question, en même temps que se multipliaient les déclarations de loyauté à la république américaine. Ici, la politique des Franco-Américains, résignés à ne plus revenir au Canada, contrariait le programme des nationalistes canadiens-français qui encourageaient le rapatriement. Pour faciliter l'intégration dans la société américaine, on chercha à ouvrir des «bureaux d'information" susceptibles d'aider les immigrants canadiens-français à devenir des citoyens américains, selon le vœu de plusieurs. Peut-être inspirés par l'exemple acadien, les Franco-Américains aussi adoptèrent un drapeau différent des Canadiens, choisissant de faire flotter le bleu-blanc-rouge de la France.

À ces idées sur la religion, l'école, la langue, le journalisme, la naturalisation, et sur bien d'autres questions, correspond un programme d'action. Beaucoup de résolutions, plus ou moins pratiques, préconisèrent des mesures favorables aux objectifs définis lors des conventions. 
LES GRANDS CONGRÈS PATRIOTIQUES CANADIENS-FRANÇAIS

Quant à la participation franco-ontarienne à ces conventions américaines, elle fut accidentelle. Un compte rendu de la huitième convention, tenue à Chicago en 1872, notait que la Société Saint-JeanBaptiste d'Albany était représentée par «Joseph Laporte, né à Ottawa». En 1874, Stanislas Drapeau, du ministère fédéral de l'Agriculture à Ottawa, participait à la réunion de l'union canadienne-française de secours mutuels, à New-York. En 1886 à Rutland, le curé Chagnon citait de manière laudative un discours de l'évêque de Peterborough, Mgr Jean-François Jamot (1828-1886), prononcé à Rochester (NewYork) en 1885. Ce texte fut reproduit en entier par Gatineau dans le compte rendu de la convention de 1886.

Ce texte de l'évêque Jamot, d'ailleurs, traduisait bien la «conception du monde" que véhiculaient alors le clergé et les élites laïques du Canada français. L'évêque de Peterborough affirmait que "Tous ensemble, nous devons rester fidèles à ces deux choses si bien faites pour marcher ensemble: notre foi de catholique, notre patriotisme de Canadien-Français». Jamot rappelait ensuite que les Franco-Américains, tout en étant des citoyens loyaux, avaient reçu de la Providence la mission de rester catholiques et de défendre le français. Il faut, disait-il, enseigner cette langue partout et ne pas suivre «l'exemple ridicule» de ceux qui vont jusqu'à changer leur nom. Le point essentiel, toutefois, restait la foi: "Allons à l'église canadienne-française; louons Dieu, confessons-nous en langue française quand cela se peut [...]. Je vous recommande l'école! l'école surtout! car c'est elle qui assurera le salut de vos chers enfants [...] le bon Canadien est catholique, comme ses pères, catholique 
pratiquant». Selon Jamot, les catholiques du Canada vivaient une meilleure situation que les FrancoAméricains puisqu'ils possédaient leurs propres écoles catholiques, comme en Ontario ${ }^{35}$.

Charles Thibault, avocat d'Ottawa, participait à ce congrès de Rutland où il prononça un discours sur «La Liberté du culte». Pendant vingt ans, Charles Thibault dit avoir participé aux conventions des Franco-Américains, précisant que «Seul à peu près de tous les hommes politiques du Canada, votre mèrepatrie, je ne désespérai jamais de votre avenir aux États-Unis. Presque seul aussi, je m'occupai de vous, je contribuai à vos organisations patriotiques ${ }^{36}$."

Les discussions suscitées lors des conventions américaines ressemblaient fort aux débats qui se déroulèrent, au Canada, lors des rencontres de la Société Saint-Jean-Baptiste.

C - Les CONVENIIONS DE MontrÉAL (1874) et DE QuEBeC (1880)

La convention de Montréal (1874). Dans La France aux colonies, Edme Rameau de Saint-Père avait lancé le projet d'une convention qui aurait regroupé toutes les communautés canadiennesfrançaises du Canada et des États-Unis ${ }^{37}$. L'idée fut

35 «Discours de feu Mgr Jamot, de Peterborough (Ontario) à la Conven-
tion de Rochester, N. Y., 18 août 1885 , cité dans Gatineau, Histoire
des conventions générales..., p. 157-159. Cette conférence fut d'abord
publiée par H.-J.-J.-B. Chouinard, Fête nationale des Canadiens-
Français [...] 1881-1889, Québec, 1890, p. 97-102.
36 "Discours prononcé par M. Charles Thibault, d'Ottawa, Ont., avocat
et secrétaire des arbitres du Canada, prononcè à la seizième Conven-
tion nationale des Canadiens-Français des États-Unis, tenue à Rutland
(Vermont)», dans Gatineau, Histoire des conventions générales...,
p. 224 . Le texte du discours est reproduit in extenso, p. 224-232.
${ }_{37}$ Voici le texte en question: «L'idée mère d'un lien général entre tous 
ensuite reprise par l'abbé Henri-Raymond Casgrain, par Stanislas Drapeau, d'Ottawa, enfin par Étienne Parent et par le révérend M. Primeau. Avec ses quelque 1500 membres, la Société Saint-Jean-Baptiste de Montréal, fondée par Duvernay, regroupait, dans la métropole du Canada, beaucoup de personnalités canadiennes-françaises du monde politique (surtout des bleus, toutefois) et du monde économique. Le rassemblement général que plusieurs souhaitaient eut finalement lieu en 1874 , supposément le «quarantième" anniversaire de la Société Saint-JeanBaptiste de Montréal. Puisque l'organisme n'avait été fondé qu'en 1843 , l'année 1874 représentait en fait l'anniversaire du premier banquet que Duvernay avait organisé, en 1834 .

L'invitation à la Convention générale des CanadiensFrançais, sous forme de manifeste, s'adressa aux sociétés nationales du Canada et des États-Unis. Son comité organisateur «comprenait des FrancoAméricains, des Acadiens, des Franco-Manitobains et des Canadiens-français de la province de Québec», mais pas de Franco-Ontarien ${ }^{38}$.

les groupes français de l'Amérique, et de leur conservation par un appui mutuel, idée à laquelle nous en avons appelé déjà à propos des Acadiens, est contenue dans la société Saint-Jean-Baptiste; il suffirait d'en développer l'application par la création de relations plus fréquentes et plus étroites entre ces groupes isolés et le foyer central. Ainsi feraient par exemple l'établissement de quelque députation et visite périodique semblable à celle qui fut faite il y a quelques années aux Canadiens du Détroit; la publication d'un journal spécial, organe de la société et qui serait le signe visible du lien qui rattacherait tous les groupes canadiens entre eux et avec le Canada lui-même[...]". Voir: E[dme] Rameau [de Saint-Père], La France aux colonies. Etudes sur le développement de la race française hors de l'Europe, Paris, A. Jouby, 1859, p. 242-243.

${ }^{38}$ Dans Robert Rumilly. Histoire de la Société Saint-Jean-Baptiste de Montréal..., voir en particulier le chapitre septième, "La Convention générale des Canadiens français», p. 87-107. Pour cette dernière 
La convention connut le succès. Les marchands canadiens-français pavoisèrent leurs édifices, les décorations couvrirent les rues et les places publiques s'illuminèrent. Accueillis par des fanfares, les trains arrivaient en grand nombre à la gare Bonaventure. Deux cent cinquante wagons transportèrent les quelque 18000 Franco-Américains venus à Montréal. Après la messe chantée par Mgr ÉdouardCharles Fabre à Notre-Dame, le long défilé de la Saint-Jean-Baptiste se mit en branle, serpentant dans les rues de Montréal. Annoncés par les bannières, suivaient les zouaves, les sections de la société (barreau, médecins, notaires, clergé), puis les ministres, le premier ministre de la province, les chefs politiques, les corps de métier (tailleurs de pierre, tanneurs et cordonniers, peintres et forgerons, carrossiers, charrons, typographes, plombiers et ferblantiers, briquetiers, menuisiers et charpentiers, bouchers). Le défilé s'allongea sur deux milles et demi $^{39}$. Quatre-vingt-onze sociétés (mais pas celle de Québec!), douze chars allégoriques, trente et une fanfares défilèrent pendant trois heures.

Puis vinrent les inévitables discours. Les 1200 convives rassemblés à l'Hôtel de ville burent à la santé de la Reine, du Prince de Galles, de la famille royale, du gouverneur général, du président des États-Unis, du "Captif du Vatican» (c'est-à-dire le pape), du lieutenant-gouverneur, des gouvernements fédéral et local, du clergé, de la fête du jour, de la France, des Franco-Américains, des sociétés nationales, des

\footnotetext{
citation, p. 104. Sur les conventions de Montréal et de Québec, voir aussi René Dionne, «1910. Une première prise de parole collective en Ontarlo français», dans Cahiers Charlevoix 1, 1995, p. 98-99.

${ }^{39}$ Rumilly, Histoire de la Société Saint-Jean-Baptiste de Montréal..., p. 103.
} 
LES GRANDS CONGRÈS PATRIOTIQUES CANADIENS-FRANÇAIS

«sociétés sours de la Puissance», de la presse et, finalement, des dames.

La convention générale des Canadiens-Français, quant à elle, réunit quelque 400 délégués à la salle des jésuites. Les sommités du monde politique prirent la parole, traitant des questions nationales: l'instruction publique, les missions, la colonisation, l'émigration. Chaque sujet donna lieu à des résolutions appropriées. Mais c'est l'affaire Riel qui provoqua le plus de débats, certains voulant que la convention se prononçât sur le sujet, d'autres voulant éviter d'embarrasser le gouvernement. Quelques délégués tentèrent même de nommer Louis Riel, chef de la rébellion du Manitoba en 1869-1870 et désormais fugitif, comme représentant des métis et des Canadiens-Français de l'Ouest. L'évêque de TroisRivières, Mgr Louis Laflèche, prononça un discours sur la question de l'émigration. Bien d'autres discours encore suivirent.

Le "malheur des temps», selon l'expression de H.-I.-J.-B. Chouinard, avait empêché la Société de Québec de participer "en corps" à la convention de 1874 à Montréal. En catastrophe, on avait envoyé dans la métropole une délégation de quelques personnes. Même la Société Saint-Jean-Baptiste de Québec reconnut le succès de sa rivale qui, la première, réussit à réunir «dans une même fête, des envoyés de tous les groupes canadiens, et en inaugurant parmi nous l'ère des conventions nationales, à l'instar des conventions canadiennes des ÉtatsUnis ${ }^{40}$ ». Ernest Myrand, selon le style superlatif qui caractérisa souvent les descriptions des congrès, nota

${ }^{40}$ Chouinard, Fête nationale des Canadiens-Français célébrée d̀ Québec en $1880 \ldots$, p. 42 . 
dans La Minerve que l'événement «restera longtemps dans le souvenir du peuple canadien et dans les annales de notre histoire. Elle [la convention] sera une preuve manifeste de la vitalité de notre race et de la force de notre patriotisme ${ }^{41}$.»

La participation franco-ontarienne à ce congrès fut peu reluisante. Parmi les organisateurs de la fête, on reconnaissait Stanislas Drapeau, fonctionnaire d'Ottawa, mais il était membre de la délégation de la province de Québec. Parmi les autres participants, on remarqua Philippe-A. Landry, futur sénateur et futur président de l'Association canadienne-française d'éducation de l'Ontario. Joseph Tassé aussi participa à ce congrès de Montréal. Avec ses quelque 75000 personnes, l'Ontario français ne semble pas avoir été identifié comme groupe distinct. Peut-être les considérait-on encore comme faisant partie du "Canada-Uni» (1841-1867), le régime politique qui avait réuni le Haut et le Bas-Canada sous un même gouvernement, avant la création des provinces de l'Ontario et du Québec en 1867. L'Ontario français était tellement invisible que l'on proposa en 1874 un projet d'Union nationale canadienne-française d'Amérique (on avait pris bien soin de préciser "canadienne-française», non «française ${ }^{42}$ ), une fédération dont le siège social serait à Montréal. Dans le comité d'organisation, on avait prévu des places pour les Acadiens, les Franco-Américains, les FrancoManitobains et les Québécois, mais rien pour les Franco-Ontariens.

\footnotetext{
${ }^{41}$ Ernest Myrand, cité dans Chouinard, Fête nationale des CanadiensFrançais célébrée d̀ Québec en 1880 ..., p. 42.

${ }^{42}$ Voir Rumilly, Histoire de la Société Saint-Jean-Baptiste de Montréal..., p. 104.
} 
La convention de Québec (1880). Anciennes et durables, les jalousies entre Montréal et Québec ont pris bien des formes: rivalités commerciales, rivalités politiques, rivalités intellectuelles. Pour l'une et l'autre, tout fut prétexte à défendre ses droits. Devant un Montréal ultramontain qui voulait se transformer en nouvelle Rome, un Québec gallican prétendait, modestement, tenir en Amérique le rôle d'Athènes. La ville-forteresse possédait depuis 1852 son université catholique, exclusivité qu'elle luttait férocement pour conserver contre les impudentes prétentions de Montréal et d'Ottawa. En 1912 le maire de Québec, Napoléon Drouin, justifia ainsi sa ville: "plus qu'ailleurs, nous nous en flattons, nous avons pu garder dans leur intégrité les traditions des ancêtres, le culte du passé, la religion du souvenir. Plus qu'ailleurs peut-être aussi, nous avons conservé intactes et pures de tout alliage la langue des aïeux et la mentalité française ${ }^{43} . "$

Le rapport enthousiaste de la "délégation» envoyée à Montréal par la Société Saint-Jean-Baptiste de Québec, en 1874, fit germer l'idée de tenir une fête semblable à Québec. La décision, prise en 1879 , fut de tenir l'année suivante, le jour de la Saint-JeanBaptiste, une Convention nationale des CanadiensFrançais $^{44}$. Le Manifeste ${ }^{45}$ du 14 octobre 1879, publié

\footnotetext{
${ }^{43}$ Premier Congrès de la langue française au Canada. Québec, 24-30 juin 1912. Compte rendu, Québec, Imprimerie de l'Action sociale, 1913, p. 231.

${ }^{44}$ Le secrétaire-général de la convention, H.-J.-J.-B. Chouinard, a publié les actes de cette «convention": H.-J.-J.-B. Chouinard, Fête nationale des Canadiens-Français célébrée à Québec en 1880 ... Cf. note 16. Sur la Convention de 1880, voir aussi Robert Rumilly, Histoire de la Société Saint-Jean-Baptiste de Montréal, p. 120-124.

${ }_{45}$ «Manifeste de la Société Saint-Jean-Baptiste de Québec - Projet d'une convention canadienne-française à Québec», texte dans
} 
dans les journaux, lança l'invitation à toutes les sociétés sours du Canada et des États-Unis. Après avoir décrit les origines de la Société Saint-JeanBaptiste, le document en rappelait les buts: doter les Canadiens-Français d'une organisation régulière et permanente, les unir, les faire se fréquenter, promouvoir leurs intérêts nationaux et sociaux. Québec voulait suivre les traces de Montréal: «Ce que nos amis de Montréal ont fait avec honneur et avec éclat pour le nom canadien-français, en 1874, nous avons entrepris de le faire, à Québec, le 24 juin prochain [1880]».

Ces "grandes assises de la nation", nous dit le manifeste de convocation, fourniraient aussi l'occasion de faire visiter la ville de Québec, «le berceau de notre nationalité». Selon le document, «L'histoire, la tradition et les souvenirs, les monuments, tout contribuerait à donner à une fête de ce genre, célébrée à Québec, un caractère particulier de grandeur et de majesté». C'est la terminologie même qu'utiliseront, quelques décennies plus tard, les promoteurs des trois Congrès de la langue française au Canada.

Le clergé et l'épiscopat appuyèrent fortement le projet. En tout, quatorze comités furent mis sur pied (levée de fonds, recrutement, organisation du défilé avec des chars allégoriques, élaboration du programme musical, etc.), les activités de chacun étant soigneusement notées, avec détails et noms, pour le rapport final qui parut l'année suivante. En février 1880 , la Société de Québec envoya son président, J.P. Rhéaume, en.mission à Ottawa et à Montréal, puis, le mois suivant, aux États-Unis, afin de prépa-

Chouinard, Fête nationale des Canadiens-Français célébrée d Québec en 1880..., p. 97-105. 
LES GRANDS CONGRÈS PATRIOTIQUES CANADIENS-FRANÇAIS

rer la fête et de recueillir des souscriptions.

Le Rapport de la convention, publié peu après l'événement, contenait, au dire même de Chouinard, le détail «heure par heure» de la fête. Tout y passe: l'arrivée des Hurons, des ouvriers, des élèves, des Américains, des Acadiens, des députés, des voyageurs, de la magistrature et du barreau, des professionnels. "Le drapeau blanc fleurdelisé se déploie lentement, au souffle de la brise matinale, à côté du drapeau d'Albion; mille oriflammes se rapprochent, se croisent et s'éloignent dans la plaine [d'Abraham] ${ }^{46}$.»

Dans son discours, l'évêque de Sherbrooke, Mgr Antoine Racine, parla lui aussi, comme Mgr Laflèche à Montréal en 1874 , de la vocation du peuple canadienfrançais, de la fidélité à sa vocation et à la manière de continuer «cette alliance de la religion et de la patrie, pour suivre la voie que Dieu nous a tracée ${ }^{47}$ ». Puis s'étira le long défilé avec ses drapeaux, ses délégations, ses bannières, ses corps de musique, ses insignes, ses chars allégoriques, la cavalerie, les pompiers, les zouaves pontificaux, les zouaves-pompiers, les corps de métier, divers groupes sociaux. Pendant quatre heures, 10000 personnes défilèrent, sous les arches et le long des rues, aux applaudissements de la foule. Suivirent le banquet et les feux d'artifice. Le banquet se déroula dans «la gaîté franche et gauloise», avant de passer aux santés, seize au total. P.-J.-O. Chauveau, dans le toast à la France, évoqua «la grande famille française [...] agenouillée au pied de l'autel [...] sur ce sol empourpré du sang de

\footnotetext{
${ }^{46}$ Fête nationale des Canadiens-Français célébrée d Québec en $1880 . .$. , p. 163.

${ }^{47}$ Fête nationale des Canadiens-Français célébrée d Québec en $1880 \ldots$, p. 180.
} 
Montcalm et de Wolfe». C'est aussi Wilfrid Laurier qui affirma qu'il n'y a pas «de pays qui jouissent de plus grandes libertés que le nôtre".

Dans son Rapport, Chouinard consigna «l'enthousiasme indescriptible [...] le caractère imposant, la splendeur inusitée des fêtes, et par dessus tout la valeur incontestable de ce que nous pouvons appeler la partie intellectuelle de la démonstration ${ }^{48}$ \%. L'évêque de Trois-Rivières, Mgr Louis Laflèche, parla de la mission providentielle du peuple canadien-français, notant que son maintien démontrait la volonté de Dieu ( "Digitus Dei est hic»). D'Ottawa, l'évêque J.Thomas Duhamel apporta aussi son appui, confiant que cette démonstration «donnera au peuple canadien l'occasion d'affirmer sa fidélité à la religion et sa résolution inébranlable de conserver sa langue et ses institutions. J'espère que l'œuvre de la colonisation occupera la plus sérieuse attention des hommes éminents qui prendront part aux délibérations."

Parallèlement à la convention, diverses autres rencontres eurent lieu: l'Union Allet des anciens zouaves, les sociétés de secours mutuels, un «Congrès catholique» organisé par le Cercle de Québec ${ }^{49}$. Mais la plus importante réunion, évidemment, fut la Conven-

\footnotetext{
${ }^{48}$ Fête nationale des Canadiens-Français célébrée d Québec en $1880 \ldots$, p. ix.

${ }^{49}$ Voir Chouinard, Fête nationale des Canadiens-Français célébrée d Québec en $1880 \ldots .$, p. 234 ss. Voir aussi le Tableau VII: «Convention des sociétés de bienfaisance canadiennes-françaises: Saint-Sauveur de Québec, le 25 juin $1880 »$, pour la liste des sociétés participantes, ibid., p. 593-595. Voir aussi: Actes et délibérations. Premier Congrès catholique canadien français tenu d̀ Québec les 25, 26 et 27 juin 1880. Annuaire $n^{\circ} 3$ du Cercle catholique de Québec 1879-1880, Montréal, Eusèbe Senécal, 1880, $384 \mathrm{p}$. Cet ouvrage veut publier «les discours prononcés en séance solennelle, et les rapports présentés aux divers bureaux ou commissions du Congrès».
} 
tion nationale des Canadiens-Français, qui tint trois séances les 25 et 26 juin 1880 , dans la grande salle des promotions de l'Université Laval. Quatre questions avaient été mises à l'ordre des discussions: les moyens de promouvoir les intérêts religieux des Canadiens-Français, les droits et les devoirs des Canadiens-Français catholiques, les intérêts intellectuels, les intérêts matériels. Chouinard rapporta que le but de la convention était de «réunir dans une seule et même assemblée, toutes les forces de notre nationalité», et que si l'on n'avait pas pu tout faire, il lui semblait au moins que la réunion avait élaboré «le programme de toutes nos Conventions nationales de l'avenir, car il faudrait des années pour l'étude et la considération des idées qu'il énonce ${ }^{50} \%$.

De nombreux discours, reproduits dans le rapport général publié en 1881 , reprirent les thèmes de la convention, en élaborant à leur sujet. La convention adopte, pendant que «toute l'assistance se tient debout», une adresse au Souverain Pontife. Dans son discours, le juge Routhier parla aussi de la mission de la race française au Canada, de son histoire, affirmant que «les pères de la nationalité canadiennefrançaise ont été de ces élus de la Providence». Routhier prévoyait, pour l'avenir du peuple canadienfrançais, une vocation française, de race latine, une «mission sociale, intellectuelle et religieuse». L'honorable P.-A Landry prononça un discours sur la situation des Acadiens. La deuxième commission recommanda la création d'une «union de tous les Canadiens», en insistant pour qu'elle s'appelât canadienne-française, et non française. En outre, on

${ }^{50}$ Chouinard, Fête nationale des Canadiens-Français célébrée d̀ Québec en 1880 ..., p. 257. 
préféra ne pas arborer le tricolore français, à saveur révolutionnaire, et on s'objecta au choix de la Marseillaise comme chant national, lui préférant plutôt Vive la Canadienne.

La commission de la colonisation ne put se réunir, mais des résolutions furent soumises à la convention. L'évêque Laflèche parla du luxe et du manque d'économie qui appauvrissaient les familles canadiennes, phénomène à l'origine de l'émigration des CanadiensFrançais vers les États-Unis. Lors du rapport de la cinquième commission (sciences, lettres et beauxarts), on fit lecture de quelques rapports, dont celui de Benjamin Sulte sur les lettres ${ }^{51}$, où il notait l'absence d'un public pour les livres. Sulte termina par une série de recommandations qui reprenaient les suggestions formulées, trois ans plus tôt, lors de la Convention littéraire tenue à Ottawa en 1877. Siméon Lesage prononça un discours sur l'agriculture, tandis que Joseph Tassé parla de l'émigration ${ }^{52}$, affirmant que la "province de Québec se serait sans doute développée plus promptement si elle n'eût pas écoulé de son sang généreux vers la Nouvelle-Angleterre, Manitoba et Ontario; mais il n'y a pas dans le fait, tel qu'il existe, raison de désespérer de l'avenir, oh! non». Pamphile Lemay parla, lui, de la littérature canadienne-française et de sa mission. On adopta aussi une résolution pour que les Acadiens et les Canadiens-Français, "ces deux rameaux si vivaces qui représentent le génie de la France en Amérique»

\footnotetext{
51 "Rapport de M. Benjamin Sulte sur les lettres», dans ibid., p. 414416.

52 Pour le discours de Joseph Tassé, voir dans Chouinard, p. 359-374. Trois ans plus tard, Joseph Tassé reprenait son texte dans Aux CanadiensFrançais émigrés. Discours, Ottawa, Imprimerie du Canada, 1883, 14 p.
} 
LES GRANDS CONGRES PATRIOTIQUES CANADIENS-FRANÇAIS

scellent «un pacte d'alliance fraternelle indestructible».

Parmi les quatorze comités créés pour la Fête nationale des Canadiens-Français, il y avait le "Comité de musique», nommé le 15 mars 1880 et composé de vingt-trois membres. Il organisa plusieurs concerts, fit chanter plusieurs chœurs. On avait songé à faire adopter «un hymne ou chant national accepté par tous les Canadiens-Français", mais le temps manquait pour faire un concours. On invita donc Calixa Lavallée, artiste réputé, à composer cet hymne, sur les paroles du juge Adolphe-Basile Routhier. C'est ainsi qu'après la messe du 24 juin 1880 , on chanta le God Save the Queen puis, suivant le discours de Mgr Antoine Racine, on interpréta l'hymne de Calixa Lavallée, pièce intitulée Ô Canada. Ce morceau était évidemment appelé à un très grand avenir puisque pendant près d'un siècle, avant de devenir l'hymne national de tous les Canadiens, il fut d'abord l'hymne national des Canadiens-Français ${ }^{53}$.

L'idée d'une fédération, l'Union nationale française de l'Amérique du Nord, fut relancée dans l'intention de réunir chaque année «tous les groupes d'origine française» pour la fête nationale, d'obtenir pour la race française sa juste part d'influence sur le continent, de veiller aux intérêts nationaux; en feraient partie «tous les membres des sociétés nationales ou les sociétés de secours». La devise de la fédération devait être «l'Union fait la force», son drapeau «le tricolore de la France» (proposition rejetée d'ailleurs) et l'insigne «la feuille d'érable et le castor», tandis que «l'air national» serait la Marseillaise (proposition

${ }^{53}$ Ibid., p. 140. 
également rejetée). Dans l'organisation de l'Union, on prévoyait sept grandes divisions (Québec, Ouest, Maritimes, Pacifique et trois divisions américaines). L'Ontario n'entrait dans aucune de ces catégories.

À Québec, on se félicita du résultat, les Québécois se flattant que la convention de 1880 représentât un modèle. Chouinard proclamait modestement, en latin, «Si vis monumentum, circumspice!" La lettre de l'archevêque de Québec, Elzéar-Alexandre Taschereau, au début du volume, abondait dans le même sens: "Quand une nouvelle génération, qui n'aura pas vu cette Convention de 1880 , voudra aussi, imiter notre exemple, elle ne saura mieux faire que de s'inspirer des mêmes pensées, et de suivre le même programme, pour avoir le même succès ${ }^{54}$." À beaucoup d'égards, la convention de 1880 annonçait les Congrès de la langue française. On peut déjà en délimiter une série de caractéristiques: les longs préparatifs, la mise en marche avec ses comités, les convocations, le régime des accueils, les défilés, les nombreuses cérémonies, les chars allégoriques, les visites aux monuments historiques, les discours, la présence de toutes les sommités religieuses et politiques, les séances plénières, le fonctionnement en commissions, l'adoption de rapports et de résolutions et, peu de temps après, la publication des actes dans de gros volumes contenant les discours, les rapports, les résolutions. Et, partout, la déférence aux autorités religieuses et politiques.

Tous ne partageaient pas ce grand bilan admiratif. C'est par exemple le cas de L.-O. David qui écrivait, en 1881: «Le temps des vaines démonstrations, des

\footnotetext{
${ }^{54}$ Fête nationale des Canadiens-Français célébrée d Québec en $1880 . . .$, p. viil.
} 
paroles inutiles est passé ${ }^{55} »$. Ce libéral se moquait en effet des bannières et des chars, du catholicisme excessif et ostentatoire, des chants de gloire, de l'éloge des vertus de la race, des rubans et des colliers brillants, des insignes et autres objets. David préconisait plutôt des remèdes pratiques, notant qu'on dépensait des sommes d'argent pour des rubans et des bannières, alors qu'il n'y avait "pas une seule salle nationale, pas un institut, pas une bibliothèque».

Montrer, réunir et prescrire. Ces trois fonctions d'un symbole s'exercèrent tout au cours de ces congrès aux États-Unis, à Montréal et à Québec. Le message commun se transmit d'autant plus facilement que chaque rencontre donna lieu à la publication des actes. Dans la province de Québec, il n'y eut plus d'autre convention comme telle, même si des fêtes importantes se produisirent à Montréal en $1884^{56}$ et à Québec en 1889.

En 1884, la Société Saint-Jean-Baptiste de Montréal décida de convoquer un congrès national, à l'occasion du "cinquantième» anniversaire de la Société. Messe, exposition, pique-nique, chars allégoriques, illuminations, feux d'artifice, tout y était ${ }^{57}$. De nombreuses personnalités politiques, religieuses et artistiques canadiennes-françaises participèrent à ce congrès présidé par l'ancien premier ministre

\footnotetext{
${ }^{55}$ L.-O. David, Mélanges historiques et littéraires (Montréal, Librairie Beauchemin, 1917, 238 p.), chapitre «1881 - La Saint-Jean-Baptiste», p. 136-138.

${ }_{56}$ P. Ph. Charette, 1834-84. Noces d'or de la Saint-Jean-Baptiste. Compterendu officiel des fêtes de 1884 d Montréal, Montréal, Typ. du Journal le Monde, 1884 , vili-514 p. +20 gravures.

${ }^{57}$ Rumilly, Histoire de la Société Saint-Jean-Baptiste de Montréal..., pp. 130 ss.
} 
provincial, P.-J.-O. Chauveau. Des sujets désormais classiques furent à l'ordre du jour: l'agriculture, l'émigration, le rapatriement des émigrés. Quant au projet de fédération des sociétés nationales, lancé à Montréal en 1874, repris à Québec en 1880 , il fut à nouveau entériné. On nota les progrès accomplis, notamment la fondation de paroisses dans les nouvelles régions, y compris dans l'est de l'Ontario. L'idée de construire un «Monument national» fut lancée. Laflèche fit un discours, liant à nouveau la sauvegarde de la foi et celle de la langue. Il s'agit done de thèmes connus et appelés à un grand avenir: la religion, la langue, les mours, les institutions, le Canada, le saint patron.

Plusieurs groupes ontariens participèrent au défilé de 1884, comme les Sociétés Saint-Jean-Baptiste du comté d'Essex, d'Amherstburg, de Pointe-aux-Roches, de Windsor, de Pin Court [Paincourt], de Cornwall, d'Alexandria, du comté de Prescott, d'Ottawa. S'y étaient aussi rendues la fanfare de Sainte-Anne et l'Union Saint-Joseph d'Ottawa. Un des chars, déjà, honorait Dollard des Ormeaux et ses dix-sept compagnons (le char de la section du Coteau Saint-Louis montrait une palissade avec, au centre, un Dollard tenant une bannière). Le député ontarien Joseph Tassé, au cours de la convention, fit un discours ${ }^{58}$.

Cinq ans plus tard, en 1889, la Société Saint-JeanBaptiste de Québec profita de sa fête patronale pour marquer l'inauguration d'un monument, sur le site du Fort Jacques-Cartier, c'est-à-dire le site où Jacques Cartier s'était établi en $1535^{59}$. Le monument Cartier-

\footnotetext{
${ }^{58}$ Cité dans Charette, 1834-1884. Noces d'or..., p. 201-207.

${ }^{59}$ H.-J.-J.-B. Chouinard, Fête nationale des Canadiens-Français célébrée à Québec 1881-1889. Histoire - Fêtes annuelles - Conventions -
} 
LES GRANDS CONGRÈS PATRIOTIQUES CANADIENS-FRANÇAIS

Brébeuf honorait Cartier et le jésuite Jean de Brébeuf, car les jésuites, en arrivant à Québec, avaient choisi le même site pour leur premier établissement. Ces événements s'inscrivaient dans la suite de l'inauguration, en 1855, du Monument aux Braves. Dans le rapport de ces fêtes, on répétait souvent que Québec était le «berceau du Canada-français».

Dans le défilé de la Saint-Jean en 1889, formant la "quatorzième division», marchaient la «Société SaintJean-Baptiste d'Ottawa, avec fanfare, drapeaux et insignes», suivie de l'Union Saint-Joseph d'Ottawa "avec bannière et insignes", de même que des délégations de la Société Saint-Pierre, de l'Union SaintThomas et de l'Association catholique de Secours mutuels d'Ottawa. Aussi, le conservateur Philippe Landry fit un discours remarqué. Le compte rendu indique également que parmi les onze sommités qui formaient «l'CEuvre du Monument Cartier-Brébeuf», se trouvait J.-C. Taché d'Ottawa. Ces événements indisposèrent même le fanatique Mail de Toronto, ce qui provoqua une réponse de Faucher de SaintMaurice, dans un texte intitulé «Un mot aux francophobes d'Ontario ${ }^{60} "$.

\section{D - LES CONVENTIONS ACADIENNES}

Lors de la convention de 1874 à Montréal, les Acadiens ne possédaient aucun regroupement distinct. En 1880, pour la rencontre de Québec, l'abbé Camille Lefebvre, curé de Memramcook, organisa une délégation de soixante-dix personnes qui se regroupèrent à Moncton, pour se rendre ensemble à

Documents - Inauguration du Monument Cartier-Brébeuf, Québec, Imprimerie Belleau \& Cie, 1890, p. 2.

${ }^{60}$ Chouinard, Fête nationale 1880-1889, p. 474-481. 
Québec, en train. C'est là que les rejoignit Pascal Poirier, arrivé d'Ottawa. Une des sept commissions de la convention de 1880 regroupait les Acadiensfrançais, comme les appelait Chouinard, sous la présidence du député G.-A. Girouard, avec Pascal Poirier comme secrétaire. La commission écouta le rapport préparé par Poirier «sur la situation des Acadiens dans la Confédération». La commission invita le clergé à fonder dans chaque paroisse des sociétés de colonisation. Selon Poirier, le petit peuple acadien avait "complètement disparu en 1755 ", mais après un siècle d'effacement, il renaissait enfin. En 1885, Pascal Poirier devint le premier sénateur acadien, puis, en 1890, Landry fut le premier Acadien nommé juge, en attendant la nomination par Rome du premier évêque acadien (Édouard-Alfred Leblanc) en 1912. Le rapport de la commission, en 1880, parlait de la colonisation et du collège de Memramcook. Surtout, on décida de convoquer, l'année suivante, une convention des Acadiens des trois provinces maritimes ${ }^{61}$.

Le premier grand rassemblement des Acadiens eut effectivement lieu les 20 et 21 juillet $1881^{62}$. La convention de Memramcook fut organisée par un comité présidé par Pierre-A. Landry, ministre des Travaux

${ }^{61}$ «Septlème commission: Des Acadiens. - Procès-verbal. - Rapports», dans Chouinard, Fête nationale des Canadiens-Français...1880-1889, p. 445-475. Le rapport de Poirier est reproduit, pp. 446-460. Sur la création de l'identité acadienne, à la fin du siècle dernier, voir J.-Yvon Thériault, L'Identité d̀ l'épreuve de la modernité. Ecrits politiques sur l'Acadie et les francophonies canadiennes minoritaires ([Moncton], Éditions d'Acadie, [c1995], 323 p.), notamment p. 222-229.

62 Sur la convention de Memramcook, voir Chouinard, Fête nationale des Canadiens-Français... 1881-1889 (Québec, 1890), p. 8-12. Aussi: Robert Rumilly, Histoire des Acadiens, 2 tomes, Montréal, Fides, [c1959], 1038 p. Chouinard indique dans son ouvrage de 1890 que N.-E. Dionne a publié dans le Courrier du Canada des correspondances décrivant la convention de Memramcook. 
publics du Nouveau-Brunswick, qui fit une tournée de propagande. On invita chaque paroisse à envoyer trois délégués (outre le clergé, qui est délégué d'office). Environ 5000 personnes se présentèrent au collège de Memramcook. Le ministre fédéral Hector Langevin vint d'Ottawa.

La convention travailla en commissions, la première portant sur le choix d'une «fête nationale pour les Acadiens des provinces maritimes», la deuxième sur l'éducation, la troisième sur l'agriculture, la quatrième sur la colonisation et l'émigration, enfin la cinquième sur la presse et la nécessité de l'encourager. Cette thématique se rattachait fort bien à celle des autres conventions de l'époque, tant aux ÉtatsUnis qu'au Canada. À la messe inaugurale, l'abbé M.-F. Richard prononça un discours dans lequel il développa trois grandes idées: qu'un peuple ne saurait être heureux sans suivre les sentiers de la vertu et de la justice, que la religion a exercé une influence bénéfique sur le peuple acadien, enfin qu'il existe des moyens propres à faire avancer les Acadiens sur la voie du bonheur et de la prospérité.

Après des débats animés entre les tenants de la Saint-Jean-Baptiste et les promoteurs d'une fête distincte, ce furent ces derniers qui l'emportèrent, amenant les délégués à consacrer l'Acadie à l'Assomption de la Sainte Vierge, bien que le ministre Landry eût préféré la Saint-Jean et d'autres la Saint-Louis. Outre

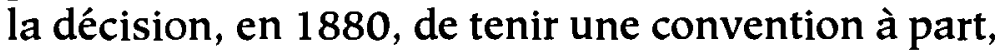
ce choix d'une patronne fut un premier geste "séparatiste» destiné à affirmer le particularisme acadien. En réponse aux vœux de la troisième commission, on fonda sur place une société de colonisation. 
La deuxième convention des Acadiens eut lieu à Miscouche (île-du-Prince-Édouard) en 1884. Ce congrès confirma l'Assomption comme fête nationale des Acadiens et choisit pour hymne national l'Ave Maris Stella. On adopta aussi, pour drapeau, le tricolore français avec une étoile d'or au coin supérieur gauche. Il y fut à nouveau question de colonisation et d'émigration. Pour organiser ces grands rassemblements, on mit sur pied la Société nationale L'Assomption. C'est elle qui convoqua, en 1889 , la troisième convention des Acadiens, tenue l'année suivante à Pointede-l'Église (Nouvelle-Écosse). On y discuta de la colonisation et de la question scolaire. La quatrième convention eut lieu à Arichat (île Madame, NouvelleÉcosse), et la suivante, en 1905, à Caraquet.

Depuis la "convention" acadienne de Memramcook, en 1881, les Acadiens, avec leur nouveau drapeau, leur nouvelle fête patronale, leur nouvel hymne national et leur nouvelle identité, formèrent la première "société distincte» en Amérique française. Bien que ne se considérant plus comme des Canadiens-Français, les Acadiens participèrent plus tard aux grands Congrès de la langue française au Canada, avec les FrancoAméricains, tant ceux de la Nouvelle-Angleterre que les Cadiens de la Louisiane.

\section{III - LES CONGRĖS PATRIOTIQUES ONTARIENS}

L'Ontario aussi a connu tôt les conventions de la Société Saint-Jean-Baptiste. En juin 1851, on fêta la Saint-Jean à Toronto, où séjournait le parlement provincial, dans la cathédrale Saint-Michel. Le jésuite R.-J. Tellier prêcha un sermon de circonstance ${ }^{63}$. L'an-

${ }^{63}$ Discours prononcé d la cathédrale de Toronto par le Père R.-J. Tellier, 
née suivante, à Ottawa, s'organisait une section de la Société Saint-Jean-Baptiste, un organisme dont l'histoire, au début, se confondit avec celle de l'Institut canadien-français. La société d'Ottawa était appelée à exercer une forte influence dans les milieux francoontariens ${ }^{64}$. D'autres sections de la Société SaintJean-Baptiste se formèrent dans l'Est, dans le Sud-Ouest et bientôt dans le Nord.

La Société Saint-Jean-Baptiste d'Ottawa avait été fondée par I. Champagne et quelques autres. Évoquant en 1883 les débuts de la Société en Ontario, Benjamin Sulte, alors président de la Société SaintJean-Baptiste d'Ottawa, nota les progrès réalisés par la population française de cette province. Selon le compte rendu publié par N.-E. Dionne, Sulte

fait connaître et apprécier le patriotisme des Canadiens français de la vallée de l'Ottawa. Il y a cinquante ans, il

de la Compagnie de Jésus, le 24 juin 1851, jour de la fête et en présence de l'Association de St. [sic] Jean-Baptiste, Toronto, Rollo Campbell, $1851,17 \mathrm{p}$.

${ }^{64}$ Sur la Société Saint-Jean-Baptiste d'Ottawa, voir: Madeleine Charlebois-Dirschauer, «La Naissance des soclétés sœurs: l'Institut canadien-français et la Société Saint-Jean-Baptiste de Bytown (18521856)», dans Solitude rompue. Textes réunis par Cécile CloutierWojciechowska et Réjean Robidoux en hommage d David M. Hayne (Ottawa, Éditions de l'Université d'Ottawa, "Cahiers du C.R.C.C.F.», 1986), p. 38-46. Voir aussi Henri Lallier, "La Société Saint-JeanBaptiste d'Ottawa. Un centenaire», dans Vie française 8(5), janvierfévrier 1954, p. 304-308; Laurier Rivet, La Saint-Jean-Baptiste d Ottawa (1853-1953), Mémoire de maîtrise, Université d'Ottawa, 1976, 171 p.; Joseph Tassé, «La Fête St. [sic] Jean-Baptiste. Discours prononcé par $M$. Joseph Tassé au banquet national à Ottawa, le 24 juin 1873 ", dans Revue Canadienne 10, 1873, p. 520-526; Fête patronale des Canadiens français, organisée par l'Association St-Jean-Baptiste d'Ottawa, [Ottawa], 1935, [13 p.]; Programme officiel des fêtes: Grand ralliement des Canadiensfrançais d Ottawa 21-24 juin 1913, Ottawa, La Cle d'Imprimerie d'Ottawa, 1913, 84 p.; [Louis Charbonneau], Programme-Souvenir d l'occasion du Centenaire de la Société Saint-Jean-Baptiste d'Ottawa: 1853-1953, Ottawa, Le Droit, 1953, 56 p. 
était presque impossible à nos compatriotes de Bytown de se déclarer Canadien-français; on leur en faisait un crime. On avait organisé une sorte de police secrète qui avait pour but de détruire le nom français dans la vallée de l'Ottawa. Ce système absurde était surtout dû au mauvais choix de l'immigration faite alors.

La première célébration de la fête de S[ain]t-Jean-Baptiste créa presque une révolution au milieu de ce peuple hostile aux Canadiens français. La procession eut lieu, mais avec la plus grande crainte. Cette affirmation de nos nationaux eut cependant un excellent effet, car depuis lors une entente de plus en plus cordiale s'est établie entre les Canadiens français et les nationalités étrangères, et aujourd'hui tout va pour le mieux.

M. Sulte est d'opinion qu'il importe de conserver le nom de Canadien-français, et tant que les Anglais du Canada ne parleront pas le français, il est ridicule de s'appeler simplement Canadien ${ }^{65}$.

Selon H.-J.-J.-B. Chouinard, écrivant en 1881, la Société Saint-Jean-Baptiste

s'est implantée de bonne heure dans la riche et puissante province d'Ontario, où elle existe depuis longtemps dans le comté d'Essex, et depuis deux ans dans Toronto, sa capitale, où le 24 juin 1879, nos compatriotes célébraient la fête de la Saint-Jean-Baptiste, sous les auspices de Mgr l'Archevêque Lynch, dans sa cathédrale Saint-Michel ${ }^{66}$.

Dans un tableau statistique, Chouinard indiquait l'existence en Ontario de sept sections: Amherstburg, Windsor, Sandwich, Lafontaine, Saint-François, Comté de Prescott et Ottawa ${ }^{67}$. En Ontario, les premières tentatives de fédération eurent lieu en 1900

${ }^{65}$ Discours de Sulte, résumé dans Dionne, Fête nationale des CanadiensFrançais..., p. 120-121.

${ }^{66}$ H.-J.-J.-B. Chouinard, Fête nationale des Canadiens-Français célébrée ¿̀ Québec en $1880 \ldots$, p. 32.

${ }^{67}$ Chouinard, Fête nationale des Canadiens-Français célébrée d̀ Québec en $1880 \ldots$, p. 606. 
LES GRANDS CONGRÈS PATRIOTIQUES CANADIENS-FRANÇAIS

et en $1906^{68}$, mais la Fédération des Sociétés SaintJean Baptiste de l'Ontario ne se constitua qu'en 1921.

Deux congrès patriotiques majeurs se déroulèrent en Ontario français: le congrès des sociétés SaintJean-Baptiste à Windsor, en 1883 , et, surtout, le Congrès d'éducation des Canadiens-Français d'Ontario, en 1910. Les thèmes abordés, le type de participation, les activités, beaucoup, ici, rappelait les autres congrès tenus aux États-Unis, au Québec et en Acadie.

\section{A - LE CONGRES DE WINDSOR (1883)}

Les congrès de Montréal (1874) et de Québec (1880) avaient démontré l'intérêt d'organiser des rassemblements patriotiques généraux.

En Ontario, la plus ancienne région de peuplement canadien, remontant au milieu du XVIII ${ }^{e}$ siècle, se trouvait le long de la rivière du Détroit, dans la région de l'Assomption (aujourd'hui dans la ville de Windsor, au sud-ouest de l'Ontario). Les premiers colons français s'établirent ici à compter des annêes 1740 , occupant des terres à l'Assomption, mais aussi en aval, le long de la Petite Côte. À la fin du XIX siècle, le peuplement gagna les régions en amont de Windsor, au sud du lac Sainte-Claire, dans les environs de Pointe-aux-Roches, Belle-Rivière, SaintJoachim, Paincourt, de même qu'à l'intérieur des terres du comté d'Essex, voire de Kent, plus à l'est.

\footnotetext{
${ }^{68}$ Annonçant déjà le grand congrès canadien-français d'Ontario qui se tint en 1910, ll y eut au début du siècle, au sein de la Société SaintJean-Baptiste d'Ottawa, un projet de «Fédération catholique et nationale des Canadiens-Français de la province d'Ontarlo». Voir à ce sujet: René Dionne, «1910. Une première prise de parole collective en Ontario français», dans les Cahiers Charlevoix 1, 1995, p. 41-43.
} 
Les colons qui s'établirent alors sur ces terres faisaient partie d'un vaste mouvement migratoire qui, depuis l'est du Canada, s'étendait vers le Mid-Ouest américain, à Chicago et au-delà. Ainsi, la population française du Michigan était alors considérable, ce qu'atteste bien, à l'époque, la présence d'une vingtaine de «sociétés nationales» dans ce seul État ${ }^{69}$.

La plus «mémorable» tentative de réunir en congrès les sociétés patriotiques de l'Ontario et du Michigan eut lieu en 1883, à Windsor, à l'occasion de la Saint-Jean-Baptiste, fête qu'on célébra le 25 juin $1883^{70}$. À cette occasion, la société d'Essex accueillit de «nombreux frères français partis de tous les coins du Canada et des États-Unis», accourus de Pointe-aux-Roches, Amherstburg, Paincourt, Détroit, Lansing, Milwaukee, Bay-City, Chatham, Ottawa, Montréal et Québec. Bref, pour citer N.-E. Dionne, auteur d'un compte rendu de la rencontre, "Toute la famille canadienne[-]française avait envoyé des représentants». Mais ce qui rehaussa le plus le prestige de cette rencontre, ce fut la présence de quelques invités de marque ${ }^{71}$. Ces illustres visiteurs purent constater l'état de la communauté franco-ontarienne, ses succès et ses misères.

\footnotetext{
${ }^{69}$ T. S[ain]t-Pierre, Histoire des Canadiens du Michigan et du comté d'Essex, Ontario, Montréal, Typographie de la "Gazette», 1895, [iv]348 p. Voir surtout le chapitre sur les "Sociétés nationales", p. 247260.

70 N.-E. Dionne, Fête nationale des Canadiens-Français célébrée d Windsor, Ontario. Le 25 juin 1883, Québec, Imprimerie Léger Brousseau, 1883,152 p. Un compte rendu de la rencontre et le texte des discours se trouvent aussi dans H.-J-.J-B. Chouinard, Fête nationale des Canadiens-Français [...] 1881-1889, Québec, 1890, p. 17-54. ${ }^{71}$ Le clergé local était bien représenté, d'abord par les pères basiliens de Windsor, mais aussi par le clergé de l'extérieur, l'abbé HenriRaymond Casgrain, l'abbé Émard (de Montréal), l'abbé A.-D. Gélinas (de Yamachiche). À la messe diacre-sous-diacre, les places d'honneur
} 
Comme à Montréal (1874), à Québec (1880), à Memramcook (1881) et aux conventions francoaméricaines, le programme comportait un volet religieux (la messe, les sermons, le défilé), mais aussi une rencontre patriotique, sous la forme d'une convention. Les activités du 25 juin 1883 à Windsor commencèrent par la messe, ce qui permit à N.-E. Dionne de signaler le caractère catholique de cette rencontre:

Qu'il était beau et imposant le spectacle de tous nos Canadiens de l'ouest d'Ontario, au commencement de leur fête nationale, venant s'agenouiller au pied de l'autel du Seigneur, afin de montrer qu'avant tout ils sont catholiques, qu'ils n'ont pas dégénéré des hardis pionniers et explorateurs qui allèrent un jour, il $\mathrm{y}$ a près de deux siècles, planter la croix et arborer l'étendard de la civilisation sur les bords de la rivière Détroit ${ }^{72}$.

La partie religieuse se déroula dans l'église de l'Assomption, de Windsor. On profita de l'occasion pour faire une quête «au profit d'une nouvelle église canadienne[-]française que l'accroissement de la population a[vait] rendue nécessaire dans Windsor". Mlle Joséphine Baby et J.-G.-H. Bergeron, député de Beauharnois, aussi Mlle Hedwidge Ouellette et le docteur J.-P. Rhéaume, se chargèrent de cette collecte. Une chorale chanta la $12^{\mathrm{e}}$ messe de Mozart.

étaient nombreuses: le docteur C.-E. Casgrain, sir Hector Langevin, ministre fédéral, le député ontarien Honoré Robillard (Russell), le juge T.-J.-J. Loranger (de Montréal), F.-E. Campeau d'Ottawa, Théodule Girardot de Windsor, l'honorable Adolphe Caron (ministre de la milice), le sénateur F.-X-.A. Trudel, Benjamin Sulte (président de Société Saint-Jean-Baptiste d'Ottawa), le docteur J.-P. Rhéaume d'Amherstburg, Siméon Lesage (président de la Société Saint-Jean-Baptiste de Québec), N.-E. Dionne, T.-C. Casgrain (professeur à l'université Laval), N. Levasseur, L.-J. Demers, D. Odette, J.-U. Prieur. La société de Toronto manquait, mais son président, $L$. Charlebois, avait envoyé ses regrets. D'Ottawa, Joseph Tassé avait aussi envoyé des regrets.

${ }^{72}$ N.-E. Dionne, Fête nationale des Canadiens-Français..., p. 4-5. 
Selon N.-E. Dionne, le sermon prononcé par le curé de Paincourt, l'abbé Bauer, récemment arrivé au Canada, «a tenu son auditoire sous le charme pendant près d'une heure». Bauer se félicita de prendre la parole devant "une assemblée où se trouv[ai]ent réunis les représentants et l'élite de la race canadienne répandue sur le continent américain». Le curé évoqua leur but de «raviver au cour de [leurs] compatriotes le sentiment national, en leur rappelant les hautes destinées que leur réserve la divine Providence, et, leur offrir la meilleure occasion de s'organiser à cette fin, et de se concerter sur la marche à suivre pour y arriver plus sûrement». Bien que récemment arrivé au Canada, il avait aussitôt vu l'œuvre de la Providence dans l'histoire canadienne-française: Digitus Dei est hic (le doigt de Dieu est là), la même phrase latine que Laflèche avait utilisée à Québec, trois ans plus tôt. Bauer examina aussi l'histoire du Canada, celle des fondateurs qui avaient «abandonné leur patrie pour s'en venir fonder ici, une patrie nouvelle faite à son image, $c$-à-d [sic] française et catholique ${ }^{73}$ r.

Après la messe, le défilé longea les principales rues de Windsor, avant le retour jusqu'à la rue Ouellette où on avait érigé une grande arche portant, au-dessus des portraits de sir George-Étienne Cartier et de sir John A. Macdonald, l'inscription Nos chefs canadiens. L'arche portait aussi deux autres inscriptions: $\hat{O}$ Canada, mon pays, mes amours et L'Union fait la

\footnotetext{
${ }^{73}$ Le sermon de l'abbé Bauer, dans N.-E. Dionne, Fête nationale des Canadiens-Français..., p. 9-27. À la décharge de ces providentialistes, un malin pourrait rappeler qu'à la même époque, beaucoup de libéraux expliquaient l'évolution du monde par les actions d'une «main invisible» (Adam Smith); les catholiques, plus confiants, se contentaient d'un simple doigt!
} 
force. Se suivaient, dans le défilé, les cinq sociétés Saint-Jean-Baptiste de la région (Tilbury, le comté américain de Wayne, Détroit, Sandwich, Windsor), quelques fanfares, les «délégations de Québec, de Montréal et d'Ottawa», puis des chars allégoriques et, enfin, la voiture transportant le président. La procession pavana un petit saint-jean-baptiste, rôle tenu par le jeune Pecquenot, fils du gendre de Théodule Girardot.

À quatorze heures commençait la convention, sous la présidence du docteur Charles-E. Casgrain, du vice-président $\mathrm{D}$. Odette et du secrétaire Théodule Girardot, inspecteur d'école. Sur l'estrade tout près, on remarquait, entourant le président Casgrain, sir Hector Langevin, l'honorable Adolphe Caron, le sénateur Trudel et de nombreuses autorités politiques, religieuses et culturelles. Casgrain fit le discours de présentation, rappelant la devise de la Société SaintJean-Baptiste: «Mon Dieu, ma religion, ma patrie». Il se félicitait de la présence des délégations de l'Ontario et des États-Unis, «même des extrémités de la province de Québec».

Sir Hector Langevin prononça ensuite un discours ${ }^{74}$. Étonné de trouver un milieu français «à près de trois cents lieues de notre vieux Québec», il déclara: «Comme vous, je suis habitant d'Ontario, je suis électeur à Ottawa. J'ai voté aux dernières élections locales pour un député à la législature provinciale d'Ontarior. Selon Langevin, il y avait désormais autant de Canadiens-Français en Ontario que d'Acadiens dans les provinces maritimes et il n'en tenait donc qu'aux gens d'Essex de garder leur langue. Selon le compte rendu,

${ }^{74}$ Discours de Langevin, dans N.-E. Dionne, Fête nationale des CanadiensFrançais..., pp. 44 ss. 
«Je vous dirai donc, je dirai surtout aux dames d'Essex: la conservation de notre nationalité dépend surtout des dames». Et d'ajouter, pour fixer le droit des CanadiensFrançais de vivre en Ontario: «Le drapeau anglais, c'est le nôtre. Il est le nôtre parce qu'il est le drapeau de notre Souveraine; il est le nôtre surtout parce qu'il a reçu la consécration du sang. En 1812, nous avons versé notre sang pour la défense de ce drapeau, et depuis ce temps, il doit protéger tous nos droits comme ceux de tous les autres sujets britanniques, il doit abriter la nationalité canadienne-française comme celle de nos concitoyens canadiens[-]anglais".

Langevin encourageait l'usage du français, l'éducation, mais surtout l'industrialisation:

Vous possédez le sol et vos terres sont des plus fertiles. Développez votre agriculture. Mais ce n'est pas assez. Tâchez de promouvoir vos industries. Encouragez l'établissement de ces manufactures qui ont fait la fortune de vos voisins des États-Unis. Manufacturez, afin de tirer partie de toutes les richesses de votre pays, et de fournir à vos enfants toutes les ressources nécessaires pour les attacher au sol natal et les faire bénéficier de tous les avantages naturels du Canada. Par l'industrie, vous multiplierez, au bénéfice de vos enfants, leurs chances d'avenir ${ }^{75}$.

L'homme politique résuma ensuite son discours en anglais. On pourrait difficilement taxer ce discours d'agriculturiste, étant donné l'objectif du travail dans les manufactures et de l'enrichissement, proposés aux populations françaises.

L'honorable Adolphe Caron prononça ensuite un discours où il fut question de «la grande famille canadienne-française». Il évoqua des souvenirs historiques, rappela le rôle de Québec et ses liens anciens avec la colonie du Détroit. Caron voulut aussi encourager l'usage de la langue française: "Vous devez

${ }^{75}$ Discours de Langevin, dans Dionne, Fête nationale des CanadiensFrançais..., p. 46. 
LES GRANDS CONGRES PATRIOTIQUES CANADIENS-FRANÇAIS

donc, vous surtout, mères de famille, vous attacher à la conserver intacte dans vos familles». Caron aussi résuma son discours en anglais.

Puis le jeune avocat Thomas-Chase Casgrain, professeur à l'Université Laval, prit la parole. Il rappela les fêtes à Québec en 1880: "Il y avait là, groupés autour de l'autel, les membres de la grande famille canadienne-française». Il dressa un répertoire des héros passés: Champlain, Laval, Jogues, Brébeuf, Lalemant, Montcalm, Louis-H. Lafontaine, GeorgeÉ. Cartier, mais il ajouta aussi les noms d'Adolphe Caron et de Hector Langevin, vers lequel les regards se tourneraient certainement après la disparition de Macdonald. Casgrain nota avec satisfaction l'existence d'une littérature canadienne-française (Garneau, Ferland, Taché, Chauveau, Faucher de Saint-Maurice, Bégin, Routhier). Les Canadiens-Français, capables de toutes les réussites, devaient persévérer, confiants que «notre nationalité ne peut crouler parce qu'elle a pour base la religion». Mais il y avait aussi l'éducation: «À côté de l'Église, il y a l'école, à côté du prêtre, travaillant tous les deux à l'unisson, il y a l'instituteur [...]. Vos écoles canadiennes, voilà encore un des secrets de votre force d'aujourd'hui, voilà un des moyens puissants que vous avez pris pour conserver votre nationalité». Thomas-Chase Casgrain, natif de la région de Windsor, salua ensuite les efforts de Théodule Girardot, «ce vétéran de nos luttes nationales dans le comté d'Essex [...]. Si vous avez appris à parler le français, si aujourd'hui vos enfants ont des instituteurs canadiens-français, s'ils ont l'immense avantage d'avoir des écoles canadiennesfrançaises, à qui est-ce dû, répondez; à M. Girardot». Girardot, immigrant de France, avait enseigné à Casgrain, ce qui constituait «un des plus doux 
souvenirs» de sa jeunesse. Casgrain parla de l'importance de conserver le français, à l'école, dans la famille, pour la religion.

Au sujet de l'Angleterre et du contrat que les CanadiensFrançais avaient avec elle, Casgrain expliqua: «C'est à nous, Canadiens-Français, descendants des découvreurs et des civilisateurs de ce pays, à donner aux autres nationalités l'exemple: voilà notre rôle, voilà notre mission, mission patriotique à laquelle il ne nous est pas permis de faillir». Ce fils de la région termina son discours en disant:

Un peuple, messieurs, c'est une grande famille dont les membres sont unis ensemble par les traditions, par les souvenirs, par le passé, par les aspirations de l'avenir. Il faut de temps à autre, le réunir ce peuple, appeler ensemble les enfants qui sont éloignés, les rapprocher les uns des autres, et en leur rappelant les grands souvenirs du passé, les armer contre les orages qui peuvent être cachés derrière l'horizon.

Abordant un autre thème appelé à résonner encore un siècle, Thomas-Chase Casgrain ajoutait: «Mes amis du Bas-Canada, ils l'avoueront franchement, ne vous connaissent pas assez intimement jusqu'à ce jour, ne vous ont pas montré tout l'intérêt que vous méritiez à tant de titres; on pensait bien aux Canadiens des États-Unis et on semblait ignorer qu'aux extrémités d'Ontario il y avait un groupe de 20,000 Canadiens-Français dont le patriotisme a enfanté des prodiges». Voilà un sujet que reprendront des douzaines d'orateurs au cours des Congrès de la langue française, y compris l'abbé Lionel Groulx.

Conscrit à la dernière minute en l'absence de la délégation de Montréal, le sénateur F.-X.-A. Trudel déclara qu'on avait placé la capitale du Canada (Ottawa) dans une région qu'on croyait inaccessible 
LES GRANDS CONGRÈS PATRIOTIQUES CANADIENS-FRANÇAIS

aux Canadiens-Français. Or des progrès furent accomplis: la députation fédérale française s'est imposée, quelques-uns de ses membres furent à l'origine de la Société Saint-Jean-Baptiste d'Ottawa, on fit élire trois députés canadiens-français dans l'est de l'Ontario. Trudel salua la survivance du groupe français de la région d'Essex, dans

cette riche, puissante et orgueilleuse province d'Ontario, si essentiellement Anglo-Saxonne, si envahissante, si exclusive de toute idée, de toute coutume, de toute institution française catholique, si hostile à tout ce qui tient à notre nationalité. Cette province d'Ontario [...] bann[i]ssant systématiquement la langue française, décourageant et même combattant avec acharnement tout ce qui pouvait être de nature à lui permettre de s'établir et même de se faire entendre dans ses limites? Cette province belliqueuse dont les deux cris de guerre contre l'élément catholique français ont été durant plus de vingt ans: No Popery! No French Domination! lorsque du côté du sud et de l'ouest s'avançait, avec un pouvoir non moins formidable, non moins anti-français, la grande république des États-Unis ${ }^{76}$.

Trudel nota bien que «la Confédération a réuni par le lien politique et social tous les groupes français des provinces maritimes, de la province de Québec, de celle d'Ontario, du Manitoba et de l'extrême NordOuest. Le sentiment national et les organisations de la S[ain]t-Jean-Baptiste ont rapproché les groupes et cimenté l'alliance non seulement des Canadiens habitant notre territoire mais encore de ceux qui sont disséminés, sur divers points des États-Unis». Voilà bien défini ce qu'était le «Canada français».

On fit aussi la lecture de lettres envoyées par P.-J.-O. Chauveau, par Louis Fréchette, par Joseph Tassé et par quelques autres personnalités. Puis on entendit le

${ }^{76}$ Discours de Trudel, dans N.-E. Dionne, Fête nationale des CanadiensFrançais... p. 92-93. 
discours de Siméon Lesage, président de la Société Saint-Jean-Baptiste de Québec, qui apporta, entre autres, les salutations du premier ministre de la province de Québec, J.-A. Mousseau, de trois journaux de Québec et de plusieurs personnalités de cette province. Lesage rappela que

Montréal a inauguré par la convention de 1874 , ce que je serais tenté d'appeler la convocation périodique de nos États généraux. En 1880, Québec a eu sa convention non moins brillante et non moins féconde que la première en résultats pratiques: l'une avait resserré nos liens avec tous les groupes de Canadiens épars dans les États-Unis, l'autre les a consolidés et a rattaché au tronc principal la branche acadienne des provinces maritimes. Aujourd'hui, c'est le tour de Windsor, de cette ancienne colonie du Détroit $[\ldots]^{77}$.

Lesage termina en s'adressant aux cultivateurs d'Essex: «Vous possédez sans aucun doute la partie la plus fertile du domaine canadien. Vous représentez la paroisse canadienne, telle que nous l'avons chez nous; vous êtes les maîtres absolus du sol; vous avez été et vous êtes encore la pierre angulaire de la nationalité. Continuez à vous maintenir comme l'on[t] fait vos pères». Ce discours agriculturiste tranchait sur celui de Langevin.

Avant de se quitter et de se retrouver au banquet du soir à l'hôtel Crawford, la convention adopta une résolution:

Que, vu que la langue française est la langue de nos ancêtres, et que sa conservation parmi nous est une des principales sauvegardes de notre religion et de nos traditions nationales, le plus grand encouragement lui soit accordé, surtout dans nos écoles et de la part des hommes d'état [sic] de notre origine ${ }^{78}$.

${ }^{7}$ Le discours de Siméon Lesage, dans N.-E. Dionne, Fête nationale des Canadiens-Français..., p. 147.

${ }^{78}$ Cité dans Dionne, Fête nationale des Canadiens-Français..., p. 127. 
En soirée, se tenait un grand banquet, dans la tradition de la Saint-Jean. Trois cents convives se rassemblèrent dans le réfectoire de l'hôtel Crawford, décoré de banderoles: Rendre le peuple meilleur; Union, Français, Patrie; Nos traditions, Jacques Cartier, Notre Dieu; Religion. Sir Hector Langevin prononça son discours, suivi de l'honorable T.-J.-J. Loranger, puis de N. Levasseur, président de la presse associée de la province de Québec. De nombreuses santés furent portées à la Reine, au gouverneur général, à la religion et au clergé, aux ministres de Sa Majesté, au 24 juin, à la France, aux États-Unis, à la province d'Ontario, aux sociétés canadiennes-françaises, aux dames, aux hôtes et à la presse.

Selon N.-E. Dionne, qui publia le compte rendu de cette rencontre, "La démonstration a été digne en tout de cette belle et patriotique fraction de la nation canadienne, qui a su prouver aux nombreux frères français partis de tous les coins du Canada et des États-Unnis ce que peuvent produire chez eux l'amour de la patrie et le culte de la religion», renchérissant, pour bonne mesure, sur «ce jour, à jamais mémorable». Par politesse peut-être, Dionne affirma que la procession de Windsor en 1883 valait celle de Québec en 1880 "si on tient compte du milieu où elle s'est faite». Joseph Rhéaume, président de la Société SaintJean-Baptiste d'Amherstburg, proposa de tenir une convention comme celle de 1883 tous les dix ans dans le comté d'Essex; étant donné leur grande utilité. Mais, selon le compte rendu du Congrès d'éducation des Canadiens-Français d'Ontario de 1910, le secrétaire Télesphore Lemay mourut et ces résolutions restèrent sans suite. 
Ce congrès de Windsor et d'autres, organisés localement, ont en quelque sort préparé le grand rassemblement de 1910 à Ottawa.

\section{B - LE CONGRÉS DE 1910 À OTTAWA}

Dans l'histoire de l'Ontario français, le Congrès d'éducation des Canadiens-Français d'Ontario ${ }^{79}$, tenu à Ottawa en janvier 1910, occupe une place centrale. C'est alors que fut fondée l'Association canadiennefrançaise d'éducation de l'Ontario (ACFÉO), un organisme que le Règlement XVII (1912-1927) allait bientôt précipiter au cour de la tourmente politique, mais c'est aussi, selon la terminologie de René Dionne, une première "prise de parole ${ }^{80}$ " par les "Canadiens-Français d'Ontario», c'est-à-dire les Franco-Ontariens. Bien qu'intéressé avant tout à la question scolaire, le Congrès de 1910 aborda aussi des questions "d'intérêt général». Ce deuxième volet (les questions générales) relie cette rencontre aux autres conventions convoquées dans le demi-siècle précédent. En Ontario, des rassemblements d'envergure avaient eu lieu en 1877 , lors de la Convention littéraire, mais aussi lors des célébrations de la SaintJean-Baptiste à Windsor en 1883. En 1910, on gardait encore le souvenir des fêtes célébrées à Ottawa en 1885, comme l'attestent Chouinard et Gatineau, qui ont parlé de la "grande Convention Canadienne à Ottawa, le 24 juin [1885 $]^{81}$ ».

${ }^{79}$ Congrès d'éducation des Canadiens-Français d'Ontario 1910. Rapport officiel des séances tenues dottawa, du 18 au 20 janvier 1910 (Questions d'éducation et d'intérêt général), Ottawa, Association canadienne-française d'éducation [d'Ontario], 1910,363 p.

Bo René Dionne, «1910. Une première prise de parole collective en Ontario français", dans les Cahiers Charlevoix 1, 1995, p. 15-124.

${ }^{81}$ Chouinard, Fête nationale des Canadiens-Français [...] 1881-1889, 
Au début de ce siècle, ce sont les problèmes de l'enseignement qui agitaient les élites francoontariennes. Le système scolaire ontarien avait été mis en place progressivement au cours du XIX ${ }^{e}$ siècle. Le personnage ontarien le plus influent dans la création du système scolaire provincial fut Egerton Ryerson, qui occupa, de 1846 à 1876 , le poste de surintendant de l'éducation. Il contribua largement à rendre l'accès à l'école plus libre, à améliorer la qualité de l'enseignement en surveillant les programmes d'études et la formation des enseignants. Mais l'amélioration de l'enseignement passait par l'uniformisation (manuels sanctionnés, formation des enseignants dans des écoles normales approuvées, cours d'études communs à toutes les écoles). Cette politique se heurta à la volonté des CanadiensFrançais de l'Ontario de posséder des écoles bilingues, le plus souvent françaises, surtout à partir de la fin du siècle dernier. Des règlements gouvernementaux en 1885 et 1890 avaient tenté, vainement, d'imposer l'anglais comme seule langue d'enseignement. Le terme d' "écoles françaises-anglaises" servait au ministère de l'Éducation de l'Ontario, créé en 1876 , pour désigner les écoles françaises ou bilingues de la province. Situées surtout dans le Sud-Ouest et dans l'Est, celles-ci se transformèrent en grand nombre, durant les années 1890 , en écoles séparées, c'est-àdire catholiques.

p. 85. Toutefois, les discussions de cette convention de 1885 , contrairement aux autres, ne semblent pas avoir engendré une publication autonome. À ce sujet, René Dionne nous signale que plusieurs articles, sous le titre "La Fête Nationale», parurent dans Le Canada pendant les mois précédant la Saint-Jean et que F.X. Valade se rendit en Louisiane au cours de l'hiver; voir J.-C. Taché, «Rapport officiel de la Fête Nationale à Ottawa", dans Le Canada $7, \mathrm{n}^{\circ} 142$, vendredi 3 juillet 1885 . 
À cette époque, deux grands courants idéologiques s'affrontaient au Canada: le nationalisme canadienfrançais et l'impérialisme britannique. L'Ontario, comme principale province du pays, connut l'affrontement de ces deux courants. Le gouvernement conservateur de James P. Whitney, élu en 1905 avec l'appui du clergé catholique irlandais, pouvait compter sur l'appui non seulement des orangistes, soutiens traditionnels du parti conservateur, mais aussi des catholiques irlandais. En somme, tout le monde, sauf les Canadiens-Français, était d'accord pour supprimer les écoles françaises. Des questions surgirent à propos des manuels approuvés, mais surtout autour de l'accréditation des enseignants dans les écoles françaises-anglaises de la province. À ce sujet, l'inspecteur Télesphore Rochon avait organisé, en mars 1907, un Congrès pédagogique afin d'étudier le régime scolaire français de l'Ontario. Ce congrès des instituteurs bilingues demanda des inspecteurs bilingues pour les écoles bilingues et aussi que des écoles modèles (écoles de formation pédagogique pour les certificats de deuxième catégorie) ouvrent à Ottawa et dans le Nipissingue. La délégation chargée de faire connaître ces résolutions au ministre de l'éducation, R.-A. Pyne, se composait de Martial Côté, président de la Commission des écoles séparées d'Ottawa, du curé I.-Urgel Forget, d'Embrun, du jésuite Guillaume Lebel, de Sudbury, et d'Aurélien Bélanger, inspecteur d'école. L'archevêque d'Ottawa, I.-Thomas Duhamel, en était le président d'honneur. Ce congrès avait réussi à porter la question scolaire à l'avant-scène. En 1909, le gouvernement commanda à son inspecteur en chef, F.W. Merchant, d'enquêter sur la situation des écoles françaises-anglaises dans l'Est. Il trouva des lacunes, alors que les menaces 
s'appesantissaient sur le régime scolaire bilingue. C'est dans ce contexte surchargé que les CanadiensFrançais de l'Ontario entreprirent, après 1908, de tenir un grand congrès pour examiner la question scolaire.

Comme les autres conventions, le congrès de 1910 bénéficia de toutes les bénédictions cléricales voulues. Ces approbations parurent, comme d'habitude, au début du livre des actes de la rencontre. Pourquoi une convention? L'abbé A. Beausoleil, curé de Fournier, répondit dans la préface:

La nécessité de réunir en une convention les CanadiensFrançais d'Ontario s'imposait donc avant toute autre tentative d'action; il fallait faire le dénombrement de nos forces, souder étroitement ensemble tous ces groupes nationaux dispersés par toute la province, étudier notre état social, donner une direction sage, ferme en même temps qu'uniforme, à nos efforts; en un mot, former bloc devant l'opinion.

Dans cette même préface, Beausoleil rappelait encore que ce projet de congrès, qu'on croyait tout juste digne «à charmer les sombres rêveries de sociologues en détresse», s'était réalisé "par une disposition providentielle des esprits et des choses». La thématique reprise par Beausoleil renvoyait au contenu des autres conventions, quand il affirmait que cette rencontre «marque d'un jalon historique l'étape nouvelle que vient de franchir la race française en ce pays», que «ce mouvement de réveil national» s'est répercuté partout, pour arrêter «l'anglification», que les Canadiens-Français de l'Ontario manquaient de la cohésion nécessaire et d'unité d'action pour résister à l'anglification, qu'il fallait mobiliser les forces, que «nos frères de la province de Québec ignorent généralement la situation plus que difficile qui nous 
est faite dans Ontario». Ces thèmes sont bien répertoriés.

Hier comme aujourd'hui, les Franco-Ontariens fondèrent en partie leurs revendications sur des droits historiques. Ainsi, le Rapport du congrès commençait par un texte intitulé "L'Ontario français. Esquisse historique», signé L[ouis] L[ejeune], auteur du futur Dictionnaire général du Canada (1931). Un deuxième chapitre, dans les actes, décrivait en détail les préparatifs du congrès de 1910. Dans ce texte, les organisateurs du congrès se réclamaient explicitement du congrès de Windsor en 1883. Par ailleurs, il y avait eu, au début de ce siècle, le projet d'une Fédération catholique et nationale des Canadiens-Français de la Province d'Ontario ou d'Union canadienne-française, un projet lancé en 1905 par Joseph-Alphonse Lévesque, de Bonfield ${ }^{82}$. Mais ces divers projets n'avaient pas abouti. Enfin, en 1907, le Congrès pédagogique avait rappelé l'importance des questions scolaires.

Le juge A. Constantineau fut le premier à discuter avec d'autres de l'idée d'un grand congrès. Le projet fut proposé explicitement, en septembre 1908, dans Le Moniteur, un hebdomadaire de Hawkesbury, où Louis des Érables et Raoul Desprès commencèrent à prêcher l'union des Canadiens-Français de l'Ontario, au-delà des divisions de partis, au point de vue de l'éducation: «L'avenir de notre race dans Ontario dépend de l'éducation que recevront les petits Canadiens-

\footnotetext{
${ }^{82}$ Raymond Tremblay, ptre, a récemment transcrit et édité le "Journal de Joseph-Alphonse Lévesque 1903-1906» et le "Journal de JosephAlphonse Lévesque 1918-1920\%. L'éditeur a produit, pour circulation privée, quelques copies des notes de Lévesque. Le manuscrit original se trouve dans les archives des jésuites de Sudbury, à la Résidence Albanel de l'Université de Sudbury.
} 
Français, c'est là un fait certain», affirmait un texte publié dans le compte rendu du Congrès. C'est le curé $A$. Beausoleil qui donna suite à ces articlesprogrammes en lançant dans un texte signé «J.B. Ontario», le 18 décembre 1908, l'idée d'un Congrès des Canadiens-Français d'Ontario. Après avoir signalé que «Les congrès, d'ailleurs, sont à l'ordre du jour», Beausoleil ajoutait:

Nous sommes plus de 235,000 Canadiens-Français ici sur le sol d'Ontario; nous y sommes pour y rester; nous y sommes pour $y$ vivre en citoyens paisibles mais déterminés à garder le précieux héritage de nos traditions nationales, notre langue, notre foi; les luttes ne nous feront pas peur, pas plus que les tracasseries administratives n'amoindriront la ferveur de nos réclamations; nous sommes unis à tout jamais; nous formons bloc; désormais, nos sympathies et nos votes iront du côté où nous trouverons justice et bienveillance ${ }^{83}$.

L'Action sociale de Québec reproduisit peu après l'article de Beausoleil, puis Le Temps d'Ottawa approuva le projet. Une réunion le 28 décembre 1908 , dans une salle de l'Union Saint-Joseph du Canada, lança officiellement le projet d'un congrès. Assistaient à la réunion le juge A. Constantineau, les abbés A. Beausoleil, S. Corbeil et O. Lalonde, aussi Côté (commissaire d'école à Ottawa), les docteurs R. Chevrier et R.-H. Parent, C.-S.-O. Boudreault (président général de la Société Saint-Jean-Baptiste d'Ottawa), J.-M. Fleury (professeur à l' "école modèle" bilingue d'Ottawa), les inspecteurs Aurélien Bélanger et V.Hector Gaboury, Arthur Charbonneau (ancien commissaire d'école). Constantineau et Beausoleil furent chargés de rédiger une circulaire pour inviter les principaux citoyens des environs d'Ottawa à une

${ }^{83}$ Cité dans Congrès d'éducation des Canadiens-Français 1910, p. 50-51. 
autre réunion le 10 janvier 1909, à l'Union SaintJoseph du Canada. La décision d'un congrès était donc prise.

La réunion fut reportée une, deux fois... pour qu'on puisse écouter le sénateur Pascal Poirier parler des congrès acadiens, ce qu'il fit finalement le 24 janvier $1909^{84}$. Poirier parla des congrès acadiens, commencés modestement dit-il; le sénateur Napoléon-A. Belcourt approuva l'idée d'un congrès; L.A. Pinard suggéra d'étudier l'idée d'une Fédération au moyen des sociétés Saint-Jean-Baptiste de la province. Un Comité du Congrès, présidé par le juge Constantineau, avec $A$. Beausoleil comme vice-président et J.-B.-T. Caron comme secrétaire, se mit alors au travail. Le Comité comprenait aussi de nombreux autres personnages, surtout d'Ottawa ${ }^{85}$

Le Comité du Congrès décida de «consulter le plus grand nombre possible de nos compatriotes dans l'Ontario». La réponse fut très favorable. Le Comité du Congrès fit rapport à une assemblée tenue le 4 mai 1909 à Ottawa, toujours dans une salle de l'Union

\footnotetext{
${ }^{84} \AA \grave{~ c e t t e ~ r e n c o n t r e ~ a s s i s t a i e n t ~ l e ~ j u g e ~ C o n s t a n t i n e a u, ~ l e s ~ s e ́ n a t e u r s ~}$ Pascal Polrier et N.-A. Belcourt, le député fédéral É. Proulx (de Prescott), les avocats J.U. Vincent et J.-B.-T. Caron, les abbés S. Corbeil et O. Lalonde, tous deux de l'archevêché, $L$. Raymond, de Bourget, $U$. Forget, d'Embrun, les oblats E. David et J.-B. Boyer, l'ancien député O. Guibord, J. Rocheleau, de Tecumseh, C.-S.-O. Boudreault, Arthur Charbonneau (ancien commissaire d'école), J. Paquette (maire d'Embrun), les inspecteurs Aurélien Bélanger et V.-H. Gaboury, et plusieurs autres.

${ }^{85}$ D'Ottawa, 1 l y avait C.-S.-O. Boudreault, A. Bélanger, A. Charbonneau, R. Chevrier, P.-M. Côté. Venant des autres régions, on remarquait aussi les députés A.-A. Aubin (Sturgeon-Falls) et Georges Pharand (comté provincial de Prescott), Édouard Proulx (comté fédéral de Prescott), D. Racine (comté provincial de Russell), le journaliste $\mathbf{H}$. Chauvin, de Windsor, Daniel Danis, de Cornwall, V.-H. Gaboury, de Plantagenet, $O$. Guibord, de Clarence-Creek, G. Pacaud, de Windsor, Georges-W. Séguin (président de l'Union Saint-Joseph) et J.-U. Vincent.
} 
Saint-Joseph du Canada. Le projet d'un Congrès fut réaffirmé. On institua un comité provisoire contenant des personnalités, où l'on retrouvait J.-O. Routhier (administrateur de l'archidiocèse d'Ottawa), N.-Z. Lorrain (évêque de Pembroke), J.-B.-E. Meunier (administrateur du diocèse de London), Elzéar-A. Taschereau (ex-juge en chef du Canada), le sénateur N.-A. Belcourt, le docteur J.-O. Réaume (ministre des Travaux publics de l'Ontario). Les officiers généraux restaient le juge Constantineau (président, de L'Orignal), l'abbé A. Beausoleil (vice-président, de Fournier), le docteur R.-H. Parent et C.-A. Séguin (secrétaires, d'Ottawa), et Emmanuel Tassé (trésorier). Il y avait en outre un comité composé de plus de soixante personnalités (députés, prêtres, professionnels, fonctionnaires).

On créa aussi plusieurs comités ${ }^{86}$, dont le Comité de l'éducation qui distribua dans toute la province une circulaire afin de recueillir des statistiques sur la population française, sur les écoles, sur l'agriculture et l'industrie et sur l'action sociale, ces renseignements devant servir de base aux discussions du Congrès.

Un Mémoire présentant le projet d'un congrès fut alors diffusé à des milliers d'exemplaires, convoquant toutes les communautés françaises de l'Ontario le 18 janvier 1910 à un congrès de quatre jours à Ottawa. On avait prévu dans chaque région des assemblées pour désigner les représentants au Congrès des Canadiens-Français d'Ontario.

${ }^{86}$ Le Comité d'éducation, présidé par P.-M. Côté, le Comité des intérêts généraux, sous la présidence de G.-W. Séguin, le Comité de la publicité, présidé par A.-D. DeCelles, le Comité de la statistique, sous la présidence d'Errol Bouchette, le Comité des finances, sous la présidence d'Emmanuel Tassé, le Comité d'organisation, présidé par Constantineau lui-même, le Comité de réception, présidé par E. Tassé. 
La Société du Monument national prêta ses salles au Congrès qui, selon l'habitude des conventions, commença par une messe pontificale, chantée à la cathédrale d'Ottawa. Au lieu des $\mathbf{3 0 0}$ délégués attendus, il y en avait 1200. Le sermon fut prêché par l'abbé L. Raymond, qui avait pris pour sujet le verset de S. Mathieu, Euntes, docete omnes gentes (Allez, enseignez toutes les nations), sujet assez approprié pour un congrès d'éducation. Il plaida pour l'union des Canadiens-Français d'Ontario ( «L'Union fait la force», dit-il). Or pour constituer un peuple, il faut remplir trois conditions: l'unité de foi, l'uniformité des mœurs et la communauté de langage. Le but du congrès était d'arriver à l'épanouissement de ces trois caractéristiques: foi, mœurs et langage.

Le Congrès commença à 14 h 30, au Monument national. Sur l'estrade, il y avait Taschereau, Belcourt, Meunier, Beausoleil, Proulx, Aubin, Morel, Pharand, Racine, E. Tassé, A. Bélanger, Caron, Charron, Côté, Parent, C.-A. Séguin et G.-W. Séguin. À la première séance du congrès, on entendit la lecture des câblogrammes reçus et le discours du juge Constantineau. Le premier acte du congrès fut de faire un «témoignage de respect, de vénération et d'affection envers le chef de l'Église». On envoya donc un télégramme («Humblement prosterné aux pieds de Sa Sainteté, le Congrès d'Éducation, représentant plus de 200,000 Canadiens-Français d'Ontario, proteste de sa soumission absolue au Saint-Siège, et implore [une] paternelle bénédiction pour ses travaux»), de même qu'à Sa Majesté Édouard VII ( «son inaltérable loyauté et l'hommage de son absolu dévouement à Sa Personne et à l'Empire»). Voilà pour le respect des autorités. 
LES GRANDS CONGRłS PATRIOTIQUES CANADIENS-FRANÇAIS

Le juge Constantineau fit l'historique du projet d'un Congrès d'éducation, mais en entendant «éducation» dans «toute son ampleur et son étendue», embrassant «une série de questions multiples qui intéressent notre foi, notre nationalité et notre vie sociale». Le juriste conclut que «Notre nom, à nous, est synonyme de loyauté, d'honneur et de gloire ${ }^{87}$ ». Puis il annonça qu'il ne pourrait continuer à occuper la présidence du Congrès. On désigna alors le sénateur N.-A. Belcourt à sa succession. Puis on entendit Taschereau (qui se dit plutôt de Québec que d'Ottawa), puis Mgr J.-E. Meunier, administrateur du diocèse de London. Les six comités déjà existants furent maintenus, mais celui de l'organisation fut remplacé par le Comité de la constitution.

Lors de la deuxième séance, le soir à 20 heures, on entendit le discours de P.-M. Côté, président du Comité d'éducation, dont le rapport fut présenté au Congrès. Ce document dressait un bilan du système scolaire provincial et énumérait les lacunes de ce régime pour les Canadiens-Français d'Ontario, ainsi que les efforts nécessaires au redressement de la situation. Une série de résolutions fut alors adoptée, demandant la reconnaissance des écoles françaises, l'augmentation de leur nombre, la reconnaissance des brevets d'enseignement. En appui à ces résolutions, l'oblat Louis Lejeune prononça ensuite un discours où ce «Canadien d'adoption et par naturalisation légale» traita de l'éducation en général, de l'éducation morale, pour conclure que le Congrès inaugurait «une cuvre grandiose, féconde, durable». Lejeune fut suivi par le curé J.-A. Myrand, qui plaida pour des écoles pratiques d'arts et métiers.

${ }^{87}$ Discours de Constantineau, dans Congrès de 1910, p. 122. 
Le deuxième jour, le Congrès reçut le rapport du Comité des intérêts généraux, présenté par son président G.-W. Séguin. Le document recommandait plusieurs mesures: réclamer plus de magistrats canadiens-français, faire nommer plus qu'un sénateur (on en voulait un deuxième), demander le plus d'écoles séparées possible. L'abbé S. Corbeil fit alors un discours au sujet des écoles séparées. Pour sa part, le père André Paquet, de l'Université d'Ottawa, traita de deux questions complémentaires, à savoir les chantiers et la colonisation. Le Comité attira aussi l'attention du Congrès sur le problème de la tempérance et, en dernier lieu, demanda une proposition pour rallier de manière permanente les CanadiensFrançais d'Ontario, peut-être par les mutualités.

Le Comité des intérêts généraux n'osait pas encore proposer la création d'un journal, français et catholique, indépendant des partis, mais il croyait qu'une telle publication était «absolument nécessaire dans cette province». Quant à C.-S.-O. Boudreault, que le Comité des intérêts généraux avait chargé de traiter de la question, il soumit alors un rapport sur la fondation d'un journal: «il faut l'union des CanadiensFrançais», disait-il. «Le journal, voilà le grand facteur de combat des temps modernes!» disait Boudreault, un imprimeur. Il pensait qu'un quotidien ne serait pas viable et qu'un hebdomadaire serait préférable. Le Comité recommandait de confier à l' "exécutif» de l'Association le soin de se pencher sur ce dossier.

O.-A. Rocque présenta le Rapport du Comité de statistiques, ce qui permit de dresser un portrait de l'Ontario français: population selon les régions, 45 paroisses dans treize diocèses, nombre de fonctionnaires canadiens-français. Le rapport traita des écoles 
et de la situation du français. Le jésuite Guillaume Lebel, de Sudbury, présenta le rapport statistique sur le Nouvel-Ontario: population, écoles, tableaux statistiques.

Le soir du 19 janvier, la ville d'Ottawa offrait une réception au théâtre Russell ${ }^{88}$. Devant les nombreuses personnalités réunies à cette occasion, Belcourt fit un discours où il expliqua le but du Congrès, c'est-àdire l'éducation «dans son sens réel, c'est-à-dire comme l'ensemble du développement physique, moral et intellectuel de l'homme». Il reconnut que l'éducation en Ontario n'était pas ce qu'elle devrait être et qu'il fallait l'améliorer. Le Congrès, dit-il, ne serait pas un mouvement politique, ni même "purement national» puisqu'on recevrait tous ceux qui voudraient aider. L'auditoire écouta alors, debout, la réponse du Saint-Père bénissant les congressistes. Wilfrid Laurier prononça alors un discours: "]e suis venu comme citoyen d'Ontario [...]. Je suis venu à Ottawa depuis treize ans, et j'ai bien l'intention d'y finir mes jours ${ }^{89}$.» Laurier ajouta, sur le droit scolaire, qu'«Il ne suffit pas que les enfants canadiens-français d'Ontario apprennent leur langue sur les genoux de leur mère; il faut qu'ils puissent l'étudier à l'école». Puis Mgr Routhier parla, suivi par Frank Cochrane, l'honorable Rodolphe Lemieux, Adam Beck et Charles Murphy.

${ }^{88}$ Étalent présents le maire Charles Hopewell, le sénateur Belcourt, mais aussi Mgr J.-O. Routhler, administrateur de l'archidiocèse d'Ottawa, sir Wilfrid Laurier, premier ministre du Canada, les honorables Rodolphe Lemieux (ministre des Postes), Charles Murphy (secrétaire d'État), le sénateur Pascal Poirier, les honorables Frank Cochrane et Adam Beck, deux ministres provinciaux, William Murphy (recteur de l'Université d'Ottawa), de nombreux autres députés fédéraux et provinclaux, et tous les gens du congrès.

${ }^{89}$ Discours de Wilfrid Laurier, Congrès de 1910, p. 229. 
La dernière séance du Congrès, l'après-midi du 20 janvier, fut consacrée aux "statuts», c'est-à-dire aux règlements de l'Association canadienne-française d'éducation de l'Ontario. Le bureau de direction serait composé de 25 membres choisis dans la région d'Ottawa, de tous les présidents de sections, de tous les curés canadiens-français de la province, de tous les professeurs de langue française de l'Université d'Ottawa, des supérieurs de l'Académie De La Salle et des autres institutions religieuses enseignantes, des inspecteurs canadiens-français, des prélats romains, évêques, archevêques, députés et anciens députés. Le Congrès reçut ensuite le rapport financier. Puis on procéda à l'élection de l'exécutif. N.-A. Belcourt accéda à la présidence, alors que le député de Sturgeon-Falls, A.-A. Aubin, devint premier viceprésident et G.-W. Séguin, d'Ottawa, deuxième viceprésident et trésorier; enfin, C.-A. Séguin occupa le poste de secrétaire. On nomma aussi un très nombreux exécutif. L'oblat P.-A. Paquet fit ensuite un discours, en conclusion, pour dire que le Congrès avait été un triomphe, mais il voulait parler de «la question des chantiers" sous ses angles politique, économique et social, religieux et national (les dangers, les "préservatifs»).

Le soir du 20 janvier, au terme du Congrès, eut lieu, à l'hôtel Russell, sous la présidence de Belcourt, une autre soirée. Il y eut de nouveaux discours, de Mgr J.-O. Routhier, de M. Pharand, de Wilfrid Laurier, de R.-L. Borden (chef du parti conservateur), de l'oblat W. Murphy (recteur de l'Université d'Ottawa).

L'Ontario français disposait désormais d'une association provinciale vouée à la défense de ses intérêts scolaires. Mais les efforts de l'Association pour 
obtenir justice ne provoquèrent qu'un froid silence à Toronto où le gouvernement Whitney, bientôt encouragé par le nouvel évêque oblat de London, Michael Fallon, se préparait à sévir contre l'enseignement en français. Mais en 1911, les conservateurs fédéraux de la province de Québec avaient conclu, contre Wilfrid Laurier, une alliance avec les nationalistes canadiens-français, dirigés par Henri Bourassa. Cette fragile alliance poussa les conservateurs ontariens à retarder leur projet. Mais en juin 1912, le ministère de l'Éducation de l'Ontario publiait son Règlement XVII (la "Circulaire d'instruction $n^{\circ} 17$ ») qui, à toutes fins utiles, éliminait l'enseignement en français. Ce fut le cri de départ du conflit qui allait durer quinze ans et où l'Association canadiennefrançaise d'éducation d'Ontario (ACFÉO) reçut le baptême du feu. Elle fonda en 1913 Le Droit, un quotidien qui entra de plein fouet dans la bataille pour les écoles françaises de l'Ontario. Ces conflits trouvèrent d'ailleurs un écho dans le Premier Congrès de la langue française, tenu à Québec justement en 1912.

Il appert donc que le Congrès de 1910, en Ontario français, s'inscrit dans la série des congrès patriotiques ou religieux qui jalonnent l'histoire du Canada français. Les modalités d'organisation des deux types de rassemblement, les préparatifs minutieux, la base paroissiale de l'organisation, les techniques d'animation en régions, la création de comités de toute sorte, la participation des foules, l'adoption de programmes comportant beaucoup d'activités cérémonielles, voilà autant de caractéristiques communes aux congrès religieux et aux congrès patriotiques. Les congrès religieux montrent le Canada français en prière, comme les congrès patriotiques le font voir au combat. 
IV - Les congrìs de la langue françase au Canada (1912, 1937, 1952)

Par trois fois, en 1912 , en 1937 et en 1952 , des milliers de chefs de file canadiens-français, représentant toutes les communautés françaises du continent, convergèrent sur la ville de Québec, le «berceau» de l'Amérique française. Grandioses, ces Congrès de la langue française au Canada relevaient à la fois du pèlerinage religieux, du rassemblement patriotique, de la fête populaire et du congrès scientifique, peutêtre même dans cet ordre-là. Car à la dimension scientifique de ces manifestations, répondait un non moins important volet religieux, patriotique et touristique. En chaque occasion, les rues et les édifices de la ville pavoisèrent, les grands déploiements publics se multiplièrent, des cérémonies majestueuses évoluèrent un peu partout, dans les édifices publics et religieux, ou au pied des monuments historiques. Des mois de préparatifs et d'intenses campagnes de publicité dans la presse et auprès des institutions, tant scolaires que religieuses ou politiques, avaient, chaque fois, préparé fébrilement ces retrouvailles de la "grande famille canadienne-française», venue ausculter ensemble la santé de la langue et de la culture françaises en Amérique, surtout au Canada.

Sous la direction du clergé, omniprésent, de fortes délégations accoururent des quatre horizons du continent. Recrutés dans la mouvance catholique et conservatrice, les congressistes provenaient certes en très grand nombre de la province de Québec, mais aussi de l'Acadie, de l'Ontario, de l'Ouest et des États-Unis, voire d'Haïti, sans oublier les représentants des pays étrangers, notamment de la France. Ces dirigeants des diverses communautés françaises 
du continent, délégués aux Congrès de la langue française au Canada, venaient confirmer, sur les tombes de Champlain et de Laval, leur ferme propos de défendre partout le caractère catholique et français de leurs communautés. Le ton, tantôt, est triomphaliste, tantôt pessimiste.

Le programme des congrès, soigneusement préparé, fit toujours preuve d'un grand sérieux et, pour que rien ne se perdît, de forts volumes parurent dans l'année qui suivit chaque rassemblement. Ce souci de tout rapporter atteste l'importance que les contemporains ont accordée à ces assises de la nation canadienne-française. Les actes reproduisaient in extenso le texte de tous les discours, de toutes les communications, de tous les toasts et remerciements, de tous les hommages et de tous les sermons ${ }^{90}$. Dans le cas des séances plénières, il s'agit de discours officiels, prononcés en public par des autorités religieuses

\footnotetext{
${ }^{90}$ Pour le Premler Congrès de la langue françalse au Canada (1912), voir les deux tomes suivants: Premier Congrès de la langue française au Canada. Québec, 24-30 juin 1912. Compte rendu (Québec, Imprimerie de L'Action Sociale, 1913,693 p.) et Premier Congrès de la langue française au Canada. Québec 24-30 juin 1912. Mémoires (Québec, Imprimerie de l'Action Sociale, 1914, vilt-636 p.). Pour le Deuxtème Congrès de la langue françalse au Canada (1937), voir: Deuxieme

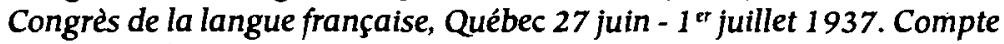
rendu (Québec, Imprimerle de l'Action Catholique, 1938, 529 p.), Deuxième Congrès de la langue française, Québec 27 juin - $1^{\text {er }}$ juillet 1937. Mémoires. 3 tomes. (Québec, s.n., 564 p. +252 p. +504 p.); le folkloriste Luc Lacourcière est le compilateur de ces volumes. Enfin, pour le Trolsième Congrès de la langue françalse au Canada (1952), voir: Troisième Congrès de la langue française au Canada. Québec 1826 Juin 1952. Compte rendu (Québec, Éditions Ferland, 1953, 475 p.) et Troisième Congrès de la langue française au Canada. Québec 18-26 juin 1952. Mémoires (Québec, Éditlons Ferland, 1953, 390 p.). Pour le Congrès de 1952, on pourra aussi consulter les travaux de la section scientifique, publiés séparément: Études sur le parler français au Canada, Québec, Presses de l'Université Laval, "La Soclété du parler français au Canada», 1955, $221 \mathrm{p}$.
} 
ou politiques, dans des circonstances solennelles. Ces textes méritent donc qu'on les tienne pour l'expression réfléchie d'idées et de valeurs où les élites canadiennes-françaises se reconnaissaient, y compris celles de l'Ontario français qui, par ses représentants, adhéra sans réserve à l'idéologie qui ralliait ces foules. Les élites réunies lors de ces congrès ont véhiculé, par leurs discours et leurs gestes, l'idéologie dominante du Canada français, un cadre homogène qui soutint, à l'échelle du continent, un important réseau d'institutions sociales et religieuses.

Au début du siècle, les citoyens de la ville de Québec conservaient encore le souvenir de la convention nationale des Canadiens-Français en 1880, des grandes cérémonies qui en 1889 avaient marqué l'inauguration du monument Cartier-Brébeuf et, plus récemment, du faste déployé lors des fêtes du troisième centenaire de la ville, en 1908. Le Premier Congrès de la langue française au Canada, en 1912, s'inscrivait donc dans une tradition.

La Société du parler français au Canada ${ }^{91}$, fondée en 1902, décida le 14 février 1911 de célébrer son dixième anniversaire, l'année suivante, par la convocation d'un grand rassemblement nord-américain, le Premier Congrès de la langue française au Canada, dont l'objectif serait d'examiner toutes les questions concernant la conservation, la défense, l'enseignement, la culture et l'extension de la langue et de la littérature françaises au Canada et dans les milieux canadiens-français ou acadiens des États-Unis ${ }^{92}$. Les

\footnotetext{
${ }^{91}$ Camille Roy, «La Société du parler français et son premier concours littéralre», dans Premier Congrès de la langue française au Canada...1912, p. 337-343.
}

${ }_{92}$ Le volume du Compte rendu du Congrès de 1912 se divise en trois 
nationalistes canadiens-français se rassembleraient autour de la langue, comme ils l'avaient fait autour de la nationalité lors des congrès patriotiques.

L'appel au public, paru le 10 avril 1911 , parlait de la mission de la France en Amérique du Nord, celle de faire survivre «le génie de notre race, et de garder pur de tout alliage l'esprit français qui est le nôtre». Conserver la langue permettrait d'atteindre cet objectif, car «elle est la gardienne de notre foi, la conservatrice de nos traditions, l'expression même de notre conscience nationale». À ce grand effort de civilisation, la Société invitait les «Canadiens français de Québec ou de l'Ontario, du Manitoba, de l'Ouest ou des États-Unis, Acadiens de l'Est ou de la Louisiane», à se réunir en congrès "pour l'étude, la défense et l'illustration de la langue et des lettres françaises au Canada». L'appel s'adressait, entre autres, aux «Canadiens français de l'Ontario, conquérants pacifiques, qui ont su lutter avec vaillance pour leurs droits, et qu'attendent peut-être des combats encore plus rudes». En parfaite continuité avec les conventions patriotiques, les organisateurs de la rencontre de 1912 parlèrent dès le départ de solidarité ("L'union fait la force») et de concertation.

On espérait transformer la rencontre en «concile œcuménique de la langue française». Vingt-cinq ans plus tard, en 1937, le rapport du Deuxième Congrès, lui, parlait «d'une convention nationale de tous les groupements de race française en Amérique». En 1952 , on parla des «états généraux de la race» pour

parties, la première, intitulée «Compte rendu» (p. 57-180); la deuxième partie, "Adresses, discours, poèmes» (p. 181-459); la troisième partie "Actes du congrès" (p. 461-622); enfin, les appendices portent le titre "Échos du congrès" (p. 625-695). 
décrire le Troisième Congrès. Ainsi, un même dessein anima l'organisation des trois Congrès de la langue française au Canada.

\section{A - LE CONGRES DE 1912}

Le Premier Congrès de la langue française se déroula à Québec du 24 au 30 juin 1912. Pour l'organiser, la Société du parler français institua un comité organisateur, secondé par des comités locaux qui, dans les grands centres de l'Amérique française, étaient chargés de faire de la propagande en faveur du congrès, de lever des fonds et d'encourager la presse locale à en parler. À Québec même, des groupes s'affairaient à recueillir des fonds, à préparer le programme, à exécuter les travaux de préparation matérielle de la rencontre. Les deux principaux bailleurs de fonds du Congrès furent les deux gouvernements de la province et de la ville de Québec. La cheville ouvrière de l'événement fut le comité organisateur qui agissait sous le patronage général de l'Université Laval. Pour l'appuyer, on créa aussi un énorme comité honorifique (ne comptant pas moins de dix présidences d'honneur, neuf vice-présidences et un comité composé de cent quarante-six personnes), puis un bureau du congrès et, enfin, un bureau des sections d'études. Une constitution et des règlements détaillés encadrèrent l'ensemble de la démarche. Le président du comité organisateur, Mgr Paul-Eugène Roy, évêque auxiliaire de Québec, put compter sur ses trois vice-présidents, le sénateur N.-A. Belcourt (Ontario), le conseiller législatif Thomas Chapais (Québec) et le juge P.-A. Landry (Nouveau-Brunswick). Selon la pratique des anciennes conventions, on prépara le congrès en mettant sur pied des commissions (initia- 
tive, finances, propagande, publicité, transports et logements, fêtes religieuses et réceptions, réception et banquet, enfin secrétariat du congrès).

Le Congrès, fin juin, coïncidait avec la Saint-JeanBaptiste, fête célébrée depuis longtemps dans toutes les communautés canadiennes-françaises. Il était donc normal que les activités de la Saint-Jean fussent intégrées à celles du Congrès, Ainsi, l'organisation des fêtes de la Saint-Jean fut laissée, comme d'habitude, à la Société Saint-Jean-Baptiste de Québec qui, avec un faste supplémentaire, monta les 23 et 24 juin un programme comprenant messe, cortège, banquet et diverses autres activités. Quant au congrès proprement dit, il comportait un programme général (séances et activités communes) et un programme des séances générales du congrès, pour les congressistes seulement, ces derniers se répartissant aussi en sessions d'étude pour discuter de divers sujets. Pour les discours du programme général, des foules considérables se présentèrent, le service d'ordre étant assuré par les zouaves de Québec et les élèves du Petit Séminaire de Québec.

La cérémonie d'ouverture, le 24 juin, marqua beaucoup de déférence aux autorités, tant religieuses que civiles: des salutations furent présentées aux représentants du roi, du pape, de la France, du gouvernement provincial, du conseil municipal, à l'épiscopat et au clergé canadiens-français, enfin à «tous nos frères rassemblés». Roy plaça le congrès «sous la double protection de la Vierge triomphante, patronne des Acadiens, et de saint Jean-Baptiste, patron des Canadiens français». En présentant des hommages au gouverneur général, le sénateur Philippe Landry, président du Sénat et futur président de l'Association 
canadienne-française d'éducation de l'Ontario, rappela l'allégeance des Canadiens-Français à l'Angleterre ${ }^{93}$. Debout, l'auditoire écouta alors le Dieu sauve le Roi. L'archevêque de Québec, Mgr L.-N. Bégin, pour sa part, protesta des sentiments catholiques du peuple canadien-français qui «ne peut être vraiment luimême que s'il est catholique» et "ne peut s'acquitter de toute sa mission providentielle que s'il mêle à ses pensées patriotiques les convictions de la foi romaine».

Le délégué apostolique, Mgr Stagni, malgré des hésitations, avait finalement décidé d'assister au congrès après avoir pris connaissance de la "si belle manifestation de dévouement à l'autorité suprême de l'Église ${ }^{94}$ ", que l'archevêque de Québec se proposait de faire. Toutefois, Stagni ne manqua pas de rappeler à tous ces «messianistes» canadiens-français que leur «belle langue» n'avait pas seulement servi à l'Évangile, mais qu'elle fut aussi «au service de l'erreur, depuis les Encyclopédistes du dix-huitième siècle, et surtout depuis la grande Révolution». Le compte rendu interpréta ces commentaires comme un éloge de la langue française. Puis la fanfare joua des airs canadiens, en commençant par le ô Canada, la foule entière se levant pour chanter cette pièce, "scène impressionnante [qui] se répétera souvent pendant le Congrès ${ }^{95}$ ».

Après le discours du premier ministre de la province, Lomer Gouin, qui souhaita la bienvenue «à tous les fils de son sang, qui habitent les provincessœurs de ce Dominion, ou qui sont devenus citoyens

\footnotetext{
${ }^{93}$ Rapport 1912, I, p. 188.

${ }^{94}$ Ibid., p. 197.

95 Ibid., p. 74.
} 
de la république américaine», y compris les «Canadiens de l'Ontario et de l'Ouest, qui font vaillamment les bons combats", c'est à l'archevêque de SaintBoniface, Mgr A. Langevin, que revint le «Salut à Québec». La proximité du tombeau de Laval, sur «ce vieux sol québécois", le remplissait d'émotion, là où se rencontraient les Acadiens, les Canadiens de l'Ouest et de l'Ontario ${ }^{96}$, ceux des États-Unis. Fort de sa fidélité aux traditions, mais aussi de sa loyauté vis-àvis des autorités britanniques, le Canadien-Français était d'autant plus français qu'il était catholique.

Au cours de la première séance générale, le mardi matin, le ministre ontarien J.-O. Réaume, qu'on présenta comme «l'homme de valeur qui honore sa race, et qui sait la défendre dans la province voisine", prononça l'adresse à la ville de Québec, le jour même, le 25 juin, où le gouvernement ontarien publiait le Règlement XVII. Réaume disait ne pas comprendre que certains voulussent éliminer le français au Canada. Il rappela que ce furent les CanadiensFrançais, «notre race», qui défendirent le Union Jack contre les Américains. Dans une phrase prophétique et annonciatrice des replis identitaires à venir, le maire de Québec, Napoléon Drouin, voyait déjà sa ville non seulement comme «le berceau de la nation canadienne", mais comme le dernier rempart de la langue et de la mentalité françaises sur le continent.

\footnotetext{
96 Voici ce que dit Mgr A. Langevin, sur un ton plutôt triomphaliste, compte tenu du Règlement XVII que le gouvernement de l'Ontario venait tout juste d'adopter: «Ils sont ici, nos frères bien aimés d'Ontario, les plus rapprochés de Québec, forts de leur nombre et de leur organisation paroissiale. Ils n'ont rien à discuter, rien à plaider, ils n'ont qu'à conserver comme des hommes, ce qu'ils possèdent par le droit naturel, conféré aux parents, et aussi par le droit d'hommes libres dans un pays de liberté pour tous». Discours d'A. Langevin, le 24 juin 1912, dans le Premier Congrès... Compte rendu, p. 206.
} 
Le mardi soir, en deuxième séance générale, consacrée aux sections littéraire et pédagogique, le congrès rendit un de ses nombreux hommages à l'Académie française, auguste aréopage de la langue française. Le mercredi, jour du "culte des traditions françaises» et d'excursion à la "campagne québecoise, sorte de pèlerinage patriotique vers l'un des coins les plus enchanteurs du terroir ancestral», cinq cents excursionnistes se rendirent "par convoi" à PetitCap, à Saint-Joachim de Montmorency, sur la Côte de Beaupré, à la maison du Séminaire de Québec. Le compte rendu ne parle que de bonne humeur, de joie conquérante, de franche gaieté, de plaisirs subtils et délicats, de l'esprit et du cour, de musique, de chant, d'éloquence, des voix ardentes "dont plus d'une se mouille de larmes». Ce reportage idyllique dit assez la représentation qu'on se faisait alors du bonheur. Cette alliance de la patrie et de la foi rattachait à nouveau ce congrès non seulement aux congrès patriotiques, mais aussi aux congrès religieux (eucharistiques ou marials). Comme le veut le dicton latin, Ubi bene, ibi patria (où l'on se sent bien, c'est là la patrie).

Au cours de la troisième séance générale, le mercredi soir, le sénateur Pascal Poirier provoqua les congressistes par un discours qui mit en cause l'euphorie générale. Il demanda qu'on cessât les compliments et les éloges assez longtemps pour faire "l'aveu public de nos coulpes, par une bonne confession générale». Dénonçant la complaisance de tous ces gens satisfaits, preuve "d'une grande faiblesse morale, ou d'une vanité excessive», le sénateur critiqua les ingrats qui, oubliant ce qu'ils avaient reçu, ne donnaient «leur sollicitude qu'aux vanités de la cour et au service de leurs ambitions". Poirier condamna «l'idée sotte que rien au monde n'est si par- 
fait que nous et nos institutions», il nota le déclin de l'influence française à Ottawa où "nous avons stupidement, criminellement peut-être [...] laissé les étrangers s'emparer du Manitoba», enfin il blâma le "défaut d'enseignement supérieur et d'écoles techniques». Il se demandait s'il ne serait pas possible de «faire son salut avec un peu moins de bruit? ${ }^{97}$ ". Tant que nous laisserons enseigner des personnes connaissant mal leur matière d'enseignement, «nous n'élèverons pas le niveau, déjà trop bas, de nos connaissances, soit du français, soit de l'histoire, soit de la géographie ou des sciences".

Cette attaque de Poirier stupéfia ses auditeurs, à tel point que le compte rendu du Congrès, quittant son style approbateur habituel, ne put s'empêcher de critiquer ouvertement le sénateur ${ }^{98}$. Heureusement pour les organisateurs du Congrès, l'orateur suivant, l'archevêque de Montréal, Paul Bruchési, dérida l'auditoire en affirmant que s'il était le confesseur de Poirier, il lui imposerait une pénitence pour ce qu'il venait de dire. Selon le prélat, qui n'apprécia pas cette attaque contre le triomphalisme linguistique, il fallait utiliser l'anglais, certes, mais il fallait que le français conservât «sa place sur la terre canadienne comme sur le blason royal». Bruchési évoqua le récent Congrès eucharistique de Montréal et son éclatant succès où l'on vit que la langue et la foi allaient de pair ${ }^{99}$.

97 Ibid., p. 280.

98 Voici ce qu'écrit l'auteur du compte rendu: uon regrette vraiment que l'orateur ne se montre pas mieux averti et surtout mieux inspiré, ne fasse pas de notre conscience un examen plus juste et d'une information plus exacte, ne regarde pas les choses d'un meilleur biais, et ne s'exerce pas à faire dans un autre esprit le compte et la critique de nos défauts", dans ibid., p. 108.

${ }^{99}$ Dans une déclaration au journaliste de l'Action Sociale de Québec, 
Le sénateur N.-A. Belcourt fit ensuite un discours traitant De l'exercice des droits reconnus à la langue française au Canada, tâche qu'il n'avait acceptée, sur l'insistance du secrétaire général Adjutor Rivard, que pour ne pas «perdre l'occasion d'offrir publiquement, au nom de nos compatriotes de la province d'Ontario, que j'ai l'honneur de représenter ici plus particulièrement, l'expression de leur profonde gratitude pour la généreuse et patriotique pensée qui a donné naissance à ce Congrès». Ce dévouement mettait fin au "grief déjà trop vieux des groupes canadiensfrançais disséminés un peu partout sur le continent nord-américain, provenant de l'indifférence, au moins apparente, à leur égard, des nôtres dans la province de Québec». Belcourt se déclarait «l'humble porteparole» de 250000 Canadiens-Français, venus chercher un encouragement dans la lutte engagée en Ontario. L'orateur divisa son discours en trois points: premièrement les «droits juridiques de la langue française au Canada», deuxièmement l'«exercice des droits reconnus à la langue française au Canada», troisièmement «l'exercice de ces droits en dehors de la province de Québec», où il fut surtout question de l'Association canadienne-française d'éducation de l'Ontario.

l'archevêque donnait ce qui, à ses yeux, avait marqué le Congrès de la langue française: «Attachement inébranlable des Canadiens français à leur foi; fidélité sans réserve au drapeau britannique; amour de la langue des ancêtres et résolution de l'aimer encore davantage, de l'étudier et de la mieux parler; affirmation d'indéniables droits dans le respect des droits des autres nationalités; enfin, doux espoir pour l'avenir - voilà, il me semble, ce qui résume le Congrès de la langue française et en découle. Le congrès a été une grande œuvre et un grand bienfait.» Ce témoignage est le premier placé dans la section "Impressions de quelques congressistes», dans Premier Congrès... Compte rendu, p. 633. 
À la quatrième séance générale, le président du congrès, Mgr Paul-Eugène Roy, fit lecture, l'auditoire étant debout, des dépêches reçues du pape, du roi et de l'Académie française. Roy présenta aussi une médaille-souvenir du Congrès au recteur Amédée Gosselin qui, lui, remit des doctorats honorifiques aux visiteurs de France (Gustave Zidler, poète partout louangé, et l'abbé Thellier de Poncheville). Mais surtout, le Congrès était venu, ce soir, écouter Mgr L.-A. Paquet qui parla de «L'Église catholique et le problème des langues nationales». Ce grand intellectuel du Canada français décrivit l'Église comme «la Reine du monde», argumentant que le catholicisme, universel, utilisait à la fois une langue liturgique (le latin) et un idiome national. Et l'orateur de louer le rôle de la langue maternelle.

Dans un discours sur "La langue française et l'avenir de notre race», le chef nationaliste Henri Bourassa décrivit les avantages de conserver la langue française, défendit le droit de la conserver, puis parla de son histoire au pays $(1774,1812,1837)$ avant d'arriver à Lafontaine, à la constitution de 1867 où "le principe de l'égalité absolue des deux langues est reconnu en toutes lettres», tant au fédéral qu'au Québec. Bourassa termina par un souvenir de Jeanne d'Arc, récemment béatifiée et dont le cour, jeté à la Seine par les Anglais, avait par voie d'eau atteint toute la terre, y compris les rives du Saint-Laurent. Le discours de Bourassa fut couronné par des tonnerres d'applaudissements et une ovation.

Le samedi matin, l'assemblée institua un Comité permanent du Congrès de la langue française au Canada, chargé de mener à terme la publication des actes du congrès, la réalisation et la continuation de 
l'œuvre du Congrès. Le Comité permanent se composait de vingt-cinq personnes habilitées à s'adjoindre d'autres membres. Parmi le comité, on reconnaissait, de l'Ontario, les noms du sénateur N.-A. Belcourt, du ministre provincial J.-O. Réaume et de l'oblat Charles Charlebois. Le samedi soir (le 29 juin 1912), le banquet de clôture regroupa près de $\mathbf{4 0 0}$ congressistes, pour une fête au Château-Frontenac.

Commencé par une messe, le Congrès allait finir de la même manière. La "messe du Congrès» fut donc célébrée à la basilique de Québec, le sermon étant fait par Mgr Guertin, évêque de Manchester (NewHampshire). En après-midi défila le «cortège patriotique de la jeunesse", organisé avec la collaboration de l'Association catholique de la jeunesse canadiennefrançaise et des zouaves de Québec et d'ailleurs, y compris d'Ottawa. Le défilé se rendit déposer des gerbes de fleurs aux monuments de Laval, de Champlain (sur la Terrasse), de Montcalm (GrandeAllée), des Braves. Puis vinrent les inévitables discours, nombreux comme toujours. La séance de clôture eut lieu le dimanche soir, le 30 juin 1912, sous la présidence de Mgr Paul-Eugène Roy, qui parla de «l'œuvre du Congrès». Enfin, le conseiller législatif Thomas Chapais traita dans son discours de «La langue, gardienne de la foi, des traditions, de la nationalité».

La participation franco-ontarienne au Congrès de 1912 se manifesta de diverses manières. Plusieurs des orateurs, en séances générales, provenaient de l'Ontario (Landry, Belcourt, Réaume). Cette présence se manifesta d'abord dans le comité organisateur, dont une des trois vice-présidences avait été attribuée au président démissionnaire de l'ACFÉO, le 
sénateur N.-A. Belcourt. Dans l'énorme comité honorifique, la présence canadienne-française de l'Ontario comprenait le sénateur Philippe Landry (une des dix présidences d'honneur), mais aussi, parmi les cent quarante-six membres, N.-Z. Lorrain (évêque de Pembroke), E.-A. Latulipe (vicaire apostolique du Témiscamingue), $O$. Charlebois (vicaire apostolique du Keewatin), J.-O. Routhier (vicaire général du diocèse d'Ottawa), deux sénateurs (Pascal Poirier et L.-O. David), L.-P. Brodeur (juge de la Cour Suprême du Canada), A. Constantineau (juge de la cour de comté de l'Ontario), A.-B. Roy (Université d'Ottawa), C.-S.-O. Boudreault (à deux titres, président de l'ACFÉO et président de la Société Saint-Jean-Baptiste d'Ottawa).

Il est évident que presque tous ces délégués francoontariens provenaient d'Ottawa. En Ontario français, la capitale culturelle fut longtemps située dans cette ville où les organismes franco-ontariens avaient presque tous leur siège social. Continuellement alimentée par l'arrivée, en provenance de la province de Québec surtout, de fonctionnaires, de professionnels, d'éducateurs et de religieux, Ottawa occupa longtemps une place éminente, non seulement en Ontario français, mais dans l'ensemble du Canada français. La contiguiité de la province de Québec assurait à l'Est ontarien un afflux migratoire constant, y compris des intellectuels parfois très connus, venus travailler dans la fonction publique, siéger au parlement, faire du journalisme, œuvrer en éducation ou se dévouer dans des communautés religieuses. La présence du gouvernement fédéral n'a jamais cessé d'attirer dans la capitale canadienne des membres de toutes les communautés françaises du pays, tant Acadiens que Franco-Manitobains ou Québécois. Une grande partie des élites franco-ontariennes se recruta 
longtemps parmi cette migration éduquée. La présence de cette élite à Ottawa a d'ailleurs favorisé l'articulation du réseau institutionnel franco-ontarien dans l'ensemble du réseau canadien-français.

La présence ontarienne se manifesta aussi par la participation aux commissions du congrès. La section scientifique comportait plusieurs sous-sections. Ainsi, dans la sous-section historique, trois des trente et un auteurs de mémoires provenaient de l'Ontario: Placide Gaudet ("Origine des premiers colons acadiens"), le dominicain Raymond-M. Rouleau («Apôtres et défenseurs de la langue française dans l'Ontario») et le jésuite Guillaume Lebel («Domaine actuel du français dans l'Ontario»). Les deux premiers sont d'Ottawa, le dernier de Sudbury. Rouleau, en présentant une liste de "héros», contribue à la définition d'un panthéon franco-ontarien ${ }^{100}$. Le juge $A$. Constantineau traita de «La situation juridique du français au Canada, spécialement dans l'Ontario» dans la sous-section juridique, tandis que dans la sous-section philologique, Rémi Tremblay présenta, avec V.-E. Breton (de Montréal), une communication sur "Le français des gens instruits au Canada», et L.-E.-O. Payment parla des «noms géographiques dans l'Ontario".

\footnotetext{
${ }^{100}$ Voici, selon Rouleau, les «apôtres» de la langue française en Ontaro, ces "grands ouvriers de la conservation française», ou, selon les termes du compte rendu, «obscurs quelques-uns, mais tous vaillants»: l'abbé Hubert (curé à l'Assomption et futur évêque de Québec), les jésuites Potier et Point, le sulpicien Marchand, un évêque irlandais (Mgr Denis O'Connor), les missionnaires oblats et jésuites, les prêtres séculiers, des évêques comme Guigues et Duhamel et, pour l'enseignement, Médard Gouin, Moran et Létourneau (ces trois, de Sandwich, réussirent en 1851 à obtenir un financement pour l'enseignement du français dans une école publique), les inspecteurs Dufort et Girardot, l'honorable Evanturel, H.-J.-B. Turgeon (fondateur de l'Institut canadienfrançais d'Ottawa en 1852).
} 
LES GRANDS CONGRÈS PATRIOTIQUES CANADIENS-FRANÇAIS

Dans la section pédagogique, quelques mémoires concernaient l'Ontario. Pour la sous-section secondaire, deux communications («L'enseignement du français dans l'Ontario» et "L'enseignement bilingue dans l'Ontario") n'eurent pas de rapporteur, tandis que l'oblat A. Normandin traita de «La mission de l'Université d'Ottawa dans la province d'Ontarion. Le père Normandin parla "de façon éloquente et convaincante» nous dit le rapport, affirmant que son université était "avant tout, catholique» et qu'elle propageait l'esprit chrétien avec des méthodes françaises et anglaises «dans la proportion voulue par des circonstances multiples et d'aspect infiniment variém. Dans la sous-section primaire, le père Charles Charlebois exposa la situation en Ontario où "des obstacles plus particuliers" prévalaient, d'où "un vœu spécial concerne cette province».

Un seul des vingt-trois mémoires de la section littéraire provenait de l'Ontario, celui de C.-A. Séguin, d'Ottawa, dont le «jeune et brillant président» fit l'histoire de l'Institut Canadien d'Ottawa [sic], fondé en 1852 et d'abord appelé le "Cercle littéraire». Dans la section propagande, on nota aussi des participations ontariennes. À la sous-section A (associations), C.-A. Latour, d'Ottawa, traita de «La langue française et les associations dans l'Ontario", parlant brièvement des unions mutuelles (Saint-Antoine, Saint-Thomas, des Artisans, de l'Alliance nationale, surtout de l'Union Saint-Ioseph fondée en 1863). Arthur Saint-Pierre, natif de Windsor, traita de «La langue française et l'Association catholique de la jeunesse canadienne-française», une fédération d'associations locales. Le sous-comité formula d'ailleurs le vœu que chaque paroisse française du pays possédât sa section de l'ACIC, formée de "défenseurs 
renseignés et virils, connaissant ses droits [de la langue française] et fermement décidés à les faire respecter».

Saint-Pierre fut suivi par Esdras Therrien qui, lui, traita de «La langue française et l'Association catholique de la jeunesse canadienne-française dans l'Ontario». Son discours semble avoir dépassé le ton modéré des présentations puisque le compte rendu dit que Therrien intervint avec uune voix émue, vibrante, sincère, on le sent, parfois même un peu violente, comme celle des gens qui souffrent ${ }^{101} »$. Le Rapporteur, Élie-J. Auclair, ajouta que certaines choses «sont malaisées à dire, si vraies et si justifiées soientelles, et le Congrès, je le crois, se doit de rester pacifique. Mais on ne saurait entendre l'écho de ces revendications sans en être ému». Therrien se plaignit vigoureusement de l'apathie de certains, parlant de divisions, d'abandon, de perte d'idéal. Auclair, diplomate, ajouta: «Il m'a semblé, messieurs, que cette note quelque peu pessimiste cachait toute une force d'action... Tant que nos compatriotes de la capitale et des «pays d'en haut» auront des chevaliers de cette ardeur, ils sauront, nous n'en doutons pas, faire une excellente besogne. D'ailleurs, les faits sont là. $M$. Therrien nous parle, lui aussi, du beau Congrès d'Éducation d'Ottawa en 1910, “d'où l'on sortit plus religieux et plus français". Il a raison ${ }^{102}$.» Auclair suggéra que ces jeunes marchent, «dans le respect des autorités constituées, avec fierté mais non sans modération dans les formes - fortiter in re, suaviter in modo! - que nos jeunes amis ontariens continuent et perfectionnent leur action! Ce sont des

${ }^{101}$ Premier Congrès... Mémoires 1912, p. 558.

102 Premier Congrès... Mémoires 1912, p. 559. 
champions de la langue et du parler, tout autant que de la foi et des croyances». Enfin, il fut question des mutuelles quand le secrétaire général de l'Union Saint-Joseph, Charles Leclerc, retraça l'histoire de cette société («La langue française et l'Union SaintJoseph»), dont un des buts était le maintien et la propagation de la langue française, comme on l'a vu lors du congrès de 1910.

Dans la sous-section B (foyer, relations sociales, presse) de la section propagande, on écouta dix-sept mémoires, dont ceux de l'abbé L.-A. Beaudoin, de Walkerville, au sujet de «La langue française et l'exercice du culte catholique dans l'Ontario», texte un peu hors-cadre, et d'Albert Carl, d'Ottawa, qui traita du sujet suivant: "Le français et la presse, dans l'Ontario». Parmi les vingt-trois mémoires de la soussection $C$ (services publics, commerce et industrie, arts et sciences), on entendit un jeune d'Ottawa, A.-Waldo Guertin, qui discuta de la situation en Ontario: «Le français dans les services publics, dans l'Ontario». Selon le Rapporteur, l'avocat Hector Bernier, "Monsieur Guertin broie done un peu de noir".

La plupart des participants venaient de la région d'Ottawa, quelques-uns du Sud-Ouest et bien peu du Nord, région encore jeune et peu développée. Aux chefs de file franco-ontariens, le Premier Congrès de la langue française au Canada donna un deuxième souffle. Ils en auraient besoin, car la bataille du Règlement XVII commençait précisément à ce moment. Le conflit allait drainer une grande partie de leur énergie pendant quinze ans, jusqu'en 1927. Durant cette période, l'Ontario français eut plusieurs fois l'occasion de mesurer la solidarité entre CanadiensFrançais. 
B - LE CONGRES DE 1937

À la fin du Premier Congrès, en 1912, Mgr PaulEugène Roy avait conclu que "notre mission, dans le Nouveau Monde, est de faire survivre, malgré les forces contraires et les allégeances nouvelles, le génie de notre race, et de garder partout pur de tout alliage l'esprit français qui est le nôtre. Or, l'usage et le développement de notre langue maternelle sont nécessaires à l'accomplissement de notre destinée; cette langue est la gardienne de notre foi, la conservatrice de nos traditions, l'expression même de notre conscience nationale ${ }^{103} . "$

La Première Guerre mondiale éclata en 1914 et chambarda la scène politique canadienne, le Canada français s'érigeant encore une fois, lors de la crise de la conscription (1917-1918), en opposition à la majorité anglaise du pays. En Ontario, la crise du Règlement XVII, commencée en 1912, s'éternisa et ne prit fin qu'en 1927. Entre-temps, le Comité permanent avait cessé d'exister vers 1922 . La société canadiennefrançaise évoluait comme le reste du pays et la majorité de la population vivait désormais dans les villes, même si les élites canadiennes-françaises, surtout religieuses, continuaient de proclamer le mérite de la vie rurale et d'en chanter la supériorité morale. Les phénomènes complémentaires de l'urbanisation et de l'industrialisation, toutefois, transformèrent inéluctablement la société canadienne-française en société urbaine où dominaient l'industrie, le commerce, le monde ouvrier. Bref, le Canada français se modernisait. La Première Guerre mondiale (19141918) finie, la prospérité revint au Canada après

${ }^{103}$ C'est une phrase que citera, en 1937, le maire de Québec, J.-Ernest Grégoire. Voir le Deuxième Congrès... Compte rendu 1937, p. 178. 
LES GRANDS CONGRÈS PATRIOTTQUES CANADIENS-FRANÇAIS

quelques années, mais la décennie des années trente, appelée la "Grande Dépression» (1929-1939), causa beaucoup de chômage, de pauvreté et de misère sociale. Divers groupes de protestation, politiques et sociaux, se mobilisèrent pour faire valoir des plans de redressement économique et social. Les difficultés économiques exacerbèrent les relations sociales, dont celles du Canada français et du Canada anglais. Cependant, la situation sociale et économique trouva peu d'échos au Congrès de 1937.

Un nouveau nationalisme canadien-français, sous l'inspiration de l'abbé Lionel Groulx, émergeait peu à peu, supplantant celui que Henri Bourassa avait défendu au début du siècle: moins triomphaliste, plus militant, axé sur le Canada français. Avec le recul de l'idéologie de Bourassa devant celle de Groulx, c'est aussi le recul d'un nationalisme canadien devant un nationalisme canadien-français. Ainsi, l'identité culturelle des Canadiens-Français se précisait. Le mouvement nationaliste demandait de plus en plus la reconnaissance des droits linguistiques, sous forme de bilinguisme officiel (chèques bilingues, timbres bilingues, affichage bilingue, monnaie bilingue, etc.) du gouvernement fédéral, avec une participation canadienne-française accrue dans la vie publique, à la fonction publique et au monde des affaires, ce qui prit souvent la forme d'une campagne d'achat chez soi. À travers ces campagnes de revendications, menées surtout depuis Montréal, ville au visage anglais malgré une majorité française, par la Société Saint-Jean-Baptiste et par des publications comme l'Action nationale, l'affirmation croissante du Canada français préparait de nouveaux affrontements avec la majorité. 
Dans la province de Québec, les revendications autonomistes provinciales jumelèrent un programme politique (Maurice Duplessis, premier ministre de la province de Québec en 1936, incarna bien cette tendance) et le nationalisme canadien-français. Ainsi, l'autonomie provinciale devint de plus en plus importante parmi les revendications des nationalistes canadiens-français, tandis que dans les provinces à majorité anglaise, les minorités françaises continuaient leurs interminables luttes pour faire reconnaître, sans grand succès d'ailleurs, leurs droits scolaires et linguistiques. Qu'était devenue l'Amérique française? Pour beaucoup, elle se composait désormais de trois parties: "Canadiens, Acadiens et FrancoAméricains», une énumération que les documents de l'époque reprirent plusieurs fois.

Ainsi, le bilan du quart de siècle qui suivit le Congrès de 1912, n'avait pas que du bon. Avait-on assez conservé la langue et ce qu'on appelait, en 1937, "l'esprit français» dans tous les centres de l'Amérique française? Mgr Camille Roy, recteur de l'Université Laval et président du Deuxième Congrès de la langue française au Canada, définissait "esprit français au sens premier, inaliénable, de ses qualités natives, au sens des valeurs morales et intellectuelles qu'il doit à son baptême, à sa formation, à sa culture traditionnelle, au sens de toute cette spiritụalité qui lui est propre et qui le fait partout s'épanouir en œuvres de marque française ${ }^{104} »$. Il s'agissait pour lui de l'esprit français «dans notre langue, dans nos lois, dans nos mœurs: voilà donc tout l'objet principal du prochain congrès». Selon Roy, il fallait procéder à un "vaste examen de notre conscience nationale».

${ }^{104}$ Deuxième Congrès... Compte rendu 1937, p. 13. 
LES GRANDS CONGRÈS PATRIOTIQUES CANADIENS-FRANÇAIS

Tel fut le but de ce Deuxième Congrès de la langue française.

Le «Bureau de direction» de la Société du Parler français prit la décision, le 2 mars 1936, d'organiser le Deuxième Congrès de la langue française au Canada. Le président du congrès, cette fois, fut Mgr Camille Roy, frère de feu Mgr Paul-Eugène Roy, le président du Premier Congrès. Les trois vice-présidents et les autres responsables de secteurs furent tous recrutés dans l'entourage universitaire et politique de Roy. Plus qu'en 1912, l'administration fut entre les mains des Québécois.

L'Appel au public fut donc lancé, dès 1936, à tous les Canadiens-Français de l'Amérique française, c'està-dire qu'il invitait «toute une race, toute une nation" à retrouver son berceau de Québec pour célébrer la langue française et étudier les mesures nécessaires pour la renforcer. Cet appel s'adressait aux chefs de file. Comme celui de 1912, le rassemblement de 1937 visait les élites, non le peuple. Les membres du Deuxième Congrès se recrutèrent dans le monde de la religion, de l'enseignement et de la politique, ce qu'on appelait alors «les forces vives des groupes de culture française d'Amérique». Les organisateurs en avaient conscience et s'en félicitaient: «L'élite française de l'Amérique du Nord s'était donné rendezvous à l'Université Laval: représentants du Roi et du Pape, archevêques et évêques, hommes d'état [sic], ministres et députés, juges et sénateurs, écrivains et professeurs, délégués des Provinces Maritimes, de l'Acadie, de l'Ontario et des Provinces de l'Ouest, de la Nouvelle-Angleterre, de la Louisiane et d'Haïti, et même de la France, et de la Belgique ${ }^{105}$ ».

${ }^{105}$ Ibid., p. 72. 
Les autorités politiques apportèrent à nouveau leur appui, surtout la province et la ville de Québec. Le maire de Québec, J.-Ernest Grégoire, précisa bien le but du rassemblement: «Depuis vingt-cinq ans, ce programme de résistance, de pénétration et d'épanouissement du français n'a rien perdu, à nos yeux, de sa nécessité». Le premier ministre Maurice Duplessis, lors de la séance publique du mercredi soir (30 juin), commença par parler de «la grande famille du Canada, des États-Unis, de toute l'Amérique et même de l'Europe ${ }^{106}$ ". Il précisa que «nous sommes tous frères en ce pays $[. .$.$] . Vous pouvez retourner$ dans vos foyers avec la certitude que jamais nous ne poserons des actes de nature à nuire à nos frères qui habitent hors de la province de Québec ${ }^{107}$.»

Quant au clergé, il souscrivait toujours à l'idée de la mission providentielle du Canada français, comme le répétait le cardinal Villeneuve qui, prenant la parole en séance publique le lundi soir 28 juin 1937, disait que devant l'histoire du Canada français, «on ne peut s'empêcher de reconnaître tant de providentielles protestations et tant de manifestes prévenances divines que, dans notre race en Amérique, on ne doive admettre une race choisie de Dieu ${ }^{108}{ }_{\Downarrow}$. Comme en 1912, primait le vocabulaire de la "nation canadienne-française», de la "grande famille canadienne-française", de la «mission providentielle».

On misa comme en 1912 sur l'appui de toutes les personnalités religieuses et politiques du Canada français. On désigna comme patron d'honneur le cardinal Jean-Marie-Rodrigue Villeneuve, le président

${ }^{106}$ Ibid., p. 347.

${ }^{107}$ Ibid., p. 348.

${ }^{108}$ Ibid., p. 188-189. 
LES GRANDS CONGRES PATRIOTIQUES CANADIENS-FRANÇAIS

d'honneur étant le "gouverneur»" 109 [sic] de la province de Québec, et les trois vice-présidences d'honneur allant au ministre fédéral de la Justice, Ernest Lapointe, au premier ministre de Québec, Maurice Duplessis, et au maire de Québec, J.-Ernest Grégoire. L'organisation a ainsi renoncé à une partie de son caractère "œecuménique" de 1912. Sous le Comité organisateur, on mit en place des comités régionaux, eux-mêmes placés au-dessus des comités paroissiaux. Cette pyramide, depuis Québec, recouvrait tous les recoins de l'Amérique française, en Acadie, partout ailleurs au Canada, aux États-Unis et jusqu'en Haïti. Des assemblées de propagande s'organisèrent partout. Le Compte rendu montre bien la place qu'occupèrent les prélats et les hommes politiques.

En réponse à l'appel lancé par Mgr Camille Roy, l'Ontario français se mobilisa. Les quelque $\mathbf{3 0 0} 000$ Franco-Ontariens, forts de l'appui de leurs six archevêques et évêques, de leurs huit prélats romains, de leurs 200 prêtres paroissiaux, de leurs communautés religieuses, de leurs associations patriotiques, nationales, ouvrières et agricoles, de leurs deux sénateurs, de leur juge à la Cour supérieure de l'Ontario, de leurs quatre juges de comté, de leurs sept députés fédéraux et autant de députés provinciaux (dont un ministre), de leurs institutions, de leur université à charte canonique, de leurs collèges et couvents, de leurs 500 écoles primaires où œuvraient 1300 instituteurs et 50000 enfants, de leurs dix inspecteurs bilingues, de leurs six professeurs d'école normale, participèrent aux préparatifs du Deuxième Congrès.

${ }^{109}$ Le Compte rendu parle plusieurs fois du "gouverneur» de Québec et décrit sa résidence de Spencerwood comme une "résidence vice-royale». Le ministre ontarien des Mines, Paul Leduc (p. 174), l'appelle correctement «M. le Lieutenant-gouverneur». 
Cette énumération triomphaliste figurait dans la brochure publiée, comme programme-souvenir, lors des fêtes organisées à Ottawa du 21 au 24 mai 1937, un mois avant le Deuxième Congrès de la langue française $^{110}$.

La forte saveur cléricale et éducative de cette liste montre la composition du leadership franco-ontarien d'alors, celui-là même qui apporta son appui au grand rassemblement de Québec. La brochure publiée à Ottawa en 1937 reproduisait, en page de couverture, le «drapeau des Canadiens-Français», c'est-à-dire l'étendard à croix blanche sur fond bleu, avec, dans chaque quartier, une fleur de lis pointant vers le centre du drapeau. À l'intérieur de la brochure de 1937, le lecteur trouvait d'abord un poème d'Albert Ferland, «Salut à la langue française», suivi d'un rappel du «Serment de 1912», formulé par Mgr P.-E. Roy lors du Premier Congrès de la langue française. Vingt-cinq ans plus tard, c'est le frère de ce dernier, Mgr Camille Roy, qui lançait à l'Amérique française le cri suivant: «Peuple canadien-français, qu'as-tu fait de ton serment?»

Le Comité organisateur du Deuxième Congrès, à Québec, s'était naturellement tourné, pour l'organisation du Comité ontarien, vers les deux sociétés ontariennes les plus actives, soit l'Association canadienne-française d'éducation d'Ontario (ACFÉO) et la Société Saint-Jean-Baptiste d'Ottawa. On recruta au sein même de ces deux organismes les membres du Comité ontarien. En 1937 comme en 1912, les organisateurs ontariens s'assurèrent d'abord de l'ap-

\footnotetext{
${ }^{110}$ Cette énumération se trouve dans l'Hommage de la région outaouaise à la langue française. Programme souvenir 21-22-23-24 mai 1937. [Ottawa, Le Droit, 1937], 33 p.
} 
LES GRANDS CONGRES PATRIOTIQUES CANADIENS-FRANÇAIS

pui de toutes les sommités religieuses et civiles de leur région. Parmi les membres d'honneur, le Comité ontarien nomma un patron d'honneur (l'archevêque d'Ottawa, Guillaume Forbes), quatre catégories de "présidents d'honneur», premièrement les évêques et les vicaires généraux, deuxièmement l'honorable J.-E. Michaud, ministre des Pêcheries, troisièmement les honorables Raymond Morand, membre du Conseil privé, les juges de la Cour suprême et d'Échiquier résidant en Ontario (c'est-à-dire les juges Rinfret, Cannon et Angers) et, quatrièmement, les sénateurs G. Lacasse et L. Côté. Suivaient six catégories de «vice-présidents d'honneur»: les prélats romains, l'honorable E.-R. Chevrier (juge de la Cour supérieure de l'Ontario), le ministre ontarien des Mines, Paul Leduc, et l'ancien ministre Paul Poisson, les juges de comté, les députés fédéraux et les députés provinciaux.

Puis venaient les membres d'office, sous la présidence du juge Albert Constantineau. Les quatre viceprésidents étaient le docteur P.-E. Rochon (ClarenceCreek), le docteur J.-M. Laframboise (Ottawa), et les deux recteurs J. Hébert (Université d'Ottawa) et R. Legault (collège du Sacré-Cour de Sudbury). Le père Arthur Joyal, directeur du secrétariat de l'ACFÉO, agissait comme secrétaire du Comité ontarien, avec son adjoint, Edmond Cloutier. Lucien Laplante (trésorier de la Société Saint-Jean-Baptiste d'Ottawa) remplissait la fonction de trésorier. Enfin, la très longue liste de directeurs contenait quatre-vingts autres noms, représentant les régions de l'Ontario, mais le grand nombre provenait d'Ottawa. En outre, on mit sur pied des comités spéciaux, à savoir les comités d'organisation, de publicité, des maisons d'enseignement, des rapports, des finances. Chacun comptait un grand nombre de membres. 
Le Comité ontarien s'efforça de créer, dans toutes les paroisses, des comités locaux afin de rejoindre l'ensemble de la population, un effort spécial étant fourni pour recruter des jeunes. Ainsi, on organisa des soirées où des conférenciers prenaient la parole. Une action concertée fut aussi entreprise, surtout dans la région d'Ottawa, dans les écoles où l'on chercha à rendre les jeunes plus sensibles à leur histoire et à leur communauté. Le clergé canadien-français, le monde de l'enseignement, les professionnels et les hommes publics furent donc présents, tout le leadership franco-ontarien ayant trouvé place dans les divers comités d'organisation. Il semblerait toutefois que les résultats furent inégaux puisque la levée de fonds réussit plus ou moins selon les régions de la province.

Le Comité général ontarien, avec son siège à Ottawa, s'appuya sur le travail des comités régionaux. Selon Constantineau, parlant à Québec le 29 juin 1937, «Des orateurs furent envoyés dans diverses parties de la province pour stimuler le sentiment national. Et à ce propos, je suis heureux de vous dire que Monseigneur Camille Roy eut l'obligeance de nous prêter main forte en faisant une tournée ontarienne, accompagné du Révérend Père Joyal.»

Le Comité ontarien fit du 21 au 24 mai une période préparatoire au Congrès. Les plus grandes manifestations se déroulèrent à Ottawa. On avait choisi le 21 mai 1937, fête de Dollard, pour sensibiliser la jeunesse à ce héros, mais, plus généralement, on voulait initier les jeunes au patriotisme. Pour ces fêtes de mai 1937 à Ottawa, un autre immense comité avait vu le jour, sous le haut patronage de l'archevêque Forbes et sous la présidence d'honneur de Mgr J.-A. 
Mayrand, curé de Sainte-Anne, et des deux viceprésidences d'honneur, celles de l'honorable Paul Leduc, ministre provincial, et d'Albert Pinard, député fédéral. Le président des fêtes, le commissaire d'école E.-A. Bourque, était secondé par le secrétaire de la commission scolaire, Ernest Desormeaux, qui agissait comme trésorier. Le comité comptait aussi plusieurs personnalités en vue de l'Ontario français.

Les fêtes d'Ottawa, en préparation du Deuxième Congrès, comprenaient une «journée d'enseignement national» (le 21 mai 1937), un «Premier Congrès des sections juvéniles de la Société Saint-Jean-Baptiste d'Ottawa» (22 mai), un pèlerinage à Eastview et un "Grand Gala artistique» (23 mai), enfin une «Grande Manifestation patriotique» (24 mai) où l'on joua des sketchs historiques écrits par Victor Barrette.

En préparation du Congrès, on avait aussi prévu une série d'enquêtes pour "savoir dans quelle mesure les centres de langue française de l'Amérique du Nord ont conservé l'esprit français», dans divers domaines (affichage, étiquetage, disques, lecture, etc.).

Le Deuxième Congrès de la langue française commença le 27 juin 1937 et se termina le jour du

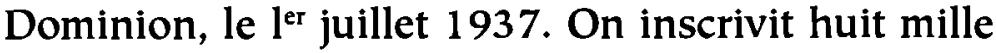
congressistes le dimanche et le lundi ( 27 et 28 juin). La participation de la province de Québec était la plus grande, évidemment, puis venaient les contingents franco-américains, très nombreux. Comme en 1912, plusieurs activités se déroulèrent simultanément. Alors que le travail des sections procédait, avec de nombreuses communications, des rassemblements publics avec force conférences se produisaient chaque 
jour. Entre tout cela, plusieurs banquets et réceptions sociales ponctuèrent la semaine du congrès.

Les femmes sont presque complètement absentes de ces délibérations, en dehors de quelques très rares exceptions. Lors des grandes cérémonies, les orateurs étaient habituellement des archevêques, évêques et autres sommités ecclésiastiques. Aussi présentes en grand nombre, les autorités civiles, notamment les juges et les hommes politiques. Venaient ensuite, en moins grand nombre, les professionnels (notamment les médecins, puis les avocats) et les groupes particuliers (les femmes, les jeunes). Lors des grands déploiements, on tentait habituellement d'assurer une représentation qui tienne compte non seulement de la ville ou même de la province de Québec, mais aussi des différentes régions de l'Amérique française. Le plus souvent, on choisissait des orateurs provenant du Québec, de l'Acadie, des ÉtatsUnis, de l'Ontario, de l'Ouest. Cette double image (les élites traditionnelles, les différentes régions) apporta une certaine définition de ce qu'on entendait alors par "Canada français», auquel on associait l'Acadie et les États-Unis (Nouvelle-Angleterre et Louisiane). Ils représentaient ce que les organisateurs du Congrès appelaient «l'élite du Canada français».

Le congrès se divisait en quatre sections, consacrées respectivement "à l'esprit français» dans la langue, dans les arts, dans les lois et dans les mours. Chaque section possédait son propre bureau et procédait à partir de questions proposées dans le programme. Les séances générales du soir avaient lieu au Colisée (Terrain de l'Exposition) et les séances générales du jour à la salle des promotions de l'Uni- 
LES GRANDS CONGRÈS PATRIOTIQUES CANADIENS-FRANÇAIS

versité Laval. Les sections siégeaient à l'université ou au Palais Montcalm.

Le dimanche après-midi (le 27 juin 1937), une Manifestation fut organisée devant les monuments de la ville. Le Compte rendu parle d'une «grandiose démonstration... un inoubliable souvenir... une première contribution de la jeunesse à l'apothéose de la langue française... présence d'une foule immense... défilé triomphal ${ }^{111} »$. Les superlatifs se multiplièrent pour décrire les événements de la semaine. Le dimanche, il s'agissait d'un défilé des jeunes dans les rues, faisant la visite des divers monuments (Laval, Champlain, Wolfe-Montcalm, Garneau, Croix du Sacrifice, Braves, Jacques-Cartier). Des bannières précédaient chaque groupe (cadets, scouts, sections de l'ACJC, JOC, JÉC, JIC, associations sportives). À chaque monument, on déposait une couronne de fleurs après un bref discours. Les sept couronnes, destinées aux sept monuments, étaient transportées sur un char allégorique où quatre jeunes filles avaient pris place, symbolisant les sections du Congrès: Langue, Loi, Arts et Mœurs. «Un autre char portait une jeune fille qui représentait la chanson française». Parmi les héros, Garneau accédait au panthéon à titre de «notre historien national».

À la séance d'ouverture, le dimanche soir, le recteur Camille Roy prononça un discours diffusé à la radio. On rendit des hommages, suivis des remerciements au «Gouverneur de la province de Québec», à l'Église, à la France, aux congressistes et à la ville de Québec. Voilà la trilogie honorée: le Roi, l'Église et la France. Des télégrammes furent envoyés au Roi

${ }^{111}$ Deuxième Congrès... Compte rendu 1937, p. 73. 
(«leurs hommages respectueux, l'assurance de leur loyauté»), au pape («l'hommage de leur piété filiale, de leur attachement à l'Église et à la personne du Souverain Pontife») et à l'Académie française ( "hommage de respectueuse admiration... leur fidélité aux meilleures traditions de la langue et de l'esprit français»).

À la deuxième séance publique, le lundi soir 28 juin, le juge Adjutor Rivard, secrétaire général du Congrès de 1912, rappela surtout ses souvenirs de cette époque, évoquant les noms illustres de cette rencontre. Le Congrès rendit ensuite un hommage au cardinal Villeneuve, qui prononça un discours sur «La survivance de l'esprit français par celle des mœurs et des traditions». Villeneuve parla de l'histoire des Canadiens-Français, l' «histoire de notre épopée mystique», soulignant de la part du Congrès ses marques de soumission, de dévouement et de loyauté au pape. Le cardinal y voyait autant «un acte clairvoyant de patriotisme qu'un devoir de profonde foi chrétienne». Sir Thomas Chapais, sénateur maintenant, présenta ensuite le délégué de l'Académie française (Louis Bertrand), qui prononça aussi un discours où il analysa les trois principales qualités de l'esprit français: le goût, la mesure et la clarté. Le recteur de l'Université de Montréal, Mgr Olivier Maurault, aborda «Le rôle de la culture française dans la vie canadienne». Maurault critiqua le "régionalisme» prôné depuis un quart de siècle: il ne s'agit pas de créer une nouvelle langue, mais «d'exprimer, en un français parfait, les modalités canadiennes de la pensée française».

La troisième séance publique, le mardi après-midi (le 29 juin 1937), était présidée par le juge Albert Constantineau, de la Cour de comté de l'Ontario. 
LES GRANDS CONGRÈS PATRIOTIQUES CANADIENS-FRANÇAIS

Après avoir fait l'éloge de Mgr Camille Roy, l'orateur loua aussi les combattants de la lutte scolaire qui ont ainsi permis la survivance. Il rappela le souvenir de Mgr Paul-Eugène Roy, de ses concitoyens de l'Ontario, N.-A. Belcourt et le Dr Réaume, mais aussi du professeur Alcée Fortier (de Tulane, aux États-Unis) et du sénateur Pascal Poirier du Nouveau-Brunswick. Cette séance, comme tant d'autres, se termina par le Ô Canada.

Le mardi soir (29 juin) avait lieu, au Colisée, la quatrième séance publique où le gouverneur général du Canada, lord Tweedsmuir, parla brièvement. Durant cette séance, on entendit aussi un discours du recteur Joseph Hébert, de l'Université d'Ottawa, sur «La survivance de la langue française par celle de l'esprit français», en plus de celle de Lionel Groulx sur «L'histoire gardienne de traditions vivantes». Le discours de Groulx produisit un grand effet. L'historien termina son vibrant discours en affirmant:

Qu'on le veuille ou qu'on ne le veuille pas, notre État français nous l'aurons; nous l'aurons jeune, fort, rayonnant et beau, foyer spirituel, pôle dynamique pour toute l'Amérique française. Nous aurons aussi un pays français, un pays qui portera son âme dans son visage. Les snobs, les bonne-ententistes, les défaitistes, peuvent nous crier, tant qu'ils voudront: "Vous êtes la dernière génération de Canadiens français...» Je leur réponds, avec toute la jeunesse: «Nous sommes la génération des vivants. Vous êtes la dernière génération des morts ${ }^{112}$ ".

Pour ces discours du 29 juin, l'estrade était décorée «aux couleurs de la France et du Canada français». Un autre programme musical termina cette soirée du 29 juin.

${ }^{112}$ Deuxième Congrès... Compte rendu, p. 310. 
Lors de la cinquième séance, le jeudi $1^{\text {er }}$ juillet 1937, l'Université Laval conféra plusieurs doctorats honorifiques à des personnalités de toutes les régions de l'Amérique française et aux représentants de la France. En hommage à l'Ontario, l'Université Laval conféra un doctorat honorifique à Paul-Émile Rochon, une façon de rendre hommage à l'ACFÉO dont il était président et «à tous nos compatriotes de l'Ontario". Un autre doctorat honorifique fut remis au recteur Joseph Hébert, de l'Université d'Ottawa, "une forteresse de vie et d'influence française», diplôme qui veut saluer le recteur originaire de la ville de Québec, mais aussi la congrégation des oblats et l'Université d'Ottawa. L'Université Laval décerna un doctorat honorifique à François-Charles-Achille Jeanneret, professeur à l'Université de Toronto, pour reconnaître le "foyer de culture française" que dirigeait ce professeur, promoteur des cours d'été en français pour les Ontariens à Sillery, «travail de bonne entente et d'éducation" que veut reconnaître l'Université Laval. Aurélien Bélanger, quant à lui, reçut un doctorat honorifique pour son rôle de chef lors des «luttes héroïques pour la liberté scolaire», lui chez qui s'incarne «la ténacité de la résistance ontarienne». On le présenta comme député, pionnier de l'ACFÉO, qui a passé sa vie comme professeur d'université et comme inspecteur d'écoles.

En soirée, au Colisée, se tenait la sixième séance publique, celle de la clôture du Congrès. On entendit de nouveaux orateurs décrire la situation de la langue et de l'esprit français dans différentes régions de l'Amérique française. Il fut question de l'Acadie (Mgr Arthur Melanson, archevêque de Moncton), des Franco-Américains (Adolphe Robert). Pour l'Ontario français, c'est le sénateur Gustave Lacasse qui traita 
de «La langue et l'esprit français dans l'Ontario».

Outre ces grandes séances publiques, le Congrès tint aussi des Assemblées générales. En outre, neuf sections furent créées, pour traiter (a) de la langue parlée, (b) de la langue écrite, (c) des arts, (d) des lois, (e) des mœurs et traditions (division $A$ ), (f) des mœurs et traditions (division $B$ ), (g) des dames et $(\mathrm{h}$ ) des jeunes. Le rapporteur de la section (f) était le dominicain P.-M. Gaudreau, d'Ottawa. Le travail "scientifique» du Congrès s'effectuait, pendant tout ce temps, dans les diverses sections.

Dans la section de la langue parlée, sur vingt-sept communications, la seule contribution ontarienne semble avoir été celle de Victor Barrette, d'Ottawa, qui parla des «Annonceurs de la T.S.F. et téléphonistes». Dans la section de la langue écrite, la participation ontarienne fut plus importante puisque sept des vingt et une communications provenaient de l'Ontario: Louvigny de Montigny, Félix Desrochers, L.-P. Gagnon, Lorenzo Côté, Léo-Paul Desrosiers, F.-A. Jeanneret, Pierre Daviault. Mais Marius Barbeau fut le seul délégué ontarien à participer aux travaux de la section des arts, dont les dix-sept communications provenaient surtout de la région de Montréal. De même, une seule communication, celle du juge G. [J.A.-S.] Plouffe, de North-Bay, représenta l'Ontario dans la section des lois. Dans la section des mours et traditions (divisions $A$ et $B$ ), deux des vingt et une communications en A (celles de Léopold Richer et de Joseph-Médard Carrière) venaient de l'Ontario, tandis que trois des dix-neuf communications en B provenaient d'Ottawa: les oblats Gustave Sauvé et A. Joyal et l'abbé R. Limoges, tous trois d'Ottawa. Dans la section des dames, Michelle Le Normand présenta 
la seule participation ontarienne, sur les onze communications présentées. Quant à la section des jeunes, elle ne reçut aucune participation de l'Ontario.

Ainsi, la participation franco-ontarienne a pris plusieurs formes, tantôt dans les grandes séances publiques, tantôt dans le cadre des sections. Ces textes furent tous publiés dans les actes du Deuxième Congrès, soit dans le volume du Compte rendu ${ }^{113}$ pour les discours faits en séances plénières, soit dans les trois volumes de Mémoires ${ }^{14}$ pour les communications faites dans les sections.

Après toutes ces communications, discours et conférences, le Deuxième Congrès finit par adopter des vœux et par faire des déclarations, ce qui représente les intentions des congressistes. Les diverses sections d'étude avaient soumis des propositions. Il y eut au total quarante-six (46) résolutions. Pour les historiens, notons que la troisième recommandation

\footnotetext{
${ }^{113}$ Dans le Compte rendu, voir les Salutations de Paul Leduc, ministre des Mines de l'Ontario, p. 174-176, le discours d'A. Constantineau, p. 219-224, du recteur de l'Université d'Ottawa, Joseph Hébert, p. 270-276, un "toste à l'Ontario» par P.-E. Rochon, président de l'ACFÉO, p. 354-356, un discours de Gustave Lacasse, p. 436-443. ${ }^{114}$ Pour les communications des participants ontariens, voir les textes de Louvigny de Montigny sur le français dans le théâtre, I, p. 302-308, de Félix Desrochers sur l'insuffisance des bibliothèques, I, p. 330-337, de L.-P. Gagnon sur la diffusion du livre français, I, p. 377-391, de Lorenzo Côté sur les anglicismes de forme, I, p. 392-398, de Léo-Paul Desrosiers sur le roman canadien depuis 1912, I, p. 405-410, de F.-C.A. Jeanneret sur l'enseignement du français aux professeurs ontariens, I, p. 421-424, de Pierre Daviault sur la traduction, I, p. 431-438, de G. [c'est-à-dire: J.-A.-S.] Plouffe, II, p. 75-93, de Léopold Richer sur l'esprit français en politique, III, p. 59-64, de Joseph-Médard Carrière sur la "survivance française au pays des Illinois», III, p. 96-101, de Gustave Sauvé sur la doctrine délétère du communisme, III, p. 147151, d'Arthur Joyal sur les religieuses enseignantes, III, p. 162-167, de Michelle Le Normand sur les familles d'hier et d'aujourd'hui, III, p. 325-329.
} 
préconisait «Que l'on fonde un plus grand nombre de sociétés d'histoire régionale et locale et que l'on invite spécialement jeunes gens et jeunes filles à en faire partie», le considérant de la proposition précisant «que l'étude de l'histoire régionale est un excellent facteur de survivance et un moyen de développer la fierté nationale». Une partie de la $44^{\mathrm{e}}$ résolution demandait $" 2^{\circ}$ Que l'enseignement de l'Histoire du Canada aux différentes étapes de la formation soit constamment renouvelé, approprié et perfectionné, de façon à procurer à notre peuple la connaissance intime de son passé et à lui fournir des éléments de conviction qui le maintiennent dans la ligne de ses hérédités catholiques et françaises». La $43^{\mathrm{e}}$ résolution demandait aussi «Que le culte de saint JeanBaptiste se répande de plus en plus, et que dans toutes les familles on ajoute à la prière du soir une invocation spéciale à ce grand patron et protecteur».

Le financement du Deuxième Congrès fut une réussite. Près de la moitié des revenus provenait d'une souscription (36086\$), dont le tiers recueilli dans la région de Québec (31,4\% exactement). Un autre $27,6 \%$ de la collecte provenait de la province de Québec ( $y$ compris un mince $4294 \$$ de la région de Montréal). L'Ontario et la Nouvelle-Angleterre avaient chacun recueilli plus de 5000 \$ (5029 \$ exactement pour l'Ontario, dont $3065 \$$ de la région d'Ottawa, ce qui représentait $61 \%$ de la souscription ontarienne). La province de Québec donna 15000 \$ et la ville de Québec 5000 \$. 
C - LE CONGRÈS DE 1952

En 1937, on institua le Comité permanent de la survivance française afin de donner suite aux recommandations du Deuxième Congrès. Le Comité de la survivance devint aussitôt un des organismes importants du Canada français, à l'origine de plusieurs initiatives importantes aux cours des trois décennies suivantes. Il fut aussi à l'origine du Troisième Congrès de la langue française en $1952^{115}$.

Le Comité siégea de 1938 à 1956 dans des bureaux mis à sa disposition par le Séminaire de Québec, puis il occupa son propre local, obtenant en 1940 une charte fédérale. Dans le Comité permanent, quinze (15) des vingt-cinq (25) places étaient réservées aux minorités. Beaucoup d'autres membres, jusqu'à la cinquantaine parfois, s'ajoutèrent, au gré des circonstances, pour représenter des organismes ou pour faire place à des personnes en vue. Chaque province canadienne avait droit à une place, sauf l'Ontario et le Nouveau-Brunswick qui en occupaient deux chacun. Cinq places étaient réservées aux Franco-Américains.

\footnotetext{
${ }^{115}$ L'histoire du Comité de la survivance a été analysée en détail par Marcel Martel, Les Relations entre le Québec et les francophones de l'Ontario. De la survivance aux dead ducks, 1937-1969 (Thèse de Ph.D., Université York, juin 1994, 320 p.), notamment le chapitre 2: «Le Conseil de la vie française en Amérique: sa naissance, sa composition et son financement", p. 59-114, et le chapitre 3: "Le Canada français à l'œuvre: le Conseil de la vie française en Amérique, 19451960", p. 115-167. Cette thèse est une importante source au sujet du Canada français et de ses relations avec le Conseil de la vie française (c'est-à-dire, avant 1952, le Comité de la survivance française en Amérique). Pour l'histoire du Comité de la survivance, voir aussi la revue du comité, Vie française. Cette revue a d'ailleurs elle-même fait l'objet d'une étude par James H. Lambert, «Vie française, 1955-1960. La solidarité, moyen de survivance dans une société menaçante», dans Idéologies au Canada français, 1940-1976 (3 volumes, Québec, Presses de l'Université Laval, 1981), tome I, p. 263-286.
} 
Les réunions avaient lieu une fois l'an, à huis clos, mais un exécutif de onze (11) membres se réunissait mensuellement. En 1938, on admit les recteurs des Universités Laval, de Montréal et d'Ottawa, privilège aboli en 1958, quand on en fit des membres d'honneur.

Le travail du Comité de la survivance s'inscrivit à l'enseigne de la solidarité. L'organisme chercha à porter secours à tous les groupes de la diaspora française du continent, mettant la province de Québec à contribution. De janvier 1941 à mai 1961, le Conseil diffusa un quart d'heure hebdomadaire au réseau radiophonique de Radio-Canada (le «Quart d'heure du Conseil»). Embrayant sur l'activité de la Société Saint-Jean-Baptiste de Québec, le Conseil demanda à partir de 1942 qu'on généralisât la semaine de la fierté nationale; dans les années 1950, c'est l'Association canadienne des éducateurs de langue française (ACELF) qui prit le relais, en implantant la semaine de la vie française. Comme la campagne de levée de fonds organisée en faveur du Congrès de 1937 avait connu un grand succès, le Comité de la survivance organisa en 1943 une levée de fonds en faveur d'un quotidien en Acadie, puis, en 1945, une nouvelle campagne vint appuyer le projet d'établir dans l'Ouest des stations de radio. Ces deux campagnes connurent des succès énormes, les fonds recueillis dépassant largement les prévisions.

Un noyau d'une douzaine de personnes assura longtemps la continuité des efforts de l'organisme: le frère Antoine Bernard, Yves Bernier, Henri Boisvert, Cyrille Delâge, Ernest Desormeaux (de l'Ontario), Georges Dumont, l'abbé Paul-Émile Gosselin, Paul Gouin, Reine Malouin, les pères Albert Plante et Adrien Pouliot, aussi l'abbé Adrien Verrette. Plusieurs 
sont membres du clergé. Selon Marcel Martel: «Les membres confient en fait leurs destinées à l'élite de Québec et d'Ottawa. À prime abord, la proximité des sièges de deux gouvernements place ces élites dans une situation privilégiée. Mais leur lobby inclut la promotion des intérêts locaux et généraux du Canada français auprès de l'épiscopat, du département de l'Instruction publique et du mandataire du Vatican $^{116}$ ». En Ontario, l'ACFÉO a tenu le rôle de section ontarienne du Comité de la survivance, alors que, au Québec, ce sont les Sociétés Saint-JeanBaptiste qui remplissaient cette fonction. Mgr Camille Roy fut le premier président du Comité permanent. Au début, le président du Conseil fut Adrien Pouliot (de Radio-Canada), le père Arthur Joyal, secrétaire général de l'ACFÉO, siégeant alors dans le Comité. Plus tard, le père Joyal le remplaça (1947-1949) et, en 1949, l'abbé Adrien Verrette devint président jusqu'en 1953. Viendront ensuite Paul Gouin (19551961 ) et Thomas-Marie Landry (1961-1965).

Au sein du Conseil, il existait une forte représentation de Québec, mais certains conflits surgirent sur la représentation de Montréal. Quant à l'Ontario, c'est d'abord le père Arthur Joyal qui siégea au conseil, remplacé ensuite par Ernest Desormeaux. Pour les groupes minoritaires, ce dernier, enseignant, secrétaire de la commission de l'assurance-chômage de 1940 à 1962 , fut le plus important ${ }^{117}$. Il fut président de l'ACFÉO de 1944 à 1953 et un des fondateurs de l'ACÉLF en 1947. Jean-Jacques Tremblay aussi siégea; originaire de Roberval, docteur en philosophie de l'Université d'Ottawa, secrétaire général de l'Union

\footnotetext{
${ }^{116}$ Marcel Martel, Op. cit., p. 101.

117 Marcel Martel, Op. cit., p. 98.
} 
LES GRANDS CONGRÈS PATRIOTIQUES CANADIENS-FRANÇAIS

Saint-Joseph du Canada, membre de l'Ordre de Jacques-Cartier, il entra au Comité permanent en 1946, délégué par l'Union des mutuelles-vie française d'Amérique. Il démissionna en 1967.

Durant cette période entre le Deuxième et le Troisième Congrès, le Comité permanent se fit le propagandiste de certaines idées, comme le concept des deux peuples fondateurs du Canada. Le Comité intervint aussi devant la commission royale Rowell-Sirois (relations fédérales-provinciales) et la commission Massey (les arts et les lettres au Canada). Le Comité se prononça souvent en faveur du bilinguisme et pour l'usage du français partout au Canada. Il appuya les démarches pour un drapeau canadien, pour des chèques fédéraux bilingues (plutôt que des chèques anglais et français différents), pour des timbres et la monnaie bilingues. Ses outils de propagande ont pris plusieurs formes: la radio, la publication d'un calendrier, d'affiches, de tracts, de sa collection Pour survivre (1943-1947) et de son périodique Vie française (fondé en 1947). Le Comité alla jusqu'à fonder les Éditions Ferland (en l'honneur de l'historien JeanBaptiste Ferland, du siècle dernier) pour publier les ouvrages du Comité. En 1947, le Conseil créa l'Ordre de la fidélité française. Au milieu des années 1940, aussi, commença la pratique des voyages de la "Liaison française», une activité annuelle organisée l'été pour que les Québécois visitent des groupes français du continent. Le Conseil versa aussi des bourses aux jeunes qui allaient étudier au Québec.

Pour les finances, le Comité put commencer sur un bon pied grâce au surplus de $22000 \$$ du Congrès de 1937 et aux subventions du gouvernement du Québec. Après 1938, le sou de la survivance, perçu dans toutes 
les écoles, devint la principale source de revenu du Comité. Plus tard, le sou fut partagé avec l'ACÉLF. En Ontario, l'ACFÉO partageait aussi le sou de la survivance avec le Comité permanent. La vente de calendriers, à partir de 1941, continua jusqu'en 1964 (l'ACFÉO achetait et vendait chaque année $9 \%$ des calendriers), 15000 au total étant vendus annuellement un peu partout. Le Fonds Jean-Talon recueillit diverses sommes, dont le surplus de quelque cinquante mille dollars du Congrès de 1952; en 1957, on tenta de faire grimper ce fonds à un million de dollars, mais il n'avait atteint que 200000 \$ en 1960.

Dès 1949, Omer Héroux, du Devoir, proposait au Comité de la survivance française la convocation du Troisième Congrès de la langue française. Renouvelée à plusieurs reprises, la proposition reçut enfin l'aval du Comité permanent en 1950. La Commission du Congrès recommanda la tenue à Québec d'un congrès de la langue française au Canada en juin 1952, année du centenaire de la fondation de l'Université Laval $^{118}$, mais aussi du cinquantenaire de la Société du parler français, du quarantième anniversaire du Premier Congrès et du quinzième du Deuxième Congrès. La Commission proposa aussi que le thème du Congrès fût l'éducation nationale. La décision fut prise aussitôt. Ainsi se constituèrent les "états généraux de la race $^{119}$ ", du 18 au 26 juin 1952 . Le congrès serait l'occasion d'une «ressaisie des forces vives autour

\footnotetext{
${ }^{118}$ Le Compte rendu du Troisième Congrès prit bien soln d'associer cette rencontre au centenaire de l'Université Laval: «Dans l'esprit de ses organisateurs, le Troisième Congrès de la Langue française devait s'insérer dans l'ensemble des manifestations organisées à l'occasion du centenaire de l'Université Laval» (Compte rendu, p. 74). 119 Troisième Congrès... Compte rendu 1952, p. 50.
} 
LES GRANDS CONGRÈS PATRIOTIQUES CANADIENS-FRANÇAIS

de notre héritage culturel». On voulait surtout faire une place aux jeunes «qui, partout, sur le continent tiennent dans leurs âmes les promesses de l'avenir». Une troisième fois, la continuité ne se manifesta pas seulement dans le type d'organisation, elle se situa aussi, peut-être surtout, dans la parfaite continuité idéologique.

En juin 1951, le Comité de la survivance créa le "Comité central» avec un exécutif appelé le «bureau du Congrès». On créa aussi cinq comités secondaires du congrès (finances, réception, propagande, manifestations publiques, étude). On décida aussi de créer des comités régionaux: un par diocèse dans la province de Québec, un pour chaque province canadienne, pour chaque État de la Nouvelle-Angleterre et pour la Louisiane. Il y avait ensuite des souscomités. Au sommet, rayonnait un Comité central, auquel se joignaient les présidents des «comités secondaires".

Comme par le passé, les organisateurs s'assurèrent de l'appui d'une foule de personnalités religieuses, politiques et culturelles. Ce Comité d'honneur comprenait «les plus hautes personnalités de la vie française en Amérique», avec deux patrons d'honneur, le lieutenant-gouverneur de la province de Québec (Gaspard Fauteux) et l'archevêque de Québec et chancelier de l'Université Laval (Maurice Roy), deux présidents d'honneur, soit le premier ministre du Canada (Louis Saint-Laurent) et le premier ministre du Québec (Maurice Duplessis) ${ }^{120}$.

${ }^{120}$ Les cinq vice-présidences d'honneur étalent occupées par l'archevêque de Montréal (Paul-Émile Léger), le juge en chef du Canada (Thlbaudeau Rinfret), le recteur de l'Unlversité Laval (Ferdınand Vandry), le juge en chef de la Cour suprême du Nouveau-Brunswick 
D'intenses efforts de propagande, à l'échelle de l'Amérique, furent réalisés. Un comité spécial adressa 4800 lettres à 2200 maisons de religieuses, de frères enseignants, d'associations laïques de tout genre. Cette intense campagne de propagande fit aussi appel à la presse et à la radio. On publia des dépliants, des brochures, des pancartes. On donna des conférences. On encouragea la publication d'articles dans diverses revues et dans les journaux. Les causeries et les entrevues se multiplièrent à la radio. On chercha à intéresser les communautés religieuses et les diverses sociétés nationales. Les vingt-six comités régionaux ( 15 au Québec, 11 ailleurs) s'y appliquèrent au niveau local, avec de nombreux voyages et contacts. Le Comité régional de l'Ontario avait à sa présidence Ernest Desormeaux, Roger Charbonneau agissant comme secrétaire.

Dès l'été de 1951, la campagne commençait en Acadie, à l'occasion du voyage de la Survivance française. Puis elle se poursuivit dans le nord de l'Ontario, du 23 au 28 septembre, par ce que le compte rendu appelle «une première tournée triomphale». Le père Gustave Sauvé et le journaliste Victor Barrette, du Droit, en compagnie de l'abbé Adrien Verrette, président du congrès, visitèrent quinze centres français. Une deuxième tournée, entre le 21 et le 27 octobre, permit de rencontrer les Franco-Ontariens de dixsept autres localités. Les rencontres se déroulaient

(Encil Michaud) et l'ex-président de l'Union Saint-Jean-Baptiste d'Amérique (Henri-T. Ledoux). Les neuf «membres» du Comité d'honneur étalent cinq archevêques, deux évêques et deux maires (Québec et Montréal). Le comité organisateur, sous la présidence de l'abbé Adrien Verrette, comprenait trois vice-présidences, occupées par les présidents des sociétés Saint-Jean-Baptiste de Québec (Henri Lallier), de Montréal (Alcide Martel) et de la Fédération des SSJB du Québec (G.A. Grondin). 
dans les écoles ou dans les salles paroissiales. La ronde ontarienne se termina par une visite, entre le 18 et le 25 avril 1952, dans la région de Kent-Essex, où Verrette, accompagné de Sauvé, du journaliste Germain Bruère et du publiciste Armand Verrette, visita une vingtaine de groupes ${ }^{121}$.

Le résultat de ces efforts, c'est que 4000 congressistes se présentèrent, du Québec, des autres provinces canadiennes, de nombreux États américains, de France, de Belgique, d'Haïti, de l'île Maurice. Le 18 juin 1952, date d'ouverture du Congrès, le Comité de la Survivance française en Amérique, créé à la suite du Congrès de 1937, tint sa réunion annuelle. On discuta de la situation en Colombie-Britannique, à Terre-Neuve et du Comité de la survivance à Paris. Le Comité de la survivance précisa aussi "les six vœux fondamentaux qui devaient être présentés au Congrès de la Langue française».

Le soir de l'ouverture (18 juin 1952), la soirée «très brillante était rehaussée par la présence de nombreux archevêques et évêques, des délégués officiels de la France... et de toute l'élite de la société québécoise». La salle était décorée "aux couleurs de la province et aux armes du Congrès". Les discours, entrecoupés de pièces musicales, furent prononcés par l'abbé Verrette, par le premier ministre Louis Saint-Laurent, par Robert D'Harcourt (membre de l'Académie française), par le recteur de l'Université Laval, Mgr Ferdinand Vandry. Verrette, «majestueusement drapé dans les plis de son manteau romain", fit un discours que la radio permit de diffuser à l'échelle du pays. Il définit ainsi l'objet de la rencontre: «Nous venons nous concerter afin d'embellir

${ }^{121}$ Troisième Congrès... Compte rendu 1952, p. 55. 
et d'illustrer davantage notre comportement catholique et français sur ce continent ${ }^{122} \%$. Il rendit hommage à l'Université Laval et aux disparus, salua les autorités religieuses et civiles, les représentants de la France, les divers organismes qui avaient appuyé l'organisation du Congrès, notamment les Sociétés Saint-JeanBaptiste et les comités régionaux. Puis s'adressant à tous les groupes présents, il fit aux Franco-Ontariens, cette salutation: "Salut à nos infatigables frères de l'Ontario qui multiplient les éclatants succès de leur pénétration dans cette importante province et qui ont juré de ne jamais céder les positions que les héros de leur résistance ont établies au prix de sacrifices inouïs ${ }^{123}$ ». La soirée se termina par le chant de l'hymne national: "Ô Canada».

Du 19 au 22 juin, les six "sections» se réunirent, au rythme de deux séances de 90 minutes chaque jour. Un total de cinquante-six (56) travaux furent présentés. Les six sections étaient les suivantes: (1) La Survivance française (Comité de la survivance française); (2) Le Parler français (Société du parler français au Canada); (3) Les Pays de langue française (Comité de la survivance française); (4) L'Éducation patriotique (ACÉLF); (5) La Jeunesse et le patriotisme (Association de la jeunesse canadienne); et (6) La Refrancisation (Paul Gouin).

La première séance des sections eut lieu le jeudi matin, le 19 juin 1952, à l'Université Laval. Dans les trois sections qui se réunirent, aucun des conférenciers, ni aucun des sujets ne concernaient directement l'Ontario. La deuxième séance des sections, le jeudi après-midi du 19 juin, permit à trois sections

\footnotetext{
122 Troisième Congrès... Compte rendu 1952, p. 72.

${ }^{123}$ Troisième Congrès... Compte rendu 1952, p. 184.
} 
LES GRANDS CONGRÈS PATRIOTIQUES CANADIENS-FRANÇAIS

de se réunir. Dans la première section, Ernest Desormeaux, président de l'ACFÉO, présenta une communication sur «La vie française en Ontario». Dans le deuxième atelier, Marcel Trudel et Fernand Grenier, cartes à l'appui, traitèrent de «La répartition des groupes de langue française au Canada depuis deux siècles". La troisième séance, sur la refrancisation, ne contenait rien sur l'Ontario français.

En remerciant le maire de Québec le jeudi 19 juin 1952, Ernest Desormeaux, président de l'ACFÉO, mentionna, "en termes aussi délicats qu'éloquents ${ }^{124}$ ", le succès des deux premiers congrès et en rappela l'importance: «Ces congrès de la langue française intensifient l'esprit et la coordination de nos groupements, ils nous font prendre conscience de nos devoirs et ils contribuent à créer chez ceux qui nous entourent une compréhension plus grande de la valeur et de la richesse de notre contribution à la vie culturelle, sociale et même économique de nos pays d'Amérique». Desormeaux nota le grand succès remporté par les deux premiers congrès de la langue française et de leurs suites: les postes de radio dans l'Ouest, l'ACÉLF fondée en 1947 et le Comité francoaméricain d'orientation.

Le soir du 19 juin se déroula le Dîner de la fidélité, ce que le compte rendu décrit comme «une des plus brillantes manifestations du Congrès». Ce fut l'occasion de remettre les insignes de l'Ordre de la fidélité française à dix personnalités de l'Amérique française. Deux des lauréats venaient de l'Ontario, Mgr Stéphane Côté et Aurélien Bélanger, tous deux absents à cause de «l'âge avancé ou l'état de santé».

${ }^{124}$ Pour le texte complet du discours de Desormeaux, Compte rendu 1952, p. 221-225. 
Les décorés furent présentés par Cyrille Delâge qui, à propos des deux Ontariens, déclara:

La province d'Ontario renferme aujourd'hui le groupement le plus considérable de Canadiens français en dehors du Québec. Sous la direction de chefs prudents et valeureux, ces compatriotes s'affirment de plus en plus comme un élément de qualité de la vie ontarienne. Le Comité de la survivance française a voulu souligner leurs combats pour la survivance, applaudir à leurs triomphes et récompenser leurs labeurs dans la personne de deux vétérans de la résistance, de l'expansion et du rayonnement franco-ontariens: Mgr Stéphane Côté, vicaire général du diocèse de Sault-Sainte-Marie, monsieur Aurélien Bélanger, longtemps député à la législature de l'Ontario ${ }^{125}$.

C'est au cours de ce dîner que le Comité de la survivance française en Amérique annonça publiquement qu'il s'appellerait désormais le Conseil de la vie française en Amérique, décision entérinée le premier jour du congrès.

En fin de soirée (le jeudi 19 juin), les congressistes purent assister à un «Hommage au Sacré-Cœur», dont c'était l'anniversaire. Soixante mille personnes, au Stade Victoria, participèrent à cette fête, en même temps qu'un autre groupe de $\mathbf{5 0} 000$, à Montréal, se réunissait à l'Oratoire Saint-Joseph. En cette occasion, Verrette «consacra au Sacré-Cour de Jésus toute l'assistance et toute la race canadienne-française ${ }^{126}$ ". La cérémonie fut diffusée sur les ondes de RadioCanada.

La troisième séance d'étude se déroula le matin du 20 juin 1952. Dans la section du «Parler français», Marius Barbeau traita des «Recherches sur le voca-

${ }^{125}$ Compte rendu 1952, p. 239.

${ }^{126}$ Compte rendu 1952, p. 86. 
bulaire des métiers». La quatrième séance d'étude se déroula le vendredi après-midi et permit des rencontres des sections de "L'éducation patriotique», en deux ateliers différents, et "Le parler français», où Pierre Daviault traita des «Anglicismes et emprunts à l'anglais».

En fin d'après-midi, l'archevêque de Québec, Maurice Roy, recevait les délégués (salle des promotions de l'Université Laval). Au cours de cette rencontre, l'archevêque «dans un saisissant raccourci historique, mit en lumière la tâche immense accomplie par les colonisateurs religieux et laïques du Canada et de l'Amérique française». Roy s'adressa aussi aux jeunes, leur rappelant leur devoir de lutter pour la préservation de la langue et de la religion. Le Compte rendu termine en disant: "Cette paternelle allocution produisit une profonde impression sur tous les délégués, qui quittèrent la salle plus déterminés que jamais à lutter pour la préservation de [sic] l'enrichissement de notre héritage culturel».

Le soir du vendredi 20 juin 1952, deux grandes fêtes se tenaient simultanément: d'une part une séance à l'occasion des noces d'or de la Société du parler français, société fondée à l'Université Laval en 1902 et présidée, en 1952, par Mgr F.-A. Savard (pièces musicales, conférences), et d'autre part une séance patriotique qui se déroula au Palais Montcalm. Au cours de cette séance patriotique, on rendit «hommage aux minorités de langue française du Canada et des États-Unis». Parmi les personnalités présentes, se trouvait Jean-Jacques Tremblay, secrétaire de I'Union Saint-Joseph du Canada, porte-parole de l'Ontario. Il avait en 1937 fait un discours remarqué et il prit à nouveau la parole en 1952. Dans son 
discours, Tremblay décrivit la volonté de résistance de l'Ontario français qui «tient à sa vie propre non pas par sentiment, mais parce qu'il a la conviction profonde de constituer une valeur humaine, une valeur de culture et de civi[li]sation, un instrument irremplaçable des œuvres de Dieu en terre d'Amérique $^{127}$ ". À cette séance patriotique participaient deux représentants de la Société Saint-Jean-Baptiste d'Ottawa, Louis Charbonneau et Albert SaintGeorges. Des représentants des autres communautés françaises du continent prirent aussi la parole. Les deux fêtes, celle de la Société du parler français et celle du Palais Montcalm, clôturèrent par le ô Canada.

Le samedi 21 juin, deux sections sur «L'éducation patriotique" se réunirent, en même temps que les sections sur "La jeunesse et le patriotisme» et «La littérature au Canada français - Symposium de la Société des écrivains canadiens». La première section sur l'éducation patriotique était présidée par Louis Charbonneau, tandis que l'autre section, sur l'éducation patriotique, entendit une conférence de Robert Gauthier, éducateur franco-ontarien en vue, sur «La langue parlée». Dans la section «La jeunesse et le patriotisme", on entendit un exposé de Gustave Hurtubise sur «L'Association de la jeunesse francoontarienne».

La sixième séance d'étude, le samedi après-midi (21 juin 1952) comprenait, comme le matin, deux sections de "L'éducation patriotique» et une de «La jeunesse et le patriotisme». Dans cette dernière section, Marius Barbeau parla des «traditions et coutumes canadiennes-françaises».

${ }^{127}$ Compte rendu 1952, p. 93. 
Le samedi, à l'Université Laval, avait lieu une remise de trente (30) doctorats honorifiques. On honora plusieurs personnalités provenant des différentes régions de l'Amérique du Nord, dont Marius Barbeau (en lettres), le ministre Lionel Chevrier (en droit), Ernest Desormeaux (en sciences sociales) et le sénateur Joseph-Raoul Hurtubise (en lettres). Barbeau, fonctionnaire au Musée national d'Ottawa, fut honoré comme «chercheur et folkloriste éminent qui a exploité avec bonheur l'histoire des traditions canadiennesfrançaises"; Lionel Chevrier, pour "ses talents exceptionnels et son dynamisme conquérant", ministre, «un Franco-Ontarien qui fait grandement honneur à ses compatriotes»; Ernest Desormeaux, «un patriote convaincu et éclairé qui a déjà fait beaucoup pour la cause de ses compatriotes franco-ontariens", directeur du Comité de la survivance, président de l'ACFÉO; Joseph-Raoul Hurtubise, au "zèle éclairé et au dévouement inlassable... déployés pour la défense de leurs [des Franco-Ontariens] intérêts", viceprésident de l'ACFÉO, «vaillant apôtre de la vie et de la culture française».

Le samedi soir (21 juin) se déroula une séance de la jeunesse au Colisée, où 15000 jeunes s'étaient rassemblés, sous la présidence de Maurice Duplessis. On les invita à se faire "les martyrs de la cause française en Amérique». En plus de nombreuses pièces traditionnelles, on leur fit entendre des discours de Gaétan Legault (président de l'Association de la jeunesse canadienne-française), de Gustave Hurtubise, de l'Ontario, de Léon Bouvier, du Massachussetts. Des conférences furent prononcées par le député René Chalout, par le chanoine Lionel Groulx, dont la présentation fut le clou de la soirée, par le premier ministre Maurice Duplessis et par l'archevêque 
Maurice Roy. Groulx définit ce que «nous sommes»: des Français et des catholiques, un héritage que les jeunes devaient conserver. Groulx s'opposait au centralisme politique qui serait «le coup mortel dirigé contre un état de choses, une liberté, des droits pour lesquels nous avons lutté pendant cent ans; le self government des provinces, c'est-à-dire aujourd'hui un Québec libre, ni serf ni colonie d'Ottawa... Québec tombé, qui voudrait encore se battre, en Amérique, pour une survivance française?» La mission de la jeunesse, c'était de se battre pour que «les Canadiens français vivent et non seulement survivent». Mais la jeunesse ne recevait pas une éducation appropriée. La soirée au Colisée se termina par le ô Canada. En fin de soirée, sur le terrain de l'Exposition, on alluma le feu de la Saint-Jean.

À cause du Congrès, la Société Saint-Jean-Baptiste avait devancé de deux jours son défilé de la fête de Saint-Jean-Baptiste («fête nationale des Canadiens français»). Le défilé de la Saint-Jean contenait douze (12) chars allégoriques, admirés par une foule de 75000 personnes: «Les délégués des pays étrangers et des groupes minoritaires furent fortement impressionnés par cette grandiose manifestation populaire, ainsi que l'attestent les témoignages rendus par de nombreux délégués».

On se rendit ensuite au parc Cartier-Brébeuf, à la Croix de Cartier, où, selon le Compte rendu, weut lieu une émouvante démonstration de la jeunesse francoontarienne». Le panégyrique de Cartier fut fait par l'abbé Guillaume Miville-Dechêne, curé de SaintFrançois-d'Assise. «Deux jeunes Franco-Ontariens, MM. Lucien Labelle et Richard Robillard, exprimèrent ensuite leur admiration pour le grand chrétien 
LES GRANDS CONGRÈS PATRIOTIQUES CANADIENS-FRANÇAIS

que fut le découvreur du Canada et pour tous ceux qui ont contribué au développement de la race canadiennefrançaise. M. Rosaire Maurice déposa ensuite une couronne de fleurs au pied du monument Cartier ${ }^{128}$." Ce fut l'occasion de musique ("Airs canadiens par la fanfare de la garde Champlain»), mais aussi d'allocutions et d'un serment au drapeau («Serment au drapeau par les sections juvéniles»). On termina par le Ố Canada.

Le 23 juin, sixième jour, les congressistes prirent la route de Trois-Rivières et de Montréal. Ils s'arrêtèrent en pèlerinage au Cap-de-la-Madeleine, où le père Paul-Henri Barabé, directeur du sanctuaire, leur souhaita la bienvenue. On dévoila une plaque, on fit le Salut au Saint-Sacrement et l'abbé Verrette consacra le Congrès à la Vierge. En après-midi, on partait pour Montréal où la Société Saint-Jean-Baptiste de Montréal les accueillit par de «magnifiques manifestations». Au cours d'un banquet, on décerna l'Ordre de la fidélité française à Lionel Groulx, à JosephPapin Archambault, à J.-B. Prince et à Victor Barrette (d'Ottawa). C'est le chanoine Lionel Groulx qui fit les remerciements, parlant des dangers de l'américanisme et du centralisme pour «notre nationalité».

Le matin du 25 juin 1952, les congressistes firent un pèlerinage à l'Oratoire Saint-Joseph, puis se rendirent à Saint-Hyacinthe où l'évêque et le maire du lieu les accueillirent. Revenus à Montréal, les délégués assistèrent à la remise, «à quatre vaillants apôtres de la survivance française au Canada», de quatre doctorats honorifiques par l'Université de Montréal, sous la présidence du recteur Olivier Maurault. Parmi

${ }^{128}$ Troisième Congrès... Compte rendu 1952, p. 108. 
les récipiendaires, il y avait Louis Charbonneau, ancien président de l'ACÉLF. En soirée, se déroula le dix-septième Gala du parler français, banquet annuel de la Société du bon parler français, suivi d'un programme artistique et de la remise de décorations (Ordre académique «Honneur et mérite» du bon parler français aux artisans du Troisième Congrès de la langue française).

Enfin, le 26 juin, les délégués officiels, "pour se reposer de leurs fatigues» quittèrent Montréal à six heures du matin afin de se rendre à Saint-Jérôme, pour une visite au monument du curé Labelle, où les attendaient l'évêque et le maire du lieu.

Le Troisième Congrès de la langue française fut aussi un succès financier, comme le Deuxième. Ses revenus de 90545 \$ (soit 88313 \$ en souscriptions, 2126 \$ en recettes du congrès et 106 \$ en intérêts courus), dépassaient ses dépenses de $39882 \$$, laissant un excédent de $50208 \$^{129}$.

Dans l'ensemble, la participation franco-ontarienne à ce congrès fut importante, certes, mais moins que lors du congrès précédent. Toute l'organisation du congrès relevait maintenant des gens de Québec seulement (sauf le président Verrette, un Franco-Américain). Mais, dans le comité d'honneur, deux Ontariens avaient trouvé place: le juge en chef de la Cour suprême, Thibaudeau Rinfret, et l'archevêque d'Ottawa, Mgr Alexandre Vachon.

La participation franco-ontarienne aux trois Congrès de la langue française au Canada aide à comprendre comment les Franco-Ontariens ont voulu s'insérer dans le réseau institutionnel du Canada français.

${ }^{129}$ Compte rendu... 1952, p. 459-460. 
Leur démarche s'explique par l'identité canadiennefrançaise dont tous, à cette époque, se réclament. En effet, ces Congrès patriotiques (ceux de la Société Saint-Jean-Baptiste, puis ceux de la langue française) constituent d'éloquents témoins des valeurs et des idées qui avaient cours dans le Canada français, dont l'Ontario français faisait partie intégrante. Les discours prononcés à Québec en 1912, en 1937 et en 1952 peuvent raisonnablement être tenus pour l'expression de la pensée des élites cléricales et éducatives de l'Ontario français. Durant cette période, l'Ontario français fait partie du Canada français par ses institutions, par ses élites, par son sentiment d'appartenance, se considérant comme la partie ontarienne du Canada français. Cette période canadiennefrançaise de l'histoire franco-ontarienne a pris fin durant les années 1960.

L'élite canadienne-française de l'Ontario, maîtresse du réseau des institutions scolaires, culturelles et religieuses de l'Ontario français, renforça intentionnellement cette identité catholique et française, jugée fondamentale à la survivance et diffusée dans les paroisses, les écoles, la presse.

\section{Conclusion}

Les divers congrès patriotiques, les congrès religieux et notamment les trois Congrès de la langue française procèdent d'une certaine unité de pensée dont le contenu, richement exprimé dans les discours, les rapports et les mémoires, révèle la «vision du monde» que partagèrent les élites du Canada français. Elles sont cléricales, ultramontaines, nationalistes, elles invoquent souvent la Providence, parlent de la mission de la nation canadienne-française, se 
réclament de la France catholique, défendent les droits du français partout au Canada, invoquent le principe des deux peuples fondateurs de la Confédération. Cette idéologie possédait aussi ses héros, un panthéon surtout religieux, certes, mais comprenant également des héros laïques.

On répéta des centaines de fois les idées maitresses de cette idéologie: la primauté de l'Église catholique, le Canada français comme "famille» dispersée en Amérique du Nord, les liens nécessaires entre la langue et la foi, le rôle particulier de la ville de Québec comme berceau de la nation canadienne-française, la défense de la culture française et catholique, d'où les hommages répétés à la France et à l'Académie française, l'éloge de la loyauté, par exemple à l'endroit de la Grande-Bretagne, les mérites du patriotisme canadien, la valeur de l'éducation française et catholique. Toutes ces idées n'auraient pas été désavouées dans les cercles de la Société SaintJean-Baptiste, loin de là.

Ces idées correspondent d'abord à une perception de ce qu'était le Canada français. Avant les années 1960, cette aire culturelle, définie par les régions occupées par les descendants des Français établis en Amérique du Nord à l'époque de la Nouvelle-France, s'appelait le Canada français. Beaucoup de discours, de 1883 à 1952, ont chanté les faits d'arme et les hommes (arma virumque cano, disait Virgile) de la «nation canadienne-française». Dans le discours au sujet du Canada français, on évoquait souvent les origines héroïques du Canada, ses débuts religieux, les liens nécessaires entre la langue et la foi, la nécessité de préserver cet héritage et la solidarité qui unissait la grande "famille canadienne-française». 
Parlant au Congrès de 1937, l'abbé Lionel Groulx donnait pour constantes du peuple canadien-français, sa foi, l'âme de toutes ses traditions, sa vocation paysanne, ses destins français. Aux maux de cette époque, Groulx préconisait deux grands remèdes: le retour à l'instinct paysan et la conscience de l'âme française du pays. C'est l'archevêque auxiliaire de Saint-Boniface qui, en 1952, a peut-être le plus clairement défini les bases de l'unité du Canada français ${ }^{130}$.

On ne peut que constater la force du réseau institutionnel canadien-français, un édifice qui dura un siècle et qui, par son idéologie nationaliste, s'avéra plus apte que ses héritières à mobiliser, à l'échelle du continent, l'ensemble des populations canadiennesfrançaises. Ces institutions ont assuré le maintien des communautés culturelles françaises, le clergé a mobilisé les élites sous l'idéologie d'un nationalisme catholique. Quel mouvement nationaliste ou même politique, aujourd'hui, pourrait espérer jouir d'un tel succès? La réussite même de ces projets dépendait de la collaboration des élites canadiennes-françaises, y compris les délégations des provinces, des régions du Québec, de l'Acadie et des États-Unis.

Quand on présentait les différents membres de la famille, le discours prenait vite une tournure homérique:

Ils seront là, Messieurs, au milieu de la famille, en bataillons serrés, quelques-uns peut-être portant au front les marques de la fatigue et de la douleur, mais tous, la main sur le cœur... C'est ainsi, Messieurs, que chacune des résistances françaises occupera sa place réservée au sein de ce grand ralliement... Nos frères d'Acadie nous reviendront, cette fois, auréolés de merveilleux accomplissements...

${ }^{130}$ Voir la citation en note 1. 
Nos frères des lointaines prairies... réconfortés des immenses bienfaits que dépose maintenant dans leurs foyers la pénétration des ondes françaises.

De l'Ontario, nous accueillerons avec joie et admiration, depuis le grand Nord jusqu'aux solides bastions d'Ottawa, ces frères vaillants qui, après quarante années de pacifiques conquêtes, nous donnent encore l'exemple le plus réconfortant de la lutte et de la résistance... Enfin, ... cette croisade de la Franco-Américanie... Et pour compléter ce bonheur de famille, nous arrivera la lointaine Louisiane... ${ }^{131}$.

Comme dans l'Iliade, les peuples ont des caractéristiques permanentes, ainsi les Acadiens sont le "peuple de la douleur», les Franco-Ontariens, les «pacifiques conquérants», les Québécois, les «fidèles aux traditions", les Canadiens-Français de l'Ouest, les «vaillants combattants», les Franco-Américains sont «restés fidèles au parler des aïeux».

La ville de Québec aspira longtemps à jouer le rôle de capitale du Canada français. Lors du Congrès de 1937, le maire, J.-Ernest Grégoire, présenta sa ville comme le uberceau de la nation Canadienne française [sic], forteresse de nos luttes constitutionnelles, tombeau de presque tous les plus grands morts de la patrie, foyer de culture catholique et française ${ }^{132} »$. Ailleurs, on parlait du «berceau de la langue», du "noble promontoire», du «roc de Québec», du «berceau de notre race», de «la vieille capitale», du "rocher historique», du «berceau de notre pays et de notre nationalité». Le maire Lucien Borne, le 19 juin 1952, hissa sa ville au rang de «ville sacrée entre toutes ${ }^{133} »$, alors que le curé Alphonse Gagnon, de la paroisse Notre-Dame, ajoutait que «tout Canadien a

\footnotetext{
131 "L'Appel au public», dans Compte rendu 1952, p. 15.

132 Compte rendu 1937 , p. 178.

${ }^{133}$ Compte rendu 1952, p. 225.
} 
LES GRANDS CONGRÈS PATRIOTIQUES CANADIENS-FRANÇAIS

deux paroisses: la sienne et puis Notre-Dame de Québec».

De toutes les métaphores employées pour décrire l'ensemble du Canada français, aucune n'eut tant de fortune que l'image de la «grande famille canadiennefrançaise». Valeur chrétienne autant que sociale, la famille devenait la parfaite image de ce que voulait être le Canada français. Ainsi, le thème de la "grande famille canadienne-française», omniprésent, rejoignait cette autre métaphore, celle du «berceau». Les "frères" des différentes régions se donnaient ainsi rendez-vous à Québec, le "berceau» de l'Amérique française. Dans l'Appel au public de 1952, l'abbé Verrette signait: «'invite donc tous les membres de la grande famille française d'Amérique à s'inscrire». Le soir de l'ouverture du Congrès de 1952, Verrette reprit le même thème, parlant cette fois de "cette émouvante réunion de famille». On parla aussi, avec une métaphore voisine, «des enfants dispersés de la grande famille».

La patrie du Canada français, c'est le Canada, non le Québec. On chantait, dans le Ô Canada, «la terre de nos aïeux, près du fleuve géant», certes, mais la vallée laurentienne leur semblait un point de départ, le berceau si on veut, d'une grande épopée qui trouvait son accomplissement dans la présence française partout dans la Confédération canadienne. Le soir inaugural de 1912, Mgr A. Langevin rappela la loyauté au drapeau britannique et, dans son "Salut à Québec», protesta vigoureusement de la loyauté des Canadiens-Français. Dans le "toste au Canada", le mercredi 30 juin 1937, le ministre fédéral J.-Encil Michaud commença son intervention ainsi: «Il n'est pas possible de prononcer ou d'écrire ce mot "Canada" 
sans évoquer l'idée de patrie. Canada est synonyme de patrie pour les Canadiens français». Cette «patrie canadienne-française ce n'est plus seulement le sol de Québec, mais bien chaque endroit où se conserve le patrimoine que nous a légué la vieille France». Et Michaud de rappeler l'invitation au Congrès signée par Mgr Camille Roy: «Le Deuxième Congrès... n'est pas le congrès d'une ville ni d'une région... Il est le congrès de la nation canadienne-française, où qu'elle soit représentée au Canada...».

Aussi, le Canada français forme une nation catholique. Pour le Congrès de 1912, on parlait de «pèlerinage à Québec», d' "épopée mystique», de "terre sacrée», de «berceau de l'Amérique française». Ce vocabulaire, employé dans le contexte de grandes cérémonies à caractère politico-religieux, où accouraient des milliers de personnes, faisait pénétrer les auditeurs encore mieux dans le monde des symboles et des valeurs religieuses. Toujours, le clergé a occupé une place d'honneur. C'est lui qui parle pour le Canada français la plupart du temps. La soumission au pape et à l'épiscopat est explicite et totale. Le respect de l'autorité est loué en toute occasion. Les protestations de foi sont multiples et fréquentes. Langevin, en 1912, dénonça «les voix accusatrices qui cherchent à semer la défiance entre le clergé et le peuple et qui prônent une émancipation malsaine», affirmant que «l'histoire proclame hautement que nous sommes restés français parce que nous sommes restés catholiques» et que «Nous serons d'autant plus français que nous serons catholiques» ("Qui se a Christo separat, exul est patria» - S. Ambroise). Les Canadiens-Français étaient souvent qualifiés de «fils de l'Église catholique», l'Église étant «leur Mère». On lui exprima toujours une vive reconnaissance, on 
rappela les hauts faits de son clergé. C'est une Église de martyrs, de missions, de défenseurs de la foi, de dévouement.

Avec cette idée d'un "peuple catholique», où la Providence intervient, il n'y a qu'un pas pour affirmer que ce peuple a reçu une mission divine particulière. En 1912, Mgr Paul-Eugène Roy l'affirmait dans son discours inaugural: "Notre mission, dans le Nouveau Monde, est de faire survivre, malgré les forces contraires et les allégeances nouvelles, le génie de notre race, et de garder pur de tout alliage l'esprit français qui est le nôtre». La langue était gardienne de la foi.

Comme signes extérieurs de ces adhésions religieuses et politiques, beaucoup de symboles furent mis à contribution. Les drapeaux, les oriflammes et les gonfalons flottèrent toujours au-dessus des rassemblements. Ils sont porteurs de message, ils rappellent des idées. Au fil des ans, de nombreuses discussions se produisirent autour du choix d'un drapeau. Dès le XIX ${ }^{e}$ siècle, les débats commencèrent. Fallait-il adopter le drapeau de la France (le tricolore bleu-blanc-rouge), ou le pavillon royal blanc semé de lis? Les Acadiens adoptèrent un drapeau différent (1884), alors que se généralisait ailleurs le drapeau de Carillon, tôt surmonté d'un Sacré-Cœur saignant.

Les idées ambiantes touchaient principalement aux questions de la nationalité: la langue, l'histoire, la religion. La médaille-souvenir du Premier Congrès illustre merveilleusement bien cette vision du monde. Elle s'attache à un ruban "aux couleurs spéciales adoptées par le Congrès: blanc et bleu d'azur", la bélière étant formée par deux rameaux d'érable. Le 
revers de la médaille porte la mention Premier Congrès de la langue française, Québec, 1912, avec en exergue une parole de Gustave Zidler ( «très cher poète canadienfrançais d'adoption»), "C'est notre doux parler qui nous conserve frères». L'avers de la médaille est très chargé de signification. D'après la description qui figure au Compte rendu:

La médaille porte, à l'avers, la figure d'une jeune mère canadienne, personnification idéale de notre nationalité, dans une noble posture, le bras droit reposant affectueusement sur l'épaule du fils aîné, à qui elle interprète les hautes leçons de patriotisme rayonnant au livre de notre histoire, que, de la main gauche, elle tient appuyé sur ses genoux et ouvre à l'endroit où se détachent les mots aimés de Champlain, de Laval, de Montcalm et de Lévis. Sur le sol, aux pieds de la mère canadienne, le fils cadet, un tout jeune enfant, a interrompu les ébats de son âge et tournant vers le groupe qui le domine une figure où brille un air d'intelligence et de précoce attention, il prête aussi l'oreille aux enseignements maternels. Dans le lointain de la perspective apparaît une modeste église canadiennefrançaise, avec son clocher à la pointe effilée, se détachant sur le fond des premiers contreforts des Laurentides. Au bas de ce délicieux tableau on lit ces simples mots, très expressifs: Parlons français! ${ }^{134}$.

Cette image d'Épinal contient une riche symbolique: la mère, l'enfant, la leçon d'histoire, le panthéon des héros, l'église avec son clocher, le paysage laurentien. La charge signifiante de cette scène est lourde. On fit frapper ces médailles en bronze patiné, mais aussi une centaine en bronze argenté pour le Comité organisateur et une en or, remise à Étienne Lamy de l'Académie française. Le compte rendu du Congrès décrit cette médaille en détail, ce qui montre bien la valeur des symboles qu'elle porte.

${ }^{134}$ Compte rendu 1912, p. 61-62. 
En dehors de ces marques de loyauté (au pape, à la Grande-Bretagne, à la France), les symboles eurent nettement tendance à devenir canadiens. Dès les années 1870 , on préféra l'adjectif canadien-français à français. Ferdinand Roy, juge en chef de la Cour de magistrat, disait en 1937 qu'il «s'agit pour nous non pas de redevenir des Français tout court, ni d'être des Canadiens tout court, mais bien de demeurer des Canadiens Français ${ }^{135}$ \%. Par conséquent, on sortait de préférence les symboles canadiens. Le Ô Canada se chantait haut et fort, à toutes les occasions. Une résolution encouragea même les enseignants à le faire chanter régulièrement dans les écoles.

$\mathrm{Si}$ de nombreux orateurs proclamèrent vigoureusement la loyauté des Canadiens-Français à la Grande-Bretagne et la soumission au pape, il y eut cependant toujours une place éminente réservée à la France, même si le nombre des Français présents y était minuscule. Pour la France, c'est le cœur qui parle. Lors des hommages à l'Académie (le mardi soir, 26 juin 1912), A.-B. Routhier disait:

L'Angleterre est pour nous la meilleure des belles-mères, une des rares belles-mères qui savent se faire aimer de leurs gendres. Mais la France, elle est pour nous la Magna parens, la grande, l'illustre, l'immortelle aieule, et l'Académie est notre Alma Mater, la Mère nourricière et féconde sur les genoux de laquelle nous avons appris à parler, qui nous a donné la vie intellectuelle, et qui nous la conserve, en nous distribuant le pain substantiel de la forte prose et le vin pétillant de l'éloquence et de la poésie.

En 1937, comme en 1912, le représentant de l'Académie française fut l'objet de mille sollicitudes. On signala expressément sa présence chaque fois

${ }^{135}$ Compte rendu 1937, p. 110. 
qu'il participa à une activité. Par lui, on rendit d'infinis hommages à la France, particulièrement à son Académie, gardienne depuis toujours de la langue française. S'adressant aux représentants de la France, de la Suisse, de la Belgique et du Luxembourg, lors de l'hommage devant le monument Montcalm, le solliciteur général de la province de Québec, Antoine Rivard, répéta en 1952 le plaisir de les voir "sur le sol de Québec, berceau de la race française en Amérique». Il parla de "l'affection de cette France éternelle à laquelle, malgré tous les éloignements et toutes les épreuves, nous sommes demeurés indéfectiblement attachés». Rivard leur rappela:

Nous avons résisté à bien des assauts, triomphé de bien des dangers. Nous n'avons pas changé. Je serais tenté de dire que nous avons été, dans la grande famille française, les premiers soldats de la résistance. Il est bien possible que vous trouviez que notre culture manque de profondeur, que notre langue souffre de la pauvreté de son vocabulaire, des imperfections que les anglicismes et les barbarismes y ont glissées. Vous me permettrez bien de vous dire que nous ne rougissons pas de ces déficiences: ce sont les cicatrices des blessures que nous avons reçues dans les combats que nous avons livrés pour demeurer catholiques et français ${ }^{136}$.

Dans les congrès, une partie des débats porta constamment sur les droits du français, ses droits historiques selon les traités et les lois, sa situation dans les différentes régions. Le sénateur Landry, en 1912, affirma que le Congrès avait justement pour raison d'être de "solennellement affirmer le droit sacré que nous avons de parler notre langue». Ce droit, conquis par les premiers colons, par les missionnaires, par les martyrs qui apportèrent la civilisation, fut ensuite reconnu par l'Angleterre dans l'Acte consti-

${ }^{136}$ Troisième Congrès... Compte rendu 1952, p. 168. 
tutionnel de 1867. Selon Landry, «ce droit n'est pas confiné à la seule province de Québec, mais il est aussi, dans tout le Dominion, l'incontestable apanage de la race française».

Même le docteur J.-O. Réaume, membre du gouvernement ontarien qui adoptait à ce moment précis (juin 1912) le Règlement XVII, se laissa aller à encourager Québec à maintenir le français et, dans un discours qui laisse pantois tellement il contredit les actions du gouvernement Whitney, le ministre ajoutait:

L'idée seule qu'un temps pourrait venir où le doux parler français ne se ferait plus entendre, dans ce pays conquis à la civilisation par nos pères, nous inquiète et nous émeut. Nos descendants auraient raison de mépriser notre mémoire si, par notre manque de vigilance, nous laissions, un jour, les ennemis de notre race nous ravir le trésor du verbe ancestral.

N'est-il pas étrange de voir certains hommes, qui, tout en appartenant à une autre race que la nôtre, sont des citoyens canadiens comme nous, souhaiter la disparition de la langue française en ce pays [...].

Compatriotes, ensemble, jurons aujourd'hui, sur l'autel de la patrie, une inviolable fidélité à notre langue, et prenons ensemble l'engagement formel d'en assurer la survivance par l'enseignement que nous ferons donner à nos enfants $[\ldots]$.

[...] loin de moi le désir de voir le français supplanter l'anglais en ce pays ${ }^{137}$.

Toute l'argumentation est donc là: droits moraux, peu de droits constitutionnels, manque de respect des droits!

Dans la défense du Canada français, l'histoire, plus exactement la mémoire du Canada français, joua

${ }^{137}$ Premier Congres... Compte rendu 1912, p. 217. 
un rôle critique. L'histoire occupa toujours, dès l'époque des congrès patriotiques de la Société Saint-JeanBaptiste, une place importante. La fidélité aux origines, idée reprise souvent, prit la forme d'un très grand respect de l'histoire. Ce respect se manifesta par l'hommage rendu aux héros, mais aussi par la fidélité à la foi et à la langue des ancêtres. Accompagnant l'idéologie décrite plus haut, une certaine interprétation de l'histoire s'imposait, où les héros de la NouvelleFrance occupaient une place de choix. Dans beaucoup de discours, il fut question des origines, de la fondation, du berceau, des débuts français et catholiques du Canada français. Cette histoire en était une de lutte. Lors de l'ouverture, le 18 juin 1952, Verrette s'écrit: «Il y a trois siècles que nous persévérons! Vivre, c'est lutter, c'est bâtir et restaurer».

Lorsque l'historien Marcel Trudel, en 1952, présenta une communication devant la section d'éducation patriotique, il commença par une explication: "Les historiens canadiens-français de la nouvelle génération, suivant en cela les directives du chanoine Groulx, s'appliquent aujourd'hui à n'être que rigoureusement scientifiques ${ }^{138} »$. Cela ne signifiait pas une «opposition entre histoire scientifique et éducation patriotique ou nationale», loin de là: «Disons plus: l'une et l'autre sont corrélatives. D'une part, l'éducation patriotique doit être fondée sur les données les plus sûres de l'histoire, sinon on aboutit au culte vain des mythes». Le «culte vain des mythes», dont parlait Trudel, est-ce une allusion aux héros que les congrès précédents et beaucoup d'historiens avaient adulés? Trudel précisa que «l'histoire doit

${ }^{138}$ Mémoires 1952 , p. 229 . Pour le texte complet de la communication, voir p. 229-240. 
d'abord exister en fonction du pays, puisqu'elle représente précisément ce que ce pays a de plus personnel et de plus intime, son passé». Est-ce une indication du conflit qui mena à la publication séparée des travaux scientifiques des universitaires, en 1955 ?

Une galerie de héros se dressait devant les congressistes, un panthéon dont la composition changea peu au cours des ans. Les grands discours publics, les héros honorés sur les médaillons qui décorent les salles publiques, les monuments visités lors de grandes cérémonies d'hommages sont autant de sources pouvant renseigner sur le nom des héros les plus admirés. Une première catégorie, au-dessus des autres, comprend les noms de Montmorency Laval, de Samuel de Champlain, auxquels sont habituellement associés les noms de Jacques Cartier, Marie de l'Incarnation, Marguerite Bourgeoys, Dollard des Ormeaux, Jacques Marquette, La Salle, Iberville, Frontenac, Montcalm. Plus tard s'ajoutèrent, quoique avec un peu d'hésitation, les héros de 1837 et du Canada-Uni, d'ailleurs Lafontaine plus que Papineau.

Dans la Salle des exercices, où se déroulèrent les séances générales de 1912, on avait construit une estrade et orné la salle de décorations, de bannières et d'oriflammes. Sur les tiges de support des galeries, avaient été placés «d'élégants médaillons, ornés de banderoles en harmonie avec l'ensemble, et au nombre de soixante-dix, done chacun portant le nom d'un grand personnage de notre histoire». Le choix des "héros» figurant sur ces médaillons indique assez les personnes jugées dignes de faire partie du panthéon 
du Canada français ${ }^{139}$. À cette époque, le culte des héros faisait partie non seulement de la vie intellectuelle, mais même de l'historiographie naissante du Canada français ${ }^{140}$.

Lors du Deuxième Congrès, en 1937, de nombreuses cérémonies se déroulèrent devant les monuments historiques de la ville de Québec. Le programme avait même prévu une "démonstration de la jeunesse aux monuments de Québec", avec dépôts de couronnes. Les monuments visités nous font déjà reconnaître les héros mis de l'avant en 1912: le monument Laval, le monument Champlain, le monument Wolfe-Montcalm, le monument Garneau, le monumentà la Croix du Sacrifice (soldats de la Première Guerre mondiale), le monument aux Braves, le monument Jacques-Cartier. Lors du Congrès de 1937,

\footnotetext{
${ }^{139}$ Voici la liste de ceux qui eurent l'honneur d'un médaillon: Jacques Cartier, Champlain, Laval, Lévis, Frontenac, Montcalm, Maisonneuve, Laviolette, Boucher, Dollard, Hertel, Morin, Talon, Hébert, Brébœuf (sic), Lalemant, Briand, Plessis, Bédard, Cartier, Papineau, Lafontaine, Chauveau, Painchaud, Meilleur, Grouard, Parent, Viger, Drucourt, Lefebvre, Blanchet, Villiers, Iberville, Bardy, Marquette, Joliet, Le Loutre, Maillard, Poutrincourt, Taschereau, Sigogne, Pothier, Mademolselle de Verchères, Jeanne Mance, Duvernay, La Vérendrye, Taché, Laflèche, Bienville, Lemoyne de Sainte-Hélène, Marguertte Bourgeoys, Marle de l'Incarnation, Catherine de Saint-Augustin, Madame d'Youville, Madame Drucourt, Lagacé, Garneau, Fréchette, Charlevoix, Larue, Ferland, Tardivel, Laverdière, Buies, Crémazie, Legendre, Faucher de Saint-Maurice, Casgrain, Lusignan, De Gaspé.

${ }^{140}$ Voir, sur cet aspect historlographique, Serge Gagnon, "Le XVI ${ }^{e}$ siècle canadien de Narcisse-Eutrope Dionne à Marcel Trudel», dans Revue de l'Université d'Ottawa/ University of Ottawa Quarterly 47, 1977, p. 65-83; Serge Gagnon, Le Québec et ses historiens de 1840 d 1920. La Nouvelle France de Garneau d Groulx (Québec, Presses de l'Université Laval, «Cahiers d'histoire de l'Université Laval» 23, 1978 , 474 p.); Serge Gagnon, «The Historiography of New France, 19601974», dans Journal of Canadian Studies/ Revue d'études canadiennes 13(1), 1978, p. 80-99 et aussi dans Carl Berger (sous la direction de), Contemporary Approaches to Canadian History (Toronto, Copp Clark Pitman, 1987), p. 28-51.
} 
on procéda au dévoilement, à l'Hôtel-Dieu de Québec, d'une plaque offerte par la Commission des Sites et Monuments historiques du Canada à l'occasion du troisième centenaire de fondation de l'Hôtel-Dieu.

Une dévotion particulière se développa en faveur de Dollard des Ormeaux (1635-1660), objet de grande ferveur pactriotique et jeune héros proposé à la jeunesse comme modèle de dévouement (il donna sa vie pour sauver la Nouvelle-France). Bien que contesté, Dollard devint un important héros canadien-français ${ }^{141}$. Mais il existait aussi d'autres héros. Lors de son discours, le soir de l'ouverture de 1937, le lieutenantgouverneur de la province de Québec, E.-L. Patenaude, après avoir rappelé la vaillance des ancêtres et leur loyauté, proposa comme modèle Barthélemy Joliette, fondateur du village de L'Industrie et entrepreneur ${ }^{142}$. Selon Patenaude, il fallait retrouver le courage et l'héroïsme d'autrefois.

Outre les illustres personnages proposés à l'admiration de toute l'Ámérique française (Cartier,

\footnotetext{
141 Pour une analyse de la vie de Dollard et une discussion historiographique de la question, voir André Vachon, «Dollard Des Ormeaux, Adam", dans Dictionnaire biographique du Canada I de l'an 1000 d̀ 1700 ([Québec], Presses de l'Université Laval, [c 1966], p. 274283). Plus récemment, Jean Laporte a relancé le débat autour de l'emplacement précis de la batalle du Long-Sault (question que l'article d'André Vachon ne soulève même pas), site qui se trouve en Ontario. Pour Lionel Groulx et pour les nationalistes canadiens-français de Montréal, ce site sacré ne pouvait être ailleurs qu'au Québec. On l'avait donc fixé dans les environs de Carillon, en sol québécois. D'autres, partant de traditions orales survivant dans la région, et réconfortés par des fouilles archéologiques, avaient fixé l'emplacement de la bataille à la bale des Sauvages, à quelques kilomètres au sud-est de Hawkesbury, en sol ontarien. Voir: Jean Laporte, La Vieille Dame, l'archéologue et le chanoine. La Saga de Dollard des Ormeaux, [Ottawa], L'Interligne, [c1995], 143p.

${ }^{142}$ Deuxième Congrès... Compte rendu 1937, p. 155.
} 
Champlain, Laval, Montcalm), les participants francoontariens au Congrès ont aussi eu l'occasion de mettre de l'avant le nom des héros franco-ontariens. Beaucoup des héros de la Nouvelle-France (Champlain, les Martyrs canadiens, les explorateurs, Dollard des Ormeaux, les missionnaires) avaient des liens directs avec l'histoire de l'Ontario français. Mais à ces héros, les délégations ontariennes aux congrès de la langue ont ajouté d'autres noms, assez naturellement choisis parmi les combattants contre le Règlement XVII, une plaie encore vive en 1937 et en 1952. Dans son discours à la séance d'ouverture, en 1937, le ministre des Mines, Paul Leduc, avait mentionné les noms de Landry et du père Charlebois. Deux jours plus tard, le juge Albert Constantineau, qui présidait la séance générale du mardi après-midi (29 juin), dressait aussi sa liste: il rappelait les noms des sénateurs Landry et Belcourt, mais aussi de Samuel Genest, d'Aurélien Bélanger, du docteur Rochon (président en exercice de l'ACFÉO en 1937), de C.-S.-O. Boudreault, du docteur A.-T. Charron, du chanoine L.-C. Raymond. Mais il précisait qu'on n'avait pas assez nommé le «modeste Père Charles Charlebois, qui fut l'âme de l'Association d'Éducation Canadienne française d'Ontario durant un quart de siècle», de son successeur le père Joyal, sans nommer «les noms de ces valeureux patriotes, prêtres et laïques, qui, en collaboration avec moi, ont organisé le Congrès de 1910 , lequel créa l'organisme qui rendit possible la lutte scolaire commencée en 1912, et sans lequel toute résistance efficace eût été impossible».

Prenant la parole lors de la séance de clôture en 1937, le sénateur Lacasse mentionna le modèle que représentait Dollard des Ormeaux, mais il parla surtout des adversaires du Règlement XVII, mettant au- 
devant les sénateurs Landry et Belcourt, Mgr ÉlieAnicet Latulipe, mais aussi "d'autres noms vénérés que la reconnaissance de notre peuple franco-ontarien conserve comme des joyaux précieux dans l'écrin de son héroïque histoire»: les Charlebois, Meunier, Beaudoin, Émery, Armstrong, Freeland, Genest «et tant d'autres auxquels l'historien donnera leurs justes places dans le martyrologe canadien ${ }^{143}$ ». Cette idée de martyrologe entre parfaitement dans l'univers des martyrs de la foi, mais ici, martyrs de la langue et de la foi. Lors du congrès de l'ACFÉO, en 1934, les participants avaient entériné le choix des Saints Martyrs canadiens, récemment canonisés, comme patrons des Franco-Ontariens.

Parmi les recommandations du Premier Congrès, il y avait des résolutions demandant que «les noms des plus vaillants apôtres et défenseurs de notre idiome en ce pays soient pieusement conservés et souvent rappelés aux enfants du Canada par ceux qui sont chargés de leur enseigner", dans les écoles et les collèges. On demandait encore que les CanadiensFrançais érigeassent à ces apôtres des monuments dans les endroits qu'ils avaient illustrés par leurs sacrifices et leurs travaux, des «monuments dignes de leur mémoire et de leurs œuvres». On louait les Canadiens-Français de l'Ouest qui avaient alors l'intention d'ériger un monument à la mémoire de La Vérendrye.

${ }^{143}$ Deuxtème Congrès... Compte rendu 1937, p. 443. 
Il a existé, au temps du Canada français, une véritable «culture de congrès». Ils expriment ce que les élites canadiennes-françaises proposent comme projet social. Les trois congrès de la langue française au Canada, à la suite d'une série de congrès patriotiques organisés par la Société Saint-Jean-Baptiste, constituent des symboles du Canada français. Ils ont, dans leur organisation et dans leurs activités mêmes, montré ce qu'était le Canada français, quỉ en étaient les porte-parole, quelles valeurs catholiques et françaises ils défendaient. Ces congrès furent aussi l'occasion de réunir tous les membres de la famille canadienne-française. Enfin, ces rassemblements ont prescrit certaines conduites visant le maintien et la survie du Canada français ${ }^{144}$.

Quinze ans après le Troisième Congrès de la langue française, un groupe gravitant autour de la Société Saint-Jean-Baptiste de Montréal prit l'initiative de rassembler les Etats généraux du Canada français. Ce congrès tint une rencontre préparatoire en 1966 , puis ses assises en 1967 et en 1969. Dès 1967, la division entre les représentants de la province de Québec et ceux des autres régions canadiennes éclata au grand jour. Si bien que l'ACFÉO décida de ne pas participer aux séances de 1969 . En exposant la rup-

\footnotetext{
${ }^{144}$ En 1957, le Congrès de la refrancisation prit un caractère plus scientifique que les précédents. Il n'appartient plus, par son contenu, aux congrès patriotiques. Il ne tient déjà plus le rôle politique qu'eurent les congrès patriotiques et les Congrès de la langue française. Les exposés relèvent du monde de la linguistique et de l'université, non plus de l'action politique directe. Voir: Le Congrès de la Refrancisation. Québec 21-24 juin 1957.6 tomes reliés en 3 volumes. Québec, Éditions Ferland, 1959,67 p. +88 p. +108 p. +85 p. +106 p. +117 p.
} 
ture idéologique entre les néonationalistes québécois et les Canadiens-Français des autres provinces, les États généraux consommaient la rupture du Canada français.

* L'auteur remercie ses confrères de la Société, notamment René Dionne et Jean-Pierre Pichette, et son collègue historien, Guy Gaudreau. Ils ont patiemment lu, dans sa forme préliminaire, un long manuscrit. Leurs sages et nombreuses suggestions ont permis d'améliorer ce travail. 